\title{
MÉTODOS DE REGRESSÃO E UNI-MULTIVARIADO PARA A REDUÇÃO DO NÚMERO DE REPETIÇÕES EM EXPERIMENTOS INTERMEDIÁRIOS DE UM PROGRAMA DE MELHORAMENTO DE SOJA
}

\author{
Fernando Toledo Santos de Miranda
}

\begin{abstract}
Tese apresentada à Escola Superior de Agricultura "Luiz de Queiroz", Universidade de São Paulo, para obtenção do título de Doutor em Agronomia, Área de Concentração: Genética e Melhoramento de Plantas.
\end{abstract}

\author{
PIRACICABA \\ Estado de São Paulo - Brasil \\ Fevereiro - 2004
}




\title{
MÉTODOS DE REGRESSÃO E UNI-MULTIVARIADOS PARA A REDUÇÃO DO NÚMERO DE REPETIÇÕES EM EXPERIMENTOS INTERMEDIÁRIOS DE UM PROGRAMA DE MELHORAMENTO DE SOJA
}

\author{
Fernando Toledo Santos de Miranda \\ Engenheiro Agrônomo
}

Orientador: Prof. Dr. NATAL ANTONIO VELLO

\begin{abstract}
Tese apresentada à Escola Superior de Agricultura "Luiz de Queiroz", Universidade de São Paulo, para obtenção do título de Doutor em Agronomia, Área de Concentração: Genética e Melhoramento de Plantas.
\end{abstract}

\author{
PIRACICABA \\ Estado de São Paulo - Brasil \\ Fevereiro - 2004
}




\section{Dados Internacionais de Catalogação na Publicação (CIP) DIVISÃO DE BIBLIOTECA E DOCUMENTAÇÃO - ESALQ/USP}

Miranda, Fernando Toledo Santos de

Métodos de regressão e uni-multivariado para a redução do número de repetições em experimentos intermediários de um programa de melhoramento de soja / Fernando Toledo Santos de Miranda. - - Piracicaba, 2004.

$110 \mathrm{p}$.

Tese (doutorado) - Escola Superior de Agricultura Luiz de Queiroz, 2004. Bibliografia.

1. Análise de variância 2. Delineamento experimental 3. Interação genótipo ambiente 4 . Linhagens vegetais 5 . Melhoramento genético vegetal 6 . Soja I. Título

CDD 633.34 
À Jaqueline, Laura e Manuela,

Dedico.

Aos meus pais Manoel e Dulce, Ofereço. 


\section{AGRADECIMENTOS}

Ao Prof. Dr. Natal Antonio Vello, pelo apoio e compreensão das minhas dificuldades durante a condução deste trabalho e principalmente pela valiosa orientação;

Ao CNPq pela bolsa de estudo concedida;

A CAPES, CNPq, EMBRAPA, FAPESP e FINEP pelos apoios financeiros às diferentes fases das pesquisas que originaram o germoplasma utilizado;

Ao Departamento de Genética, especialmente ao seu corpo docente, pelos ensinamentos;

À Fundação De Apoio À Pesquisa e Desenvolvimento do Oeste Baiano e à Naturalle Agro Mercantil S/A pelo tempo cedido para o execução deste trabalho; Aos funcionários do Departamento de Genética Marcos Custódio Nekatschalow, Claudinei Antonio Didoné e Antonio Roberto Cogo pela amizade e auxílio na montagem e condução dos experimentos;

Às bibliotecárias Silvana e Glória pela amizade e auxílio nas fases de revisão de literatura e revisão dos originais;

A Candida Vanderléia de Oliveira pela amizade, paciência e atenção dispensada;

Aos amigos Jair Rogério Unfried e Gustavo Capato Herrera pela indispensável ajuda na fase final deste trabalho;

Aos colegas do grupo da soja, Maurisrael de M. Rocha, Maria Clideana C. Maia, Angela C. de A. Lopes, Cláudio Yuji Tsutsumi, Fábio Pandini (in memoriam), José Francisco Ferraz de Toledo, Vanoli Fronza e Rodrigo Luiz Brogin que em todos os momentos estiveram presentes e dispostos a ajudar; 
Aos colegas do Departamento de Genética, em especial à Andrea Mittelmann, Glauce Rumin, Raimudo Nonato Vieira da Cunha, Vanderlei da Silva Santos, Aurélio Mendes Aguiar, Américo José dos Santos Reis e José Ubirajara Vieira Moreira; pela amizade;

Aos meus pais Manoel e Dulce por tudo o que tem feito por mim e pela minha família;

À Jaqueline por não ter permitido que eu desistisse. 


\section{SUMÁRIO}

Página

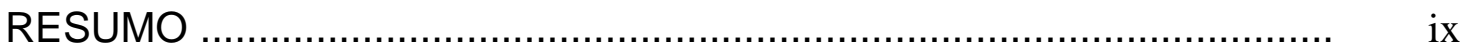

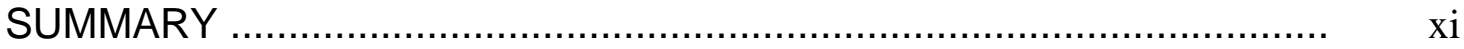

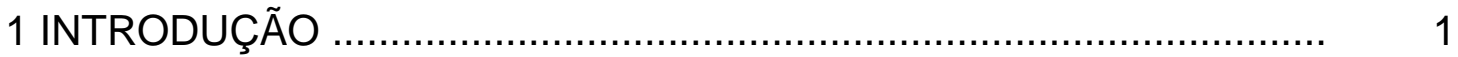

2 REVISÃO DE LITERATURA ………………….......................

2.1 Delineamentos experimentais ................................................... 4

2.1.1 Blocos aumentados ..................................................................

2.1.2 Blocos completos casualizados ...................................................... 6

2.2 Delineamentos de tratamentos ................................................

2.2.1 Metodologia de Eberhart \& Russell (1966) .................................... 7

2.2.2 Metodologia AMMI ............................................................. 9

3 MATERIAL E MÉTODOS …..................................................... 16

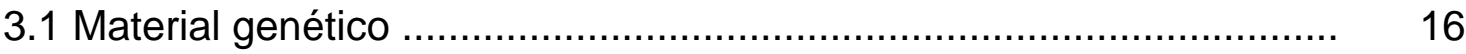

3.2 Caracterização dos ambientes .................................................... 17

3.3 Avaliação do desempenho agronômico ............................................. 18

3.4 Delineamentos experimentais .................................................... 19

3.4.1 Blocos aumentados ............................................................ 19

3.4.2 Blocos ao acaso com tratamentos comuns ................................. 20

3.4.3 Análises conjuntas .............................................................. 20

3.5 Delineamentos de tratamentos ................................................. 21

3.5.1 Método de Eberhart \& Russell (1966) ......................................... 22

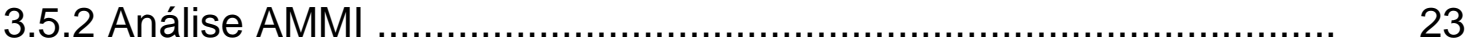

3.6 Correlações de Spearman ........................................................... 24 


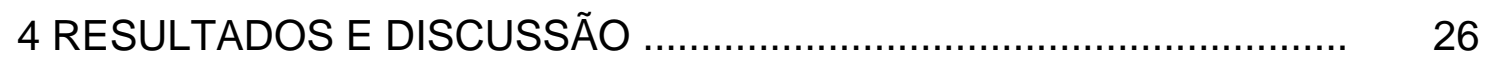

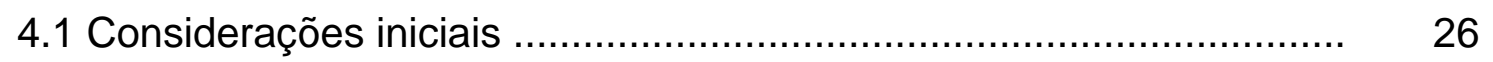

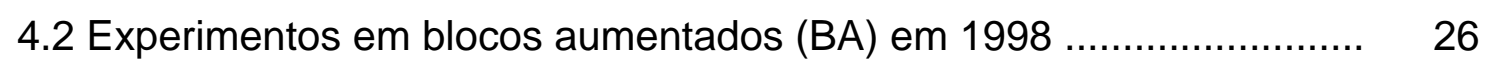

4.2.1 Análise da variância (ANAVA) dos experimentos em BA em 1998... 27

4.2.2 Metodologia de Eberhart \& Russell (1966) (ER) dos experimentos

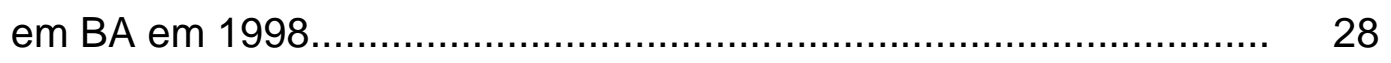

4.2.3 Metodologia AMMI dos experimentos em BA em $1998 \ldots \ldots \ldots \ldots \ldots \ldots . . . . . . . . . .29$

4.3 Experimentos em blocos casualizados subdivididos em conjuntos

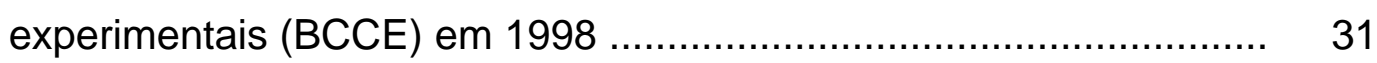

4.3.1 Análise da variância (ANAVA) dos experimentos em BCCE em 1998

4.3.2 Metodologia de Eberhart \& Russell (1966)(ER) dos experimentos em BCCE em 1998................................................. 32

4.3.3 Metodologia AMMI dos experimentos em BCCE em 1998 ............. 34

4.4 Experimentos em blocos aumentados (BA) em 1999 ....................... 37

4.4.1 Análise da variância (ANAVA) dos experimentos em BA em 1999... 37

4.4.2 Metodologia de Eberhart \& Russell (1966) (ER) dos experimentos em BA em 1999.......................................................... 38

4.4.3 Metodologia AMMI dos experimentos em BA em 1999 ................. 39

4.5 Experimentos em blocos casualizados subdivididos em conjuntos

Experimentais (BCCE) em 1999

4.5.1 Análise da variância (ANAVA) dos experimentos em BCCE em 1999

4.5.2 Metodologia de Eberhart \& Russell (1966)(ER) dos experimentos em BCCE em 1999

4.5.3 Metodologia AMMI dos experimentos em BCCE em 1999 42

4.6 Experimentos em blocos aumentados (BA) em 2000 43

4.6.1 Análise da variância (ANAVA) dos experimentos em BA em 2000.... 43 4.6.2 Metodologia de Eberhart \& Russell (1966) (ER) dos experimentos em BA em 2000 
4.6.3 Metodologia AMMI dos experimentos em BA em 2000 ................. 45

4.7 Experimentos em blocos casualizados subdivididos em conjuntos

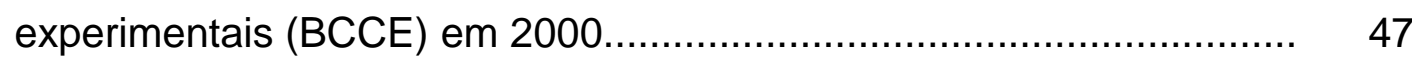

4.7.1 Análise da variância (ANAVA) dos experimentos em BCCE

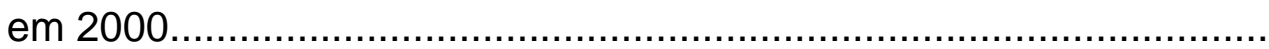

4.7.2 Metodologia de Eberhart \& Russell (1966) (ER) dos experimentos

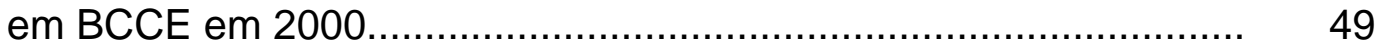

4.7.3 Metodologia AMMI dos experimentos em BCCE em 2000 ............ 50

4.8 Anava segundo a metodologia AMMI considerando conjuntamente

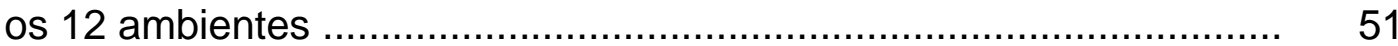

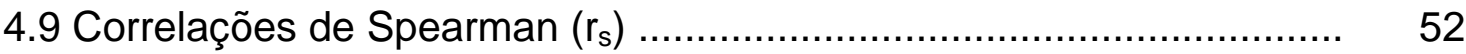

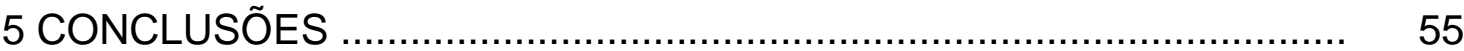

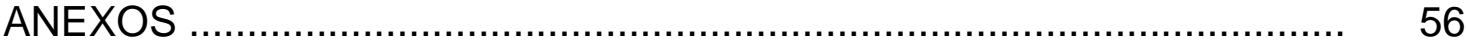

REFERÊNCIAS BIBLIOGRÁFICAS ........................................... 102 


\title{
MÉTODOS DE REGRESSÃO E UNI-MULTIVARIADO PARA A REDUÇÃO DO NÚMERO DE REPETIÇÕES EM EXPERIMENTOS INTERMEDIÁRIOS DE UM PROGRAMA DE MELHORAMETO DE SOJA
}

\author{
Autor: FERNANDO TOLEDO SANTOS DE MIRANDA \\ Orientador: Prof. Dr. NATAL ANTONIO VELLO
}

\section{RESUMO}

A fase intermediária de um programa de melhoramento de soja caracteriza-se pela avaliação de grande número de genótipos (cerca de 100 linhagens) em diversos ambientes, fato que torna esta etapa bastante dispendiosa. A utilização de métodos estatísticos que permitam uma análise da interação genótipos $x$ ambientes (GxE) mais refinada, pode permitir, com o ganho em precisão gerado, uma compensação ao aumento esperado na interação GxE em conseqüência da diminuição do número de repetições nesses experimentos. A metodologia de Eberhart \& Russell (1966) (ER) utiliza a regressão linear como ferramenta para modelar a interação $G \times E$, enquanto que a metodologia AMMI utiliza a análise da variância para modelar os efeitos de genótipos e de ambientes e a decomposição de valores singulares para modelar apenas a interação GxE. O objetivo deste trabalho foi avaliar a possibilidade de redução do número de repetições em experimentos com 72 linhagens em delineamento em blocos casualizados com duas repetições 
subdivididas em conjuntos experimentais (BCCE), conduzidos em quatro locais I épocas de cultivo e três anos agrícolas. Os experimentos foram analisados em BCCE e também em blocos aumentados (BA) considerando-se aleatoriamente uma das duas repetições. Como ferramentas auxiliares foram empregadas as metodologias ER e AMMI. A análise conjunta dos 12 ambientes através da metodologia AMMI foi utilizada como padrão para comparações, através de correlações de Spearman $\left(r_{s}\right)$. Em relação a este padrão, a média das $r_{s}$ dos três anos foi estimada em: $54 \%$ para as médias dos experimentos em BA; $64 \%$ para os experimentos em BCCE; $65 \%$ para os experimentos em BA analisados pela metodologia ER; 69\% para os experimentos em BCCE analisados pela metodologia ER; $73 \%$ para os experimentos em BA analisados pela metodologia AMMI e 74\% para os experimentos em BCCE avaliados pela metodologia AMMI. Os resultados obtidos permitiram concluir que as metodologias para o estudo da interação GxE são capazes de aumentar as $r_{s}$ com o padrão, indicando a possibilidade de redução de duas para uma repetição nos experimentos intermediários através do uso de: a) metodologia AMMI ao invés da seleção baseada nas médias das duas repetições; b) metodologia ER (em dois dos três anos avaliados) ao invés da seleção baseada nas médias das duas repetições; c) metodologia AMMI (em dois dos três anos avaliados) ao invés da seleção baseada na metodologia ER. Com a redução do número de repetições (duas para uma) é possível diminuir sensivelmente os custos com a experimentação na fase intermediária de programas de melhoramento. 


\title{
REGRESSION AND UNI-MULTIVARIATE METHODOLOGIES FOR REDUCTION OF THE REPLICATION NUMBER IN EXPERIMENTS OF THE INTERMEDIARY PHASE OF A SOYBEAN BREEDING PROGRAM
}

\author{
Author: FERNANDO TOLEDO SANTOS DE MIRANDA \\ Adviser: Prof. Dr. NATAL ANTONIO VELLO
}

\section{SUMMARY}

The intermediary phase of a soybean breeding program involves the evaluation of a large number of genotypes (about 100 lines) in several environments, becoming this a very expensive step. The utilization of statistical methods that allow a refined analysis of the genotype $x$ environment (GxE) interaction, may generate gains in precision as a compensation to the expected increase in the GXE estimate and, thus, to permit the reduction of the replication number. Eberhart \& Russell (1966) (ER) methodology utilizes linear regression to study $G \times E$ interaction; the AMMI methodology employs the analysis of variance to fit effects of genotypes and environments and singular values decomposition to fit only the GxE interaction. The objective of this research was to evaluate experiments with 72 lines in randomized block design with two replications subdivided in sets with common checks (BCCE); these experiments were carried out in four locations / sow dates during three agriculture years. The experiments were analyzed in BCCE and also in augmented blocks (BA) by 
considering only one replication taking at random. As auxiliary tools were used $E R$ and AMMI methodologies. The joint analysis of the 12 environments through the AMMI methodology was used as pattern for comparisons through Spearman correlation $\left(r_{s}\right)$. In relation to this pattern, the mean of $r_{s}$ in the three years was estimated in: $54 \%$ for means of BA experiments, $64 \%$ for BCCE experiments, $65 \%$ for BA experiments analyzed with ER, 69\% for BCCE experiments analyzed with ER methodology, $73 \%$ for BA experiments analyzed with AMMI methodology and, $74 \%$ for BCCE experiments analyzed with AMMI methodology. The results indicated that the application of auxiliary methods for understanding GxE interaction were able to increase the $r_{s}$ with the pattern, opening the possibility for reducing the replication number in the experiments of the intermediary steps of soybean breeding programs. In conclusion, it was verified the possibility to reduce from two (BCCE) by one (BA) replication by using the following auxiliary methods of analysis: a) AMMI method instead of means of two replications as the unique selection criterion; b) ER method (in two of the three evaluated years) instead of means of two replications as the unique selection criterion; c) AMMI method (in two of the three evaluated years) instead of selection as based on ER method. The reduction from two to one replication makes possible to lower reasonably the experimental costs during the intermediary step of breeding programs. 


\section{INTRODUÇÃO}

A soja (Glycine max (L.) Merrill), graças aos conteúdos de óleo e de proteína de seus grãos (aproximadamente 20 e 40\%, respectivamente), associados às elevadas produtividades em diferentes ambientes, é considerada hoje a mais importante oleaginosa no mundo, sendo utilizada diretamente no preparo de alimentos, ou indiretamente como fonte de óleo e de proteína, na composição de alimentos e rações. A soja contribui com $22 \%$ da disponibilidade global de óleos e gorduras (Becker, 1996), sendo também a principal fonte de farelos protéicos de origem vegetal.

O Brasil é o segundo maior produtor de soja do mundo com uma produção estimada para a safra 2003/04 de aproximadamente 59 milhões de toneladas em 20,785 milhões de ha, alcançando a produtividade média de 2,836 kg ha-1 (IBGE, 2004).

A posição do Brasil, de grande produtor e exportador de soja deve-se muito ao trabalho do melhoramento genético, que em relativamente pouco tempo foi capaz de adaptar a cultura às condições dos cerrados brasileiros, ou seja, dias curtos e solos ácidos (Kiihl et al., 1983). Atualmente, a soja é cultivada em praticamente todo o Brasil.

A necessidade do fornecimento contínuo de materiais mais produtivos e adaptados para as condições em que os agricultores necessitam, muitas vezes, obriga o melhorista a utilizar em seus cruzamentos apenas materiais já adaptados, sabidamente portadores de muitos genes favoráveis, fato que implica no estreitamento da base genética da soja (Delannay et al., 1983; Hiromoto \& Vello, 1986; Vello, 1985; Vello et al., 1984). Desta maneira, os 
ganhos genéticos provavelmente serão cada vez menores e mais difíceis de serem conseguidos, de maneira a forçar os programas serão forçados a trabalhar com um número cada vez maior de progênies (Sousa, 1997).

O melhoramento genético da soja tem assim, o desafio de revelar diferenças cada vez menores em experimentos cada vez maiores (Sousa, 1997). Neste sentido, Gauch Jr. \& Zobel (1996) consideram que a interação genótipos por ambientes (GXE) e o ruído (parte da GxE devida a fatores predominantemente aleatórios) são as principais causas de dificuldades na seleção e indicação de novos cultivares. Quanto a GxE, duas estratégias clássicas podem ser consideradas: a) procurar por genótipos que sejam altamente produtivos e amplamente adaptados a todas as regiões de interesse; b) subdividir as regiões de interesse em macroambientes homogêneos, de maneira que a interação GxE seja desprezível dentro de cada macroambiente. Quanto ao ruído, quatro alternativas visando a obtenção de estimativas mais precisas são apontadas pelos autores: a) melhores experimentos; b) mais repetições; c) melhores delineamentos experimentais; e d) metodologias mais detalhadas para o estudo da GxE (aplicadas às médias dos tratamentos por experimento).

A metodologia AMMI ("Additive Main Effects and Multiplicative Interaction" - Efeitos Principais Aditivos e Interação Multiplicativa) pode ser útil tanto na melhoria das estimativas das médias dos tratamentos, quanto na quantificação e entendimento da interação GxE (Gauch Jr.\& Zobel, 1996). Entretanto, apesar da atual disponibilidade de recursos computacionais, essa metodologia tem sido pouco utilizada, devido à falta de informações sobre as vantagens em relação às metodologias tradicionalmente utilizadas.

O aumento do tamanho dos experimentos é outro fator que dificulta o controle do ruído, apesar de existirem delineamentos mais eficientes, como os blocos incompletos e os delineamentos espaciais. O delineamento de blocos aumentados tem sido muito utilizado quando o objetivo é a avaliação de um grande número de genótipos com o menor custo possível. A principal razão 
para esta preferência é a grande praticidade e flexibilidade deste delineamento, além do fato de permitir que tratamentos com pequeno número de propágulos (mudas, sementes, estacas, etc) sejam analisados estatisticamente.

A combinação de um delineamento experimental simplificado e de um delineamento mais sofisticado para análise da interação GXE pode propiciar uma boa relação entre custo e benefício para a seleção de linhagens superiores em experimentos preliminares, uma vez que a maior eficiência da análise AMMI pode compensar o provável aumento da estimativa de GxE decorrente da redução do número de repetições.

Assim, o objetivo deste trabalho foi avaliar a utilização da metodologia AMMI no estudo da interação GxE como uma ferramenta que permita, através da obtenção de estimativas mais precisas para as médias dos genótipos nos ambientes, a minimização do número de repetições, ou seja, viabilizar a utilização do delineamento de blocos aumentados, para os experimentos da fase intermediária de programas de melhoramento de soja. 


\section{REVISÃO DE LITERATURA}

\subsection{Delineamentos experimentais}

\subsubsection{Blocos aumentados}

Os delineamentos aumentados foram propostos por Walter T. Federer em 1955 (Duarte, 2000), com o objetivo principal de permitir a avaliação de um grande número de progênies nas primeiras fases dos programas de melhoramento, nas quais o número de sementes ou mudas de cada genótipo é restrito. $O$ delineamento baseia-se na inclusão dos genótipos a serem avaliados em uma única repetição (tratamentos adicionais) à estrutura de um delineamento padrão (blocos ao acaso, blocos incompletos, parcelas subdivididas, quadrados latinos, etc.), formado por um número restrito de testemunhas (tratamentos comuns) (Federer, 1958; 1961a; 1961b; Federer \& Raghavarao, 1975). O balanceamento não é necessário nem para os tratamentos adicionais nem para os tratamentos comuns (Scott \& Milliken, 1993; Federer, 1998).

Federer (1961a) apresenta as análises com e sem recuperação da informação interblocos para blocos completos aumentados e para látices balanceados aumentados. Federer \& Raghavarao (1975), Federer et al. (1975) apresentam as bases para análise de delineamentos aumentados considerando linhas e colunas. Federer (1998) apresenta a análise com recuperação da informação interregressões e Wolfinger et al. (1997) apresentam os procedimentos SAS para as análises com recuperação da informação 
interblocos para delineamentos em linhas e colunas e com recuperação da informação interregressões.

Lin \& Poushinky $(1983,1985)$ propuseram a sistematização da posição dos tratamentos comuns e denominaram de delineamentos 'aumentados modificados'. O delineamento Tipo 1 (Lin \& Poushinky,1983), para parcelas quadradas ou aproximadamente quadradas e o Tipo 2, para parcelas retangulares, com uma testemunha centralizada em todos os conjuntos (controle da parcela) formados por mais quatro subparcelas que podem ser ocupadas por tratamentos regulares ou por controles da subparcela. Os autores também apresentaram o ajuste para os tratamentos regulares através da estrutura do delineamento (Método 1), por um índice de fertilidade calculado através dos controles de parcelas (Método 2) e através de regressão também baseada nos controles de parcelas (Método 3). Diversos autores testaram estas alternativas, entre eles Lin \& Voldeng (1989), May et al., (1989), May \& Kozub (1995), indicando a superioridade do Método 3.

Sousa (1997) estudou alternativas experimentais para a avaliação de progênies e comparou os delineamentos em látice, em blocos aumentados, blocos completos, testemunhas intercalares, análise da covariância com um índice ambiental, o método de Papadakis e o método das médias móveis, tendo concluído que o delineamento de blocos aumentados pode ser utilizado, desde que se aplique uma intensidade de seleção moderada. Entretanto, o delineamento, segundo a autora, não se mostrou adequado para a estimação de parâmetros genéticos e fenotípicos.

Kempton \& Gleeson (1997) consideram que o delineamento em blocos aumentados é impraticável para um grande número de genótipos, pois ele requer um grande número de testemunhas para controlar a variação. Mead (1997) considera que o principal problema na utilização dos delineamentos aumentados é que os tratamentos adicionais irão inflacionar a variância entre parcelas, devido ao aumento do tamanho do bloco. Por essa razão, o autor considera adequada a adição de apenas dois tratamentos por bloco. 
Duarte (2000) apresenta uma pesquisa detalhada sobre o delineamento de blocos aumentados, fazendo considerações sobre a análise e a natureza fixa ou aleatória dos tratamentos adicionais e dos tratamentos comuns, e sugerindo metodologias alternativas visando melhorar a eficiência de experimentos instalados em blocos aumentados através da análise espacial. O autor também apresenta os procedimentos do programa SAS para a análise com recuperação da informação interblocos e intergenotípica.

\subsubsection{Blocos completos casualizados}

A literatura clássica sobre estatística experimental é extremamente abundante com relação ao delineamento de blocos completos casualizados. Textos clássicos, apresentam todos os procedimentos para a análise e um grande número de exemplos práticos; por exemplo, Pimentel Gomes (1990) considera que o delineamento em blocos casualizados talvez seja o mais importante delineamento experimental; e Steel \& Torrie (1960) salientam que existe ortogonalidade entre blocos e tratamentos o que leva a uma grande simplicidade aritmética, tornando este delineamento mais freqüentemente utilizado que qualquer outro.

A função e a utilidade das repetições em diminuir o erro experimental, melhorando as estimativas das médias dos tratamentos, é indiscutível. Entretanto, Bos (1983) mostrou que com o mesmo investimento financeiro, o ganho genético esperado pode ser maior quando se avalia um grande número de genótipos com uma menor precisão, do que quando se avalia um menor número de genótipos com grande precisão. Já Talbot (1997) considera que o aumento do número de repetições para mais de três por local é na maioria das situações, menos benéfico que o aumento equivalente no número de locais ou anos. 
Diversos autores como Rocha (1998), Miranda (1999), Unêda-Trevisoli (1999) e Rocha (2002) têm utilizado uma variação do delineamento clássico que consiste na subdivisão das repetições em conjuntos experimentais, em que, cada subdivisão recebe uma parte dos tratamentos principais (p. ex. progênies) e alguns tratamentos adicionais (testemunhas comuns); de maneira que cada repetição conta com um número de repetições das testemunhas equivalente ao número de conjuntos experimentais. Assim, cada repetição é montada no campo identicamente a um experimento em blocos aumentados.

\subsection{Delineamentos de tratamentos}

Delineamentos de tratamentos são delineamentos que desconsideram a estrutura experimental na qual os dados foram obtidos, ou seja, delineamentos aplicados às médias dos tratamentos e que consideram fatores inerentes a estes tratamentos. Os modelos para análise da GxE são assim considerados, bem como os delineamentos genéticos.

\subsubsection{Metodologia de Eberhart \& Russell (1966)}

Os métodos mais freqüentemente usados em estudos sobre a interação GxE são os que envolvem a utilização da regressão linear ( $R L)$, destacando-se os de Finlay \& Wilkinson $\left(1963^{\mathrm{a}}\right)$, citado por Eberhart \& Russell (1966) e por Cruz \& Regazzi (1994), entre outros) e o de Eberhart \& Russell (1966). Ambos os métodos utilizam como variável independente um índice ambiental $\left(\mathrm{I}_{\mathrm{j}}\right)$, composto pelo desempenho médio dos genótipos em relação aos ambientes; assim, o coeficiente angular da reta $\left(b_{i}\right)$ é uma medida da resposta de cada

\footnotetext{
${ }^{a}$ FINLAY, K. W.; WILKINSON, G. N. The analysis of adaptation in a plant-breeding programme. Australian Journal of Agricultural Research, v.14, n.5, p.742-754. 1963.
} 
genótipo à melhoria das condições ambientais representada pelo $\mathrm{l}_{\mathrm{j}}$. A diferença entre eles é que a metodologia proposta por Eberhart \& Russell (1966), utiliza os desvios da regressão $\left(\hat{\sigma}_{d_{i}}^{2}\right)$ como medida da estabilidade dos genótipos para os ambientes testados. Eberhart \& Russell (1966) estabeleceram como genótipo ideal aquele que tivesse $b_{i}$ igual a um e $\hat{\sigma}_{d_{i}}^{2}$ o menor possível. A literatura com aplicações destes métodos é extremamente vasta, mas alguns trabalhos como os de Zobel et al. (1988), Yau et al. (1995) e Rocha (2002) estabeleceram comparações entre métodos baseados em regressão e a metodologia AMMI e, por isso, tornam-se de interesse especial para o presente trabalho.

Yau (1995) compara a utilização da análise de RL com e sem dados transformados por $\log _{10}$ com a metodologia AMMI, recomendando que a metodologia AMMI seja utilizada para estudos mais detalhados, especialmente em experimentos envolvendo redes internacionais. $O$ autor apresenta resultados que suportam a hipótese de que a metodologia AMMI é ao menos igual e freqüentemente melhor que a RL quanto à proporção da soma de quadrados explicada pelo modelo. Já Rocha (2002) considera que a AMMI foi sempre mais eficiente do que a RL, corroborando os resultados obtidos por Zobel et al. (1988) e de acordo com as previsões apresentadas por Gauch Jr. (1992).

A aplicação de métodos baseados na RL para estudos da GxE é sujeita a diversas críticas, em sua maioria baseadas na ausência de independência entre a variável reposta e o $\mathrm{l}_{\mathrm{j}}$. Outras críticas são baseadas no fato de que o $\mathrm{l}_{\mathrm{j}}$ é considerado como uma medida livre de erro, embora esta última critica foi e pode ser corrigida utilizando a metodologia de Tai (1971) que considera os erros associadas ao $\mathrm{l}_{\mathrm{j}}$. O problema de não se considerar o erro associado ao $\mathrm{l}_{\mathrm{j}}$, pode em parte, ser minimizado através da utilização de um número grande de ambientes. 


\subsubsection{Metodologia AMMI}

A metodologia $A M M I$, um método uni-multivariado, é composta pela análise da variância dos efeitos principais, no caso os efeitos de genótipos (G) e de ambientes (E) e da análise multivariada dos efeitos da interação genótipos $x$ ambientes (GxE). Gauch (1992) fez uma análise histórica, considerando os modelos que conjuntamente fazem parte da análise AMMI, a análise de componentes principais (ACP) e a análise da variância (ANAVA). Segundo o último autor, a ACP foi idealizada por Pearson em 1901, que visualizou uma matriz bidimensional com $\mathrm{L}$ linhas e $\mathrm{C}$ colunas geometricamente como $\mathrm{R}$ pontos em C dimensões (ou o contrário) e propôs um método que permite representar essa matriz em poucas dimensões. A nuvem de pontos original com muitas dimensões, pode então ser transformada em uma compreensível projeção de poucos planos.

O modelo da ACP é multiplicativo, ou seja: idealizando um exemplo com uma média geral igual a 200 e com a utilização de apenas um eixo com os escores para genótipos e ambientes iguais a 5 e 7 respectivamente, a média esperada é de $200+(5 \times 7)=235$. No caso de apenas um plano não ser suficiente para explicar adequadamente os dados, poderiam ser utilizados mais eixos do que um, gerando um modelo com mais dois escores para genótipos e ambientes que seriam multiplicados entre si e, então, adicionados ao modelo.

Proposta por Fisher em 1918, ainda segundo Gauch (1992), a ANAVA calcula estimativas a partir dos desvios para genótipos e ambientes (diferença em relação à média), que somados à média geral, resultam na estimativa de um determinado genótipo em um determinado ambiente. Assim, considerando que os desvios para genótipos e ambientes têm o mesmo valor que os escores utilizados no exemplo anterior para componentes principais, o modelo da ANAVA fornece a estimativa da média como sendo $200+5+7=212$. A análise da 
variância possui um resíduo devido à falta de aditividade, que é justamente a GxE.

Gauch (1992) considera ainda que ambas as análises buscam resumir os dados contidos em uma matriz de GxE dados em um modelo que apresenta somado à média, um componente devido a genótipos e um componente devido a ambientes. A única diferença do ponto de vista conceitual é que na ANAVA, as estimativas dos efeitos dos genótipos e dos ambientes são somadas à média geral, enquanto que na ACP elas são multiplicadas entre si e depois somadas à média geral. $O$ autor considera que apesar da ACP ser mais antiga e considerada mais eficiente, a ANAVA tornou-se muito mais popular nos anos subseqüentes, devido à simplicidade dos cálculos exigidos e à fácil interpretação do modelo aditivo. A ACP ficou em segundo plano devido ao método interativo, que exige um grande recurso computacional, indisponível na primeira metade do século passado e pela maior dificuldade para a interpretação dos efeitos multiplicativos.

Concluindo, Gauch (1992) considera que Williams (1952) $)^{\mathrm{b}}$ e Pike \& Silverberg $(1952)^{\mathrm{C}}$ inventaram concomitantemente o modelo AMMI, sob a designação de "somas de funções mais produtos de funções", nas quais é possível substituir funções por números. Estes autores utilizaram a ACP apenas na matriz GxE de resíduos resultantes da ANAVA. Desta maneira, considerando a mesma média geral, e os mesmos desvios utilizados anteriormente na ANAVA (5 e 7 para genótipos e ambientes, respectivamente) e os escores 3 e 2 (para genótipos e ambientes), obtidos a partir do resíduo deixado pela ANAVA, obtêm-se a estimativa: $200+5+7+(3 \times 2)=241$. Kempton (1984) foi o primeiro a utilizar a metodologia em dados de produtividade, enfatizando a possibilidade da utilização do gráfico biplot (Gabriel, 1971) na interpretação dos resultados.

\footnotetext{
${ }^{\mathrm{b}}$ WILLIAMS, E. J. The interpretation of interactions in factorial experiments. Biometrika, v.39, p.65-81. c PIKE, E. W.; SILVERBERG, T. R. Designing mechanical computers. Machine Design, v.24, p.131137, 159-163.
} 
Willers et al. (1995) apresentam uma breve, porém completa explanação sobre as bases da análise AMMI. Gauch Jr. \& Zobel (1996) revisaram os principais avanços da metodologia AMMI entre 1992 e 1996. Segundo os autores, nesse período a metodologia tem se mostrado útil ao melhor entendimento de interações GxE complexas, salientando a participação da análise gráfica (biplot) e a capacidade da metodologia em construir um modelo rico em padrão (parte de GxE devida a fatores desconhecidos que causam alterações sistemáticas na GxE), deixando um resíduo rico em ruído, o que segundo os autores, traduz-se em maior acurácia. A utilização da análise AMMI pode significar um ganho de acurácia equivalente a 5 a 20 repetições. Os autores mostraram como a raiz quadrada dos autovalores, que não têm unidade, multiplicada pelos autovetores de genótipos e de ambientes, que têm a mesma unidade, são convenientemente utilizados para a construção do biplot.

Gauch Jr. \& Zobel (1996) consideram que a análise AMMI pode ser útil, tanto na identificação de genótipos com adaptação ampla, quanto na identificação de macroambientes homogêneos. Os custos para a implantação de análises estatísticas mais poderosas, incluíndo-se inclusive os custos com equipamento e pessoal qualificado, são compensatórios, quando comparados a um maior número de parcelas necessárias para a mesma eficiência. Salientam que a análise estatística não precisa ser a melhor que existe, mas deve ser a melhor possível, sem deixar de ser prática o suficiente para que o melhorista possa efetivamente utilizá-la.

Fox et al. (1997) também apresentam uma breve descrição do modelo AMMI, ressaltando que a possibilidade de se predizerem as médias de uma região é controversa, e que para tal se admite que a validação baseada em repetições adicionais é relevante na predição da performance em um novo ambiente. Estes autores sugerem ainda que dentro de um grupo de ambientes adequadamente agrupados quanto a GxE, esse valor preditivo não seria útil.

Crossa et al. (1991) salientam ainda que existe o risco de que interações de um único ambiente devidas a um estresse específico sejam sobressaltadas; 
assim, os resíduos devem ser cuidadosamente monitorados, de maneira a indicar quão bem os dados foram modelados. Outro problema considerado pelos autores é o fenômeno de que um padrão homogêneo em parte dos dados indique uma maior complexidade quando considerados todos os dados em conjunto. Este aparente paradoxo sugere que a extração de ruído pela AMMI requer pesquisas adicionais.

Johnson (2001) mostrou que o modelo não aditivo de Tukey com um grau de liberdade e o modelo de Mandel de feixe de linhas retas, são casos particulares de um mais geral, com interação multiplicativa representado pela análise AMMI. O autor faz uma cronologia histórica sobre o desenvolvimento dessa classe de modelos, apresentando exemplos para o pacote computacional SAS e enfatiza a utilização desses em conjuntos de dados sem repetição. Dagnelie (2001) faz algumas ressalvas quanto à utilização de delineamentos de tratamentos em experimentos sem repetições.

Gabriel (1971) apresenta a utilização do biplot na visualização de qualquer matriz de posto dois ou que possa ser resumida em uma matriz de posto dois, com especial importância na visualização de resultados originados da ACP; Kempton (1984) apresenta a utilização e interpretação de biplots para os modelos ANAVA, RL, ACP e AMMI e sugere, ainda, a utilização de barras horizontais proporcionais às produtividades para um biplot de $A C P$, como foi posteriormente utilizado por Fox et al. (1997) em uma análise AMMI. Ambos os autores consideram que os biplot são uma interessante ferramenta para a apresentação de resultados de diversas técnicas, com especial interesse para a análise da interação GxE.

Gauch Jr. (1988) explora as implicações das abordagens pós-ditiva e pré-ditiva quanto à acurácia das estimativas obtidas. O sucesso pós-ditivo diz respeito à adequação do modelo aos dados, enquanto o sucesso pré-ditivo, diz respeito à adequação entre um modelo construído a partir de uma parte dos dados e a validação desse modelo pelos dados restantes. Essas abordagens são utilizadas na tomada de decisão quanto à adoção ou não das fontes de 
variação em um modelo incompletamente especificado, como é o caso do AMMI. Segundo o autor, a abordagem pré-ditiva, em situações em que existe muito ruído, é considerada superior à abordagem pós-ditiva, por gerar estimativas mais próximas das médias verdadeiras. Outra vantagem da abordagem pré-ditiva é que os modelos selecionados tendem a ser mais simples e mais parcimoniosos. Através da abordagem pré-ditiva, é possível separar pela análise o que é padrão do que é ruído, gerando um modelo que é capaz de predizer os dados de validação melhor que os dados usados na construção do modelo, enquanto que pela abordagem pós-ditiva, o modelo pode ser no máximo tão preciso quanto os próprios dados. É apresentado um exemplo com soja no qual, pela abordagem pós-ditiva, três IPCAs ("Interaction Principal Components Analysis" - Componente Principal da Interação) são significativos, enquanto que pela abordagem pré-ditiva, apenas o primeiro eixo é considerado no modelo, sendo muito mais parcimonioso.

Zobel et al. (1988) comparam três metodologias tradicionais (ANAVA, ACP e RL) com a AMMI, com dados de soja: a ANAVA falhou em detectar a significância da GxE; já a ACP falhou em identificar e separar os componentes principais de genótipos e de ambientes e a RL falhou ao capturar apenas uma pequena parcela da soma de quadrados da GxE; o método mais utilizado, o de Finlay \& Wilkinson, não permite uma solução de quadrados mínimos e geralmente confunde a GxE com os efeitos principais, reduzindo o poder para os testes de significância; AMMI mostrou uma alta e significativa GXE com um claro sentido agronômico, permitindo separar os ambientes quanto à latitude e os genótipos quanto à precocidade.

Gauch \& Furnas (1991) apresentaram o programa MATMODEL para análise de modelos AMMI através de validação cruzada. O programa permite a estimação de parcelas perdidas e a análise para dados desbalanceados. Os autores ressaltam que as estimativas obtidas são tão acuradas quanto a média de duas a quatro repetições. Assim, os autores sugerem a utilização de poucas 
repetições com o aumento proporcional de genótipos a serem testados, graças a essa maior acurácia do modelo.

Yau (1995) compara a utilização da análise de regressão $(R L)$ com a AMMI e recomenda que a AMMI seja utilizada para estudos mais detalhados. $O$ autor considera que AMMI é ao menos tão eficiente e freqüentemente mais eficiente que a RL.

Annicchiarico (1997) compara em quatro grupos de dados de diferentes culturas, dois procedimentos baseados em validação cruzada para testar os eixos dos componentes principais da interação GxE, explorando as facilidades do programa MATMODEL. $O$ uso do teste $F$ de $G$ ollob $^{d}, F_{G H 2}, F_{R}$ e o critério heurístico baseado na taxa de sinal-para-ruído também são pesquisados. Não houve concordância entre os métodos para a seleção do modelo e o método de Gollob foi considerado adequado apenas para pequenos conjuntos de dados. $\mathrm{O}$ autor utiliza a propriedade de que a metodologia AMMI pode ser aplicada para qualquer conjunto de dados organizados em uma matriz de linhas e colunas e como o autor estava interessado em experimentos multi-locais repetidos em alguns anos, apenas a interação genótipos $x$ locais $(G \times L)$ foi utilizada na parte multiplicativa do AMMI, de maneira a reter no modelo somente os efeitos que são mantidos entre os anos.

Tai (1999) apresentou uma metodologia alternativa para a análise AMMI com a estimação dos componentes multiplicativos através de análise de variáveis canônicas, na qual os componentes significativos podem ser facilmente identificados através de um teste de $\chi^{2}$ desenvolvido por Seal $(1966)^{\mathrm{e}}$ que indica seqüencialmente quais os autovalores que são significativamente não diferentes de zero.

Cornelius \& Crossa (1999), utilizando estimadores de encolhimento ("shrinkage"), obtiveram resultados para a validação cruzada ao menos tão

\footnotetext{
${ }^{\mathrm{d}}$ GOLLOB, H. F. A statistical model which combines features of factor analitic and analysis of variance techniques. Psychometrika, v.33, p.73-115. 1968.

e SEAL, H. L. Multiplicative statistical analysis for biologists. Willey, New York. 1966.
} 
eficientes quanto os métodos truncados ( $\mathrm{F}_{\mathrm{GH} 1}$ e $\mathrm{F}_{\mathrm{GH} 2}$ entre outros) e BLUPs ('Best Linear Unbiesed Prediction'). Os autores concluiram que os dados utilizados para a validação cruzada devem ser ajustados para as diferenças entre repetições, e que o modelo que utiliza estimadores de encolhimento é muito provavelmente o mais preditivamente acurado. Na maioria das situações sem ajuste para repetições, com ou sem ajuste para as diferenças entre repetições, estimativas de "shinkage" foram sempre melhores que para os modelos truncados. Para situações em que exista padrão na interação, ou seja, em que a interação não é independentemente distribuída, o modelo utilizando estimadores de "shinkage" é superior ao BLUP. Os resultados sugerem que o modelo utilizando estimadores de "shinkage" é tão bom quanto os métodos truncados ou BLUP, e que elimina a necessidade tanto da validação cruzada quanto do teste de hipóteses. As estimativas de encolhimento utilizando graus de liberdade de Gollob ${ }^{d}$ são praticamente idênticas às obtidas por simulação ou interação. Portanto, do ponto de vista prático, esta alternativa deve ser utilizada.

Duarte \& Vencovsky (1999) propuseram a utilização da decomposição de valores singulares (DVS) como uma alternativa à utilização da ACP na análise AMMI. Os autores apresentaram uma detalhada descrição dos cálculos utilizados, um exemplo numérico e um programa para a análise AMMI utilizando o pacote SAS.

Diversos são os exemplos de aplicação da metodologia AMMI, desde a mais comum aplicação para o entendimento da interação GxE com e sem a utilização de covariáveis ambientais (Zobel et al., 1988; Yau,1995; Annicchiarico,1997; Abamu \& Alluri, 1998; Voltas et al., 1999; Lavoranti et al., 2001; Rocha, 2002 e Miranda et al., 2002), até a utilização para a análise de dialelos (Yan \& Hunt, 2002), passando também por estudos da interação patógeno x hospedeiro (Schneider et al., 1999). 


\section{MATERIAL E MÉTODOS}

Foram avaliadas 72 linhagens em quatro locais / épocas de cultivo e três anos agrícolas, totalizando 12 ambientes. Os 12 experimentos foram delineados em blocos ao acaso com duas repetições subdivididas em conjuntos experimentais com testemunhas comuns (BCCE). As análises estatisticogenéticas foram feitas de acordo com o delineamento BCCE e, também, através do delineamento em blocos aumentados (BA) tomando-se aleatoriamente uma das repetições. As médias ajustadas desses experimentos foram analisadas em cada ano quanto à interação GxE pelas metodologias de Eberhart \& Russell (1966) (ER) e AMMI. Dentro de cada ano, as médias ajustadas das análises individuais e as médias estimadas pelas metodologias de Eberhart \& Russell (1966) e AMMI foram comparadas através de correlações de Spearman com as estimativas das médias da análise AMMI considerando-se todos os 12 ambientes.

\subsection{Material genético}

As 72 linhagens de soja (Tabela 1) são provenientes de 11 populações denominadas seqüencialmente USP-1 a USP-11 (Vello et al., 1994; Hiromoto, 1996; Miranda, 1999), sendo quatro linhagens USP-1, duas USP-2, cinco USP3, 12 USP-4, três USP-5, quatro USP-6, sete USP-8, três USP-9, sete USP-10, e 21 USP-11. As linhagens de USP-1 a USP-5 foram abertas em $F_{8}$ e as linhagens de USP-5 a USP-11 foram abertas em $F_{5}$. Estas linhagens foram 
desenvolvidas pelo programa de melhoramento genético de soja, em andamento no Setor de Genética Aplicada às Espécies Autógamas do Departamento de Genética da Escola Superior de Agricultura "Luiz de Queiroz" (ESALQ), Universidade de São Paulo (USP).

As linhagens originadas das 11 populações foram previamente selecionadas quanto à resistência ao nematóide de cisto da soja (Heterodera glycines Ichnohe; NCS) em duas ocasiões por Hiromoto (1996) e Miranda (1999). As 11 populações são oriundas de seis cruzamentos envolvendo um genitor resistente ao NCS (Forrest, Foster ou Kirby) e um genitor adaptado (IAC Foscarin-31, Primavera, Paraná, FT-2, SOC81-76 ou FT79-3408). Assim, as linhagens originárias da população USP-1 são provenientes do cruzamento 'IAC Foscarin-31 x Forrest'; da população USP-2, USP-3 e USP4 do cruzamento 'Forrest x Primavera'; da população USP-5 de 'Paraná x Kirby'; das populações USP-6 e USP-7 de 'Kirby x FT-2'; das populações USP-8 e USP-9 de 'SOC8176 x Foster' e das populações USP-10 e USP-11 do cruzamento 'Foster $x$ FT79-3408'.

Em um programa de melhoramento de soja, a fase chamada de "Intermediária" ou "preliminar de terceiro ano" é caracterizada pela última safra antes de se iniciar os "testes finais" ou de VCU (valor de cultivo e uso) conduzidos em vários anos e locais. Esta fase geralmente envolve em torno de uma centena de linhagens. As linhagens utilizadas nesta pesquisa podem ser consideradas como se nesta fase estivessem.

\subsection{Caracterização dos ambientes}

Os experimentos para avaliação do potencial agronômico das linhagens foram conduzidos em três anos agrícolas (1998/99, 1999/00 e 2000/01, de agora em diante denominados apenas por 1998, 1999 e 2000). Em cada ano foram utilizadas quatro combinações de locais e épocas de semeadura, sendo 
que para os locais Anhembi e Areão os experimentos foram instalados apenas na época considerada como normal na região (semeadura em torno de 15 de novembro); já para o local ESALQ, os experimentos foram instalados em duas épocas de semeadura (normal e 15 dias mais tarde). Portanto, os experimentos representam um total de 12 ambientes. Todos os locais (ESALQ, Anhembi e Areão), estão situados no município de Piracicaba, S.P. (2242'30" de latitude Sul, 47³9'00" de longitude Oeste e $543 \mathrm{~m}$ de altitude). O solo do local ESALQ caracteriza-se por um latossolo vermelho-escuro eutrófico de textura argilosa e relevo ondulado, situando-se dentro da área experimental do Departamento de Genética (sede da ESALQ/USP). O local Anhembi caracteriza-se por apresentar solo aluvial distrófico, com textura médio-arenosa e relevo plano; situa-se na Estação Experimental Anhembi, às margens do rio Tietê, a aproximadamente $60 \mathrm{~km}$ da sede da ESALQ. O local Areão caracteriza-se por apresentar solo podzólico vermelho-amarelo distrófico, textura médio-argilosa e relevo ondulado; situa-se na Fazenda Areão, distante cerca de $3 \mathrm{~km}$ da sede da ESALQ, junto à Rodovia Piracicaba-Limeira.

\subsection{Avaliação do desempenho agronômico}

Foram instalados, a cada ano, quatro experimentos delineados em blocos casualizados com duas repetições estratificadas em conjuntos experimentais (BCCE) com tratamentos comuns ou testemunhas (IAS-5, IAC100, IAC-Foscarin 31 e Primavera).

As parcelas experimentais foram formadas por quatro fileiras de $5,0 \mathrm{~m} \mathrm{x}$ $0,5 \mathrm{~m}$, sendo a área útil $\left(4 \mathrm{~m}^{2}\right)$ formada pelas duas fileiras centrais da parcela, descartando-se meio metro em cada uma das extremidades. A densidade de semeadura utilizada foi de 30 sementes por metro linear, visando garantir, após o desbaste, uma densidade de 20 plantas por metro linear ou 400000 plantas por ha. 
Apenas o caráter produtividade em $\mathrm{Kg} \mathrm{ha}^{-1}\left(\mathrm{Kg} \cdot \mathrm{ha}^{-1}=\frac{10 \mathrm{PG}}{4}\right.$, em que PG = peso de grãos, com aproximadamente $13 \%$ de umidade, das plantas da área útil da parcela em $\mathrm{g} / 4 \mathrm{~m}^{2}$ ) foi considerado nesse trabalho.

\subsection{Delineamentos experimentais}

\subsubsection{Blocos aumentados}

Inicialmente, os experimentos instalados no campo em delineamento de blocos casualizados estratificados em conjuntos experimentais (BCCE) foram representados por uma única repetição, escolhida aleatoriamente, e analisados como blocos aumentados (BA).

Para as análises foram utilizados os procedimentos PROC GLM do pacote computacional SAS (análise intrablocos) apresentados por Wolfinger et al. (1997) e Duarte (2000), com base no modelo:

$$
Y_{i j}=\mu+\beta_{j}+\tau_{I}+\varepsilon_{i j} \quad \text {, em que: }
$$

$Y_{i j} \quad$ é a observação do i-ésimo tratamento no j-ésimo bloco;

$\mu$ é uma constante inerente a todas as observações;

$\beta_{j} \quad$ é o efeito aleatório do j-ésimo bloco $(j=1,2, \ldots, J)$

$\tau_{i} \quad$ é o efeito fixo do i-ésimo tratamento $(i=1,2, \ldots, p, p+1, p+2, \ldots, p+t$; sendo $p$ o número de linhagens, $t$ o número de testemunhas e $p+t=v$ o número total de tratamentos).

$\varepsilon_{i j r} \quad$ é o erro experimental aleatório, $\varepsilon_{i j k} \sim \operatorname{NID}\left(0, \sigma^{2}\right)$. 


\subsubsection{Blocos ao acaso com tratamentos comuns}

A seguir, os experimentos individuais (BCCE) foram analisados como em Carvalho (1991), desconsiderando-se o efeito da interação tratamentos comuns (testemunhas) $x$ conjuntos. Assim, foi considerado o modelo:

$$
Y_{i j k}=\mu+\tau_{i}+\beta_{j}+\theta_{k}+\varepsilon_{i j k} \quad, \text { em que: }
$$

$Y_{i j k}$ é a observação do i-ésimo tratamento no j-ésimo conjunto e na késima repetição;

$\mu$ é uma constante inerente a todas as observações;

$\tau_{i} \quad$ é o efeito fixo do i-ésimo tratamento;

$\beta_{j} \quad$ é o efeito aleatório do j-ésimo conjunto;

$\theta_{k} \quad$ é o efeito aleatório da k-ésima repetição;

$\varepsilon_{i j k}$ é o erro amostral ou erro dentro de parcelas, supondo-se $\varepsilon_{i j k} \sim N I D\left(0, \sigma^{2}\right)$ e independentes.

\subsubsection{Análises conjuntas}

As análises conjuntas dos experimentos em blocos aumentados também seguiram o modelo de Carvalho (1991), pois como ressalta Duarte (2000), este modelo corresponde a uma análise conjunta de experimentos em blocos ao acaso, considerando-se os conjuntos equivalentes aos blocos e as repetições equivalentes aos ambientes.

As análises conjuntas dos experimentos em blocos ao acaso com tratamentos comuns também seguiram o modelo de Carvalho (1991), apenas 
adicionando os efeitos de ambientes e a interação entre tratamentos e ambientes. Assim, o modelo resultante é o seguinte:

$$
Y_{i j k}=\mu+\tau_{i}+\beta_{j}+\alpha_{l}+\tau \alpha_{i l}+\varepsilon_{i j k}, \text { em que : }
$$

$Y_{i j k l}$ é a observação do i-ésimo tratamento no j-ésimo conjunto na k-ésima repetição e no l-ésimo ambiente;

$\alpha_{l} \quad$ é o efeito fixo do l-ésimo ambiente;

$\tau \alpha_{i l} \quad$ é o efeito aleatório da interação tratamentos $\mathrm{x}$ ambientes;

$\varepsilon_{i j k l} \quad$ é o erro amostral ou erro dentro de parcelas, supondo-se $\varepsilon_{i j k} \sim \operatorname{NID}\left(0, \sigma^{2}\right) ;$

$\tau_{i}$ e $\beta_{j}$ definidos no item anterior.

Considerando que os genótipos estejam na fase intermediária de avaliação experimental, não há sentido em se considerar o efeito de anos, pois apenas os genótipos considerados superiores serão utilizados para os testes finais. Assim, os anos não foram considerados e as análises foram sempre realizadas dentro de cada ano.

\subsection{Delineamentos de tratamentos}

Os delineamentos de tratamentos (Eberhart \& Russell (1966) e AMMI) foram aplicados às analises conjuntas dos dados analisados em BA e em BCCE, de maneira que foram realizadas duas análises para cada um dos modelos, gerando assim quatro conjuntos de dados com todas as combinações de delineamentos experimentais e de tratamentos para cada ano. 


\subsubsection{Método de Eberhart \& Russell (1966)}

O método de Eberhart \& Russell (1966) foi utilizado como padrão para a análise da GxE. As médias estimadas pelos modelos gerados na análise foram utilizadas para a posterior comparação com as médias estimadas pelo AMMI.

O método baseia-se em uma regressão linear simples de acordo com o modelo:

$$
Y_{i j}=\mu_{i}+b_{i} I_{j}+d_{i j}+\bar{\varepsilon}_{i j} \text {, em que: }
$$

$Y_{i j} \quad$ é a média do i-ésimo genótipo no j-ésimo ambiente;

$\mu_{i} \quad$ é a média do i-ésimo genótipo em todos os ambientes;

$b_{i} \quad$ é o coeficiente da regressão linear, que descreve a resposta do iésimo genótipo em relação aos ambientes e é estimado por $b_{i}=\frac{\sum_{j} Y_{i j} I_{j}}{\sum_{j} I_{j}^{2}}$, e testado pelo teste $t=\frac{b_{i}-1}{\sqrt{\frac{Q M D_{i}}{S Q I_{j}}}}$, sob a hipótese $\mathrm{H}_{0}$ : $b_{i}=1$, em que $\mathrm{QMD}_{\mathrm{i}}$ é o quadrado médio dos desvios da regressão e $S Q l_{j}$ é a soma de quadrados do $l_{j}$;

$I_{j}$ é o índice ambiental centralizado, definido por $I_{j}=\frac{1}{g} \sum_{i} Y_{i j}-\frac{1}{g e} \sum_{i j} Y_{i j} \quad$, o que faz com que $\sum_{j} I_{j}=0 ;$

$d_{i j} \quad$ é o desvio da regressão do i-ésimo genótipo no j-ésimo ambiente e o parâmetro de estabilidade $\left(\hat{\sigma}_{d_{i}}^{2}\right)$ é estimado por $\hat{\sigma}_{d_{i}}^{2}=\frac{\sum_{j} \hat{d}_{i j}}{e-2}$ e é 


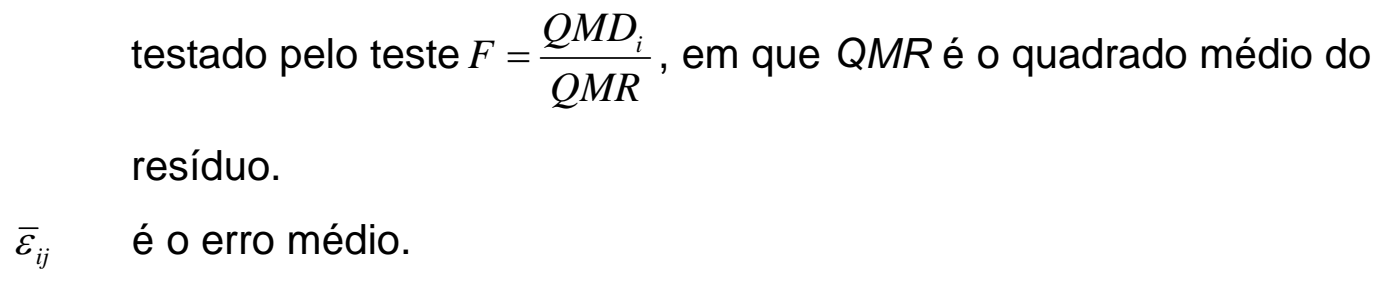

\subsubsection{Análise AMMI}

A análise AMMI ('Additive Main effects and Multiplicative Interaction' Efeitos principais aditivos e interação multiplicativa) (Gauch Jr. \& Zobel, 1996; Duarte \& Vencovsky, 1999; Chaves, 2001; Rocha, 2002) baseia-se, como o próprio nome diz, na análise em separado da parte aditiva do modelo (genótipos e ambientes), através da análise da variância e da parte multiplicativa (interação GxE) estimada por de análise multivariada (por decomposição de valores singulares). Assim, o modelo pode ser descrito por:

$$
\mathrm{Y}_{\mathrm{ger}}=\mu+\alpha_{\mathrm{g}}+\beta_{\mathrm{e}}+\sum_{\mathrm{n}=1} \lambda_{\mathrm{n}} \gamma_{\mathrm{gn}} \delta_{\mathrm{en}}+\rho_{\mathrm{ge}}+\varepsilon_{\mathrm{ger}}
$$

no qual, à semelhança de Gauch Jr. (1992):

$Y_{\text {ger }}$ é o valor observado no g-ésimo genótipo no e-ésimo ambiente e na r-ésima repetição;

$\mu \quad$ é a média geral;

$\alpha_{\mathrm{g}} \quad$ é o efeito do g-ésimo genótipo;

$\beta_{\mathrm{e}} \quad$ é o efeito do e-ésimo ambiente;

$\lambda_{n} \quad$ é o n-ésimo valor singular da matriz de resíduos (matriz GE) do modelo aditivo ( $\mathrm{Y}_{\mathrm{ij}}=\mu+\alpha_{\mathrm{g}}+\mathrm{b}_{\mathrm{e}}+\varepsilon_{\text {ger }}$ ) retido no modelo, em que $n$ é o número de componentes principais retidos no modelo $\{n=1,2, \ldots,[$ mín(G-1, E-1)]\}; 
$\gamma_{\mathrm{gn}} \quad$ é o valor do n-ésimo vetor singular correspondente ao g-ésimo genótipo;

$\delta_{\text {en }} \quad$ é o valor do n-ésimo vetor singular correspondente ao e-ésimo ambiente;

$\rho_{\text {ge }}$ é o resíduo da interação GxE ou resíduo AMMI, formado pelos $\min (\mathrm{G}-1, \mathrm{E}-1)-\mathrm{n}$ componentes principais, ou seja, os componentes principais não retidos no modelo;

$\varepsilon_{\text {ger }}$ é o erro experimental.

Os IPCAs (Componentes Principais da Interação GxE) retidos no modelo foram determinados pelo teste F desenvolvido em 1992 por P.L. Cornelius, M. Seyedsadr e J. Crossa ${ }^{\dagger}$ (citados por Cornelius et al.(1996) e Rocha (2002)):

$\mathrm{F}_{\mathrm{r}, \mathrm{n}}=\frac{\mathrm{SQ}_{\mathrm{GxE}}-\sum_{\mathrm{n}=1} \lambda_{\mathrm{n}}^{2}}{\mathrm{f}_{2} \mathrm{QM}_{\text {Erro Médio }}}$, em que $\mathrm{f}_{2}=(\mathrm{G}-1-n)(\mathrm{E}-1-n)$ são os graus de liberdade para cada IPCA, definidos em 1998 por H. F. Gollob ${ }^{d}$ citado entre outros por Gauch Jr. (1992).

Para a análise AMMI também foram obtidas as médias estimadas para cada combinação de genótipos e ambientes, que foram comparadas às médias esperadas provenientes do modelo de Eberhart \& Russell (1966) e com as médias das análises individuais.

\subsection{Correlações de Spearman}

Conhecidas também por correlações ordinais, são correlações não paramétricas entre variáveis formadas pela ordem de classificação das variáveis originais, através de dados variáveis como $r_{i}=1,2, \ldots, N$, sendo $r_{i} a$

\footnotetext{
${ }^{\mathrm{f}}$ CORNELIUS, P. L.; SEYEDSADR, M.; CROSSA, J. Using the shifted multiplicative model to search
} for "separability" in crop cultivar trials. Theoretical and Applied Genetics, v.84, n.1-2, p.161-172, 1992. 
ordem de classificação do genótipo i e N o número total de genótipos. Desta maneira, o coeficiente da correlação de Spearman entre duas médias estimadas pela combinação de BA ou BCCE e ER ou AMMI é dado por:

$$
r_{S}=1-\frac{6 \sum\left(r_{i j}-r_{i j}\right)^{2}}{g\left(g^{2}-1\right)}, \text { em que: }
$$

$r_{s}$ é o coeficiente de correlação de Spearman;

$r_{i j} \quad$ é a ordem de classificação do genótipo i na combinação j;

$r_{i j}$ é a ordem de classificação do genótipo i na combinação j';

$g$ é o número de pares $\left(r_{i j}, r_{i j}\right)$, que é igual ao número de genótipos.

As correlações de Spearman foram utilizadas para comparar as médias dos experimentos em BA, em BCCE, e as médias estimadas destes pelas metodologias ER e AMMI nos quatro ambientes dentro de cada ano. A correlação de Spearman também foi utilizada para comparar essas médias com as médias estimadas pela análise conjunta em BCCE dos 12 ambientes pela metodologia AMMI, consideradas como padrão ideal de comparação. 


\section{RESULTADOS E DISCUSSÃO}

\subsection{Considerações iniciais}

Os resultados das análises realizadas dentro de cada ano, porque na fase intermediária a seleção das linhagens é baseada em um único ano, são agora discutidos tendo em vista o número de repetições (uma para blocos aumentados ou BA e duas para blocos casualizados subdivididos em conjuntos experimentais ou BCCE) em cada um dos modelos utilizados (médias, Eberhart \& Russell (1966), ER + AMMI, ou seja, modelo aditivo para os efeitos principais e multiplicativo para a interação).

A análise AMMI combinando-se os 12 ambientes [(Anhembi, Areão, ESALQ-1 e ESALQ-2) x anos (1998, 1999 e 2000)], foi considerada a mais completa possível, gerando através do modelo selecionado as médias estimadas mais próximas o possível do ideal. Estas médias foram utilizadas como padrão de comparação para as médias ajustadas dos delineamentos experimentais e das médias estimadas dos delineamentos de tratamentos e para a combinação destes.

\subsection{Experimentos em blocos aumentados (BA) em 1998}

O cancro da haste da soja (CHS, Diaporthe phaseolorum f.sp. meridionalis) ocorreu em todos os ambientes analisados, com exceção do 
ambiente ESALQ em segunda época (ESALQ-2) em 1998; portanto neste último ambiente, a ausência de CHS favoreceu as linhagens oriundas das populações USP-6 e USP-7 descendentes do cruzamento 'Kirby x FT-2' em que 'FT-2' é suscetível e 'Kirby' é medianamente suscetível a essa doença (Miranda, 1999); as demais populações têm no mínimo um genitor resistente a CHS. A safra anterior foi o primeiro ano de cultivo de soja; antes disso, aquela área foi ocupada pela cultura do milho, o que pode explicar a entrada tardia do $\mathrm{CHS}$.

\subsubsection{Análise da variância (ANAVA) dos experimentos em BA em 1998}

Para a análise dos experimentos em 1998 foram selecionadas aleatoriamente as primeiras repetições dos experimentos em Anhembi e ESALQ-2 e as segundas repetições dos experimentos em Areão e ESALQ-1 (Tabela 2).

De acordo com a tabela 3, o experimento ESALQ-2 apresentou a maior média geral (2901 kg ha-1) seguido pelo ambiente Anhembi (2880 $\left.\mathrm{kg} \mathrm{ha}^{-1}\right)$, que teve o menor CV (13\%). O ambiente ESALQ-1 apresentou a menor média (2625 kg ha-1 ) e o maior CV (22\%). Através da ANAVA foi possível detectar a existência de diferenças significativas entre genótipos apenas em Anhembi, e o desdobramento do efeito de genótipos revelou que estas diferenças eram devidas a diferenças entre as linhagens. No ambiente ESALQ-2, o desdobramento do efeito de genótipos revelou a existência de diferenças entre testemunhas ao nível de $94 \%$ de probabilidade (Tabela 3). A comparação das médias (Tabela 4), mostrou que as 16 linhagens selecionadas $(p=20 \%)$ foram sempre mais produtivas que todas as quadro testemunhas, nos quatro ambientes de 1998. Todavia, o teste de Dunnett não detectou diferenças significativasentre as linhagens mais produtivas e a testemunha mais produtiva em nenhum dos ambientes, não permitindo uma avaliação baseada nesta 
estatística para a seleção das linhagens. A Tabela 4 também evidencia diferenças nas ordens das linhagens nos quatro ambientes, fato que já indica a possível existência de interação GxE em 1998.

A ANAVA conjunta evidenciou a existência de diferenças entre os ambientes de interação entre genótipos e ambientes (Tabela 5), o que torna não recomendável a utilização das médias gerais dos genótipos para a seleção, pois a média pode mascarar a superioridade ou inferioridade de genótipos em subgrupos de ambientes. De fato, para as médias gerais nos quatro ambientes (Tabela 6), o teste de Dunnett contra a testemunha mais produtiva não detectou linhagens superiores entre as 16 linhagens selecionadas $(p=20 \%)$.

\subsubsection{Metodologia de Eberhart \& Russell (1966) (ER) dos experimentos em BA em 1998}

A análise ER (Tabela 7) mostrou a existência de diferenças entre genótipos dentro de ambientes, o que já havia sido mostrado pela análise individual para o ambiente Anhembi (Tabela 3); a análise ER evidenciou ainda que os ambientes são responsáveis por diferenças significativas nas médias dos genótipos (Ambiente Linear) e que não existem diferenças entre os coeficientes lineares ( $G \times E$ Linear). $E$ que existem diferenças entre os desvios desvio das linhagens em relação ao modelo (Desvio Combinado). De fato a ER permitiu, através da avaliação dos parâmetros coeficientes da regressão ( $\beta$ ) e da variância dos desvios $\left(\sigma_{d}^{2}\right)$ (Tabela 8), a substituição de duas linhagens consideradas instáveis (USP-8-25 e USP-4-6) do grupo das 16 mais produtivas selecionadas $(p=20 \%)$ para a próxima fase pelas linhas USP-11-33 e USP-1121, consideradas produtivas e estáveis nesse grupo. A instabilidade das linhagens em experimentos com uma repetição (BA), deve ser considerada com cautela pois o ruído associado às diferenças ambientais dentro do experimento é somente parcialmente removido através do erro calculado apenas com as 
testemunhas. Este ruído aparece confundido com os efeitos da interação GxE, inflacionando os desvios do modelo $\left(\sigma_{d}^{2}\right)$.

A Tabela 8 mostra ainda que os ambientes ESALQ-2 e Areão foram considerados favoráveis, e o ambiente Anhembi foi considerado neutro, enquanto o ambiente ESALQ-1 foi considerado desfavorável. As médias estimadas para as 16 linhagens mais produtivas e para as 16 linhagens selecionadas pela metodologia ER também são apresentadas nesta tabela.

Considerando todos os genótipos, a correlação de Spearman entre as médias ajustadas do experimento em BA e as médias estimadas pelo modelo ER foi de 71\% (Tabela 56), variando de 66 a 80\% (Tabela 53).

\subsubsection{Metodologia AMMI dos experimentos em BA em 1998}

A análise AMMI resultou na seleção do modelo AMMI 1 $\left(\hat{Y}_{g e}=\alpha_{g}+\beta_{e}+\lambda_{1} \gamma_{g 1} \delta_{e 1}\right)$ (Tabela 9) e, considerando como linha de corte os valores maiores que 10 e menores que -10 para o primeiro componente principal da interação (IPCA 1), possibilitou a eliminação de quatro linhagens consideradas instáveis (USP-4-5, USP-8-25, USP-4-9 e USP-4-6). Em substituição a estas linhagens, as linhagens USP-11-33, USP-11-21, USP-1113 e USP-9-8 (Tabela 10) foram selecionadas. A Tabela 10 apresenta também as médias estimadas segundo o modelo AMMI 1 para as 16 linhagens mais produtivas e para as 16 linhagens selecionadas pela metodologia AMMI.

A representação gráfica em biplot (Figura 1) mostra que a grande maioria das linhagens pode ser considerada estável ou próxima da estabilidade, variando muito mais quanto à produtividade do que quanto à estabilidade, e que as linhagens mais produtivas apresentaram a tendência de estarem associadas ao ambiente Anhembi, enquanto as menos produtivas, apresentaram a tendência de estarem associadas aos ambientes Areão e ESALQ-2 (elipse 
negra). As testemunhas formaram um grupo bastante compacto variando basicamente quanto à produtividade e apresentando também uma pequena associação com o ambiente Anhembi. A disposição dos genótipos em um ângulo inclinado sugere, segundo Gauch Jr. (1992), que a utilização de um modelo de regressão linear, como o de ER pode obter um bom ajuste para estes dados.

O ambiente ESALQ-1 pôde ser considerado estável, enquanto que os demais foram considerados instáveis; o ambiente Anhembi foi o mais instável, enquanto que o ambiente ESALQ-2 o mais favorável. O ambiente Areão apresentou estabilidade intermediária e produtividade acima da média. A análise gráfica dos ambientes mostra uma disposição quase vertical, evidenciando que eles diferem basicamente quanto à GxE (elipse vermelha) e que os ambientes mais contrastantes são Anhembi e ESALQ-2 (Figura 1). A principal razão para este contraste pode ser a ocorrência de doenças, pois Anhembi é um ambiente extremamente favorável para o desenvolvimento de doenças, em especial a Mancha parda ou Septoriose (Septoria glycines), enquanto que em ESALQ-2', o potencial de inóculo para doenças ainda era considerado baixo.

De maneira geral, a metodologia AMMI permitiu uma série de interpretações biológicas dos dados, o que sem dúvida ajuda o melhorista em sua tomada de decisão. Entretanto, a eliminação de quatro linhagens consideradas instáveis, contra duas eliminadas pela metodologia de ER, deve ser tomada com cautela pois o nível de corte da metodologia AMMI é totalmente empírico. Deve-se considerar ainda que parte da variação que foi analisada como GxE deve-se ao maior ruído decorrente da utilização de apenas uma repetição, que pode ter sido determinante para a instabilidade de determinados genótipos. Entretanto, a DVS (Decomposição de Valores Singulares) tem a capacidade de identificar padrão nos primeiros eixos, deixando o ruído para o resíduo da análise AMMI. Desta maneira, não é 
possível estabelecer um relação direta entre o IPCA 1 e estes ruídos, como ocorreu para a metodologia ER entre estes ruídos e o $\sigma_{d}^{2}$.

As $r_{s}$ das médias ajustadas dos experimentos com uma repetição (BA) analisados pela metodologia AMMI com as médias brutas e com os experimentos analisados pela metodologia ER foram de 67 e $85 \%$ respectivamente (Tabela 56), mostrando que a análise AMMI e a análise de ER se eqüivaleram, o que sustenta a capacidade da análise AMMI para a seleção de modelos (Gauch Jr., 1992). Entretanto, as $r_{s}$ entre a análise AMMI e as médias são menores que as $r_{s}$ entre a análise ER e as médias, indicando que à medida em que o modelo fica teoricamente mais eficiente as $r_{s}$ entre os modelos e as médias originais diminui.

\subsection{Experimentos em blocos casualizados subdivididos em conjuntos experimentais (BCCE) em 1998}

\subsubsection{Análise da variância (ANAVA) dos experimentos em BCCE em 1998}

As ANAVAs individuais analisadas em BCCE (Tabela 11) não mostraram uma redução para os CVs; entretanto, foram capazes de aumentar a significância para as diferenças já detectadas pela análise em BA (Tabela 3, Anhembi) e detectar diferenças não detectadas anteriormente no ambiente ESALQ-1: como na análise em BA, apenas em Anhembi foram detectadas diferenças entre linhagens, em ESALQ-1, a diferença detectada entre genótipos foi devida a diferenças entre as testemunhas e em ESALQ-2 ao contraste entre linhagens e testemunhas.

O teste de Dunnett detectou apenas a superioridade da linhagem USP-627 sobre a testemunha mais produtiva (IAC-100) em ESALQ-2 (Tabela 12).

A ANAVA conjunta para os experimentos em BCCE em 1998 (Tabela 13) detectaou apenas as diferenças entre os ambientes; como a GxE foi não 
significativa, foi possível utilizar as médias dos genótipos para a seleção; entretanto, o teste de Dunnett não detectou nenhuma linhagem superior a melhor testemunha para o grupo dos $20 \%$ melhores desempenhos (Tabela 14). Isto evidencia, como na análise dos experimentos em BA, a dificuldade enfrentada pelo melhorista em utilizar procedimentos estatísticos baseados na ANAVA para seleção de linhagens no estádio preliminar de um programa de melhoramento de soja.

As médias das correlações de Spearman $\left(r_{s}\right)$ entre as médias ajustadas dos experimentos em BA e em BCCE em 1998 foi de 77\% (Tabela 56), nunca sendo menor que 71\% (ESALQ-1, Tabela 53). Em relação ao experimento em $\mathrm{BA}$, analisado pala metodologia de ER e pela metodologia AMMI, as $r_{s}$ foram respectivamente, 67 e 71\%, mostrando que as classificações das médias ajustadas foram bastante semelhantes para uma ou para duas repetições e, desta maneira, as aplicações dos modelos de ER e AMMI para os dados dos experimentos em BA mantiveram praticamente o mesmo nível para as $\mathrm{r}_{\mathrm{s}}$.

\subsubsection{Metodologia de Eberhart \& Russell (1966) (ER) dos experimentos em BCCE em 1998}

Apesar da interação GxE ser não significativa, o desdobramento desta pela ER permitiu verificar que os ambientes foram responsáveis por diferenças significativas nas médias dos genótipos (Ambiente Linear) (Tabela 15). A análise conjuntados experimentos em BCCE não detectou diferenças significativas entre os coeficientes angulares. e entre os desvios do modelo (Tabela 15). No experimento em BA (Tabela 7), foram detectadas diferenças para o desvio combinado, evidenciando diferenças quanto à estabilidade dos genótipos estudados. Esta diferença entre as análises em BA e BCCE pode ser explicada pelas melhores estimativas das médias dos genótipos propiciada pelo BCCE. 
De acordo com a Tabela 16, a análise ER permitiu ainda classificar os ambientes Areão e ESALQ-2 como favoráveis (sendo ESALQ-2 o mais favorável), o ambiente ESALQ-1 como o mais desfavorável e o ambiente Anhembi como praticamente neutro.

Do grupo das 16 linhagens mais produtivas $(p=20 \%)$, as linhagens USP4-6 e USP 4-19 puderam ser identificadas como não responsivas $(\beta<1)$ e, portanto, foram eliminadas do grupo das 16 linhagens selecionadas. As linhagens USP-4-6, USP-4-9, USP-4-10 e USP-8-4 foram consideradas instáveis. As melhores estimativas permitidas pelo experimento em BCCE e o menor valor para o resíduo médio propiciaram a identificação de um maior número de linhagens não responsivas e instáveis. Em substituição a estas linhagens, foram selecionadas as linhagens USP-3-2, USP-11-33, USP-10-30, USP-11-19 e USP-10-13 consideradas produtivas e estáveis. Para a análise dos experimentos com duas repetições (BCCE) através da metodologia ER foi possível considerar as linhagens com valores altos para os $\sigma_{d}^{2}$ como instáveis, pois os valores para a interação GxE estão mais puros.

$A r_{s}$ de $85 \%$ entre os experimentos em BA (uma repetição) e em BCCE (duas repetições) analisados pela metodologia ER (Tabela 56), permitiu que dentre as 16 linhagens selecionadas pelo experimento em BCCE também fossem selecionadas pelo experimento em BA as seguintes 10 linhagens: USP11-38, USP-4-5, USP-11-27, USP-4-12, USP-10-10, USP-11-21, USP-11-41, USP-11-33, USP-11-19 e USP-10-13.

Ainda de acordo com a Tabela 56, a $\mathrm{r}_{\mathrm{s}}$ entre os experimentos em BCCE analisado pela metodologia de ER e as médias dos experimentos em BA e em BCCE foram de 75 e 62\%, respectivamente. Esta diferença de 13\% (75\%-62\%) entre correlações é relativamente expressiva, principalmente se for considerado que as médias dos experimentos em BA e BCCE foram semelhantes em classificação, indicando possibilidade da redução do número de repetições com o uso da metodologia ER no estudo da interação GxE. 


\subsubsection{Metodologia AMMI dos experimentos em BCCE em 1998}

A análise AMMI selecionou o modelo AMMI $1\left(\hat{Y}_{g e}=\alpha_{g}+\beta_{e}+\lambda_{1} \gamma_{g 1} \delta_{e 1}\right)$ (Tabela 17), utilizando como linha de corte (Figura 1) os valores menores que 10 e maiores que 10 para o IPCA 1, foi possível identificar as linhagens USP11-38 e USP-4-10 como instáveis (Tabela 18). Estas linhagens foram então substituídas pelas linhagens USP-3-2 e USP-11-33 para formar o grupo das 16 linhagens selecionadas $(p=20 \%)$. A análise AMMI dos experimentos em BCCE em 1998, permitiu ainda considerar todas as testemunhas como estáveis (Tabela 18).

Os ambientes Anhembi e ESALQ-2 apresentaram os maiores e menores valores para o IPCA 1 (64,34 e -33,96, respectivamente) podendo ser esta combinação de ambientes considerada como a mais contrastante. Areão e ESALQ-1 apresentaram valores intermediários para o IPCA 1, mostrando alguma associação com o ambiente ESALQ-2 (mesmo sinal) (Tabela 18).

A Figura 2 do biplot para o modelo AMMI1 do experimento com duas repetições (BCCE) mostra que as linhagens, representadas em negro, em sua grande maioria estão dispostas dentro da faixa de estabilidade; entretanto, em comparação com a Figura 1 (biplot para o experimento com uma repetição, BA), um maior número de linhagens está dentro desta faixa e, de maneira geral, os genótipos estão mais próximos do valor 0 para o IPCA 1 devido à maior precisão gerada pelo BCCE. Isto mostra que o modelo AMMI não distingue entre as distorções causadas pela falta de precisão causada pelo experimento com uma repetição (BA) daquelas causadas pela interação GxE, ou seja, a Figura 1 apresenta estas distorções confundidas, enquanto a Figura 2 apresenta predominantemente as distorções devido a GxE.

A $r_{s}$ entre a análise AMMI em BA e BCCE foi mais baixa (62\%, para média de quatro locais / épocas de 1998, Tabela 56), variando de 41 a 74\% (Tabela 53) entre os quatro locais / épocas. Portanto, as duas repetições 
propiciaram maiores mudanças nas classificações dos genótipos do que a metodologia ER ou as médias.

Pela Tabela 56, as $r_{s}$ entre as médias para o experimento com duas repetições (BCCE) estimadas pelo modelo $A M M I$ e as médias dos experimentos com uma e com duas repetições foram 53 e 63\%, respectivamente; em relação às médias dos experimentos em BCCE foi de $49 \%$. A $r_{s}$ entre as médias dos experimentos em BCCE estimadas pela metodologia AMMI e as médias dos experimentos em BA foram não significativas $(P=0,0723)$. Portanto, considerando a análise AMMI como a mais completa, verifica-se que a adição de uma repetição aumentou a correlação em 10\% tanto para as médias quanto para as médias estimadas pela metodologia ER. Além disso, o decréscimo das $r_{s}$ no sentido da médias dos experimentos em BA (uma repetição) mostra que tanto a utilização de repetições quanto o emprego de delineamentos de tratamentos (ER e AMMI) para o estudo da interação GxE são eficientes em gerar estimativas mais próximas das geradas pelos experimentos com duas repetições estimadas pelo modelo AMMI.

As $r_{s}$ praticamente idênticas entre as médias dos experimentos em BCCE estimadas pela metodologia $\mathrm{AMMI}$ e as médias estimadas pelas metodologias AMMI e ER com uma e duas repetições (62 e 63\% respectivamente), juntamente com as superioridades destas em relação as $r_{s}$ com as médias (39\% para BA e $49 \%$ para BCCE), reforçam a idéia de que é possível utilizar uma repetição para a seleção de linhagens na fase intermediária do programa de melhoramento desde que se utilize a metodologia AMMI como ferramenta auxiliar.

De maneira semelhante ao observado para BA (Figura 1), nos experimentos em BCCE (Figura 2), as testemunhas novamente apareceram dispostas em um grupo bastante compacto, em que todas puderam ser consideradas estáveis e menos produtivas que a média geral. A estabilidade destes cultivares comerciais é esperada, especialmente em cultivares com alta longevidade como é o caso de 'IAS-5', 'PRIMAVERA' e 'IAC Foscarin-31'. A 
estabilidade também é esperada em cultivares com resistência a estresses bióticos e abióticos como é o caso da 'IAC Foscarin-31', resistente à acidez do solo (Mascarenhas et al. 1990) e 'IAC-100', resistente a insetos e a doenças de final de ciclo (Miranda et al., 2003a; Miranda et al. 2003b). Porém, a produtividade inferior à média não era esperada para o grupo das testemunhas, embora isto possa ser explicado pela superioridade dos novos genótipos (linhagens selecionadas) em relação aos mais antigos (testemunhas). Entretanto, a testemunha IAC-100 não apresenta um potencial produtivo para concorrer com a maioria dos cultivares em condições normais de cultivo, sendo especificamente utilizada para a produção de soja orgânica. A testemunha IAS5 , embora com um elevado potencial produtivo, é apenas moderadamente resistente ao cancro da haste (Yorinori, 1996), o que sem dúvida prejudicou o seu desempenho, dada a ocorrência mais ou menos intensa desta doença. $A$ testemunha IAC Foscarin-31, um dos cultivares mais plantados para a rotação com cana-de-açúcar no Estado de São Paulo, foi prejudicada principalmente nos ambientes de alta fertilidade (ESALQ-1 e ESALQ-2) devido ao seu maior acamamento.

A análise da Figura 2 permitiu visualizar claramente 0 contraste entre 0 local Anhembi e os outros dois locais (Areão e ESALQ). O local Anhembi apresenta uma topografia plana, solo bem arenoso, com acidez corrigida pela aplicação de calcário dolomítico, tornando-se um ambiente muito favorável ao cultivo da soja, fato que poderia explicar as médias bem mais elevadas de produtividade de grãos, relativamente aos locais Areão e ESALQ. Nas Figuras 1 e 2, os ambientes se dispuseram verticalmente, mostrando que as principais diferenças entre eles foram devidas a GxE, as quais foram capturadas pelo IPCA 1. Mantido este padrão, apenas os ambientes Anhembi e ESALQ-2 seriam suficientes para gerar dados para a seleção de linhagens na fase intermediária, diminuindo pela metade os custos de instalação destes experimentos. 


\subsection{Experimentos em blocos aumentados (BA) em 1999}

\subsubsection{Análise da variância (ANAVA) dos experimentos em BA em 1999}

Para a análise dos experimentos em 1999 foram escolhidas aleatoriamente as segundas repetições dos experimentos em Anhembi e ESALQ-2 e as primeiras repetições dos experimentos em Areão e ESALQ-1 (Tabela 2).

As ANAVAS individuais dos experimentos em BA de 1999 (Tabela 19), permitiram verificar que o local Anhembi apresentou a maior média (3732 kg ha-

${ }^{1}$ ) e o menor CV (12\%), sendo possível detectar diferenças entre os genótipos $(G)$; no e desdobramento de $G$ em linhagens $(L)$, testemunhas $(T)$ e linhagens versus testemunhas (LvsT), foram detectadas diferenças entre L e LvsT. O ambiente Areão apresentou a menor média (1539 kg ha-1) e o maior CV (25\%); neste ambiente ocorreu um problema de matocompetição, com forte infestação de plantas daninhas reduzindo o potencial produtivo das linhagens e a precisão do experimento. No ambiente ESALQ-2, com média intermediária (2486 kg ha-1) e CV (24\%) considerado alto, também foi possível detectar apenas diferenças para LvsT. O ambiente ESALQ-1 apresentou média (2319 kg ha-1) e CV (19\%) semelhantes aos apresentados pelo ambiente ESALQ-2, entretanto, a ANAVA não detectou diferenças significativas para nenhuma das fontes de variação.

A Tabela 20 apresenta as médias dos genótipos e os valores de probabilidade para o teste de Dunnett contra a melhor testemunha; embora as diferenças entre as melhores linhagens e a melhor testemunha tenham sido muito altas (cerca de 50\%), que não foi detectado nenhum contraste significativo entre as médias nos experimentos em BA de 1999.

A ANAVA conjunta dos experimentos em BA em 1999 (Tabela 21) permitiu observar que existem diferenças entre os ambientes e entre genótipos, 
e que as diferenças entre genótipos são devidas a diferenças entre linhagens e no contraste linhagens vs. testemunhas.

De acordo com a Tabela 22, o teste de Dunnett possibilitou a identificação da linhagem USP-10-10 (3540 kg ha-1) como superior à testemunha mais produtiva (IAS-5, com $2381 \mathrm{~kg} \mathrm{ha}^{-1}$ ).

\subsubsection{Metodologia de Eberhart \& Russell (1966) (ER) dos experimentos em BA de 1999}

A Tabela 23 mostra que a ANAVA, segundo a metodologia de ER, evidenciou a existência de diferenças entre genótipos dentro de ambientes e que os ambientes são responsáveis por diferenças significativas nas médias dos genótipos (Tabela 23), não detectando diferenças entre os $\beta$ e entre os $\sigma_{d}^{2}$ dos genótipos estudados.

A Tabela 24 indicou apenas três linhagens com $\beta$ significativos, e sete linhagens selecionadas com $\sigma_{d}^{2}=0$. As linhagens USP-8-2, USP-11-21 e USP10-18 apresentaram adaptação específica a ambientes favoráveis.

Em 1999, a $r_{s}$ entre as médias e as médias estimadas pela metodologia de ER foi de 55\%, evidenciando que a ER foi capaz de modificar a ordem de classificação dos genótipos nos ambientes pela aplicação do modelo (Tabela 56). Pela Tabela 54, as $r_{s}$ entre as médias ajustadas e as médias estimadas pelo modelo ER variaram de $83 \%$ (ESALQ-2) a 38\% (Areão); esta última correlação pode ter sido tão baixa porque envolve o local Areão, onde ocorreu o problema com infestação de plantas daninhas. 


\subsubsection{Metodologia AMMI dos experimentos em BA em 1999}

De acordo com as Tabelas 25 e 26, o modelo selecionado pela metodologia AMMI foi o modelo AMMI 0, ou seja, apenas foram considerados

os efeitos de genótipos e de ambientes $\left(\hat{Y}_{g e}=\alpha_{g}+\beta_{e}\right)$, ou seja, não foi levado em conta o efeito da interação. Isto implica que a classificação das médias dos genótipos selecionados não muda em relação às médias ajustadas do experimento em BA, entretanto, para a composição das médias estimadas não foi levado em conta o efeito da interação.

Pela Tabela 56, a $r_{\mathrm{s}}$ entre as médias estimadas pela metodologia AMMI e as médias ajustadas dos experimento em BA foi de $52 \%$, que a metodologia AMMI foi capaz de alterar as classificações dos genótipos nos ambientes, de maneira semelhante ao observado com o método ER. A $r_{s}$ entre as médias estimadas para BA pelas metodologias ER e AMMI foi de 68\%, mostrando que as médias estimadas resultantes tem maior correlação entre si do que médias originais.

\subsection{Experimentos em blocos casualizados subdivididos em conjuntos experimentais (BCCE) em 1999}

\subsubsection{Análise da Variância (ANAVA) dos experimentos em BCCE em 1999}

A Tabela 27 evidencia que Anhembi foi o local mais favorável com 3672 $\mathrm{kg} \mathrm{ha}^{-1}$, apresentando também o menor CV (13\%) e Areão o mais desfavorável com $1598 \mathrm{~kg} \mathrm{ha}^{-1}$ e $26 \%$ de CV, seguindo a mesma tendência da análise em BA 1999. Os ambientes ESALQ-1 e ESALQ-2 apresentaram médias e CVs semelhantes (2204 $\mathrm{kg}^{-1}$ ha $21 \%$ e 2487 e $20 \%$ respectivamente) e relativamente intermediários. 
A ANAVA detectou diferenças significativas entre genótipos em todos os ambientes para os experimentos instalados em BCCE em 1999. Em Anhembi, estas diferenças foram devidas a diferenças entre linhagens $(L)$ e ao contraste entre linhagens e testemunhas (LvsT), o mesmo ocorrendo com o ambientes ESALQ-2. No ambiente Areão foram detectadas diferenças entre $L$, entre testemunhas $(T)$ e para LvsT. No ambiente ESALQ-1 foram encontradas diferenças entre $L$ e entre $T$.

Pela Tabela 28, apesar das melhores linhagens terem produzido cerca de $50 \%$ a mais do que a melhor testemunha, o teste de Dunnett detectou linhagens significativamente mais produtivas que a melhor testemunha nos experimentos em BCCE em 1999; no entanto, o teste detectou a superioridade da testemunha mais produtiva (IAC Foscarin-31 com $1748 \mathrm{~kg} \mathrm{ha}^{-1}$ ) em relação à testemunha IAC-100, que produziu apenas $918 \mathrm{~kg} \mathrm{ha}^{-1}$ no local Areão.

A ANAVA conjunta dos experimentos em BCCE em 1999 (Tabela 29) detectou diferenças entre ambientes e entre genótipos (G). No desdobramento de $G$ foi possível verificar que estas diferenças ocorreram entre linhagens $(L)$ e no contraste LvsT. A interação GxE não foi significativa (Tabela 29), permitindo que as médias dos genótipos fossem utilizadas para a seleção. Entretanto, o teste de Dunnett (Tabela 30) não detectou nenhuma linhagem significativamente superior à testemunha mais produtiva, apesar das melhores linhagens terem produzido muito mais que a melhor testemunha.

A correlação de Spearman entre a classificação das médias ajustadas dos experimentos em BA (uma repetição) e em BCCE (duas repetições) em 1999 foi de 79\% (Tabela 56), variando de 72 a 89\% (Tabela 54), evidenciando que os experimentos com uma ou com duas repetições geram médias brutas bastante semelhantes. Como ocorreu entre as médias nos experimentos em $B A$, as médias dos experimentos em BCCE também apresentaram $r_{s}$ mais baixas com as médias dos experimentos em BA estimadas pelas metodologias de ER e AMMI (56 e 66\% respectivamente). 


\subsubsection{Metodologia de Eberhart \& Russell (1966) (ER) dos experimentos em BCCE em 1999}

A metodologia de ER foi capaz de detectar diferenças entre genótipos dentro de ambientes (E) e para E Linear. Não foram encontradas diferenças entre os coeficientes angulares, nem para os desvios do modelo (Tabela 31).

O estudo dos parâmetros estimados também não possibilitou encontrar linhagens inadaptadas ou instáveis no grupo das 16 linhagens selecionadas (Tabela 32). A análise ER permitiu ainda identificar os ambientes Areão e ESALQ-1 como desfavoráveis, o ambiente Anhembi como favorável e o ambiente ESALQ-2 como relativamente neutro.

As $r_{s}$ entre as médias estimadas para os experimentos em BA e em BCCE analisadas pela metodologia ER foram de $74 \%$ (Tabela 56), variando de 92 a 61\% (Tabela 54), evidenciando novamente que à semelhança do que ocorreu com as médias brutas, as médias estimadas pela metodologia ER também foram semelhantes. A $r_{\mathrm{s}}$ entre as classificações das médias ajustadas dos experimentos em BCCE e as classificações das médias estimadas pela metodologia ER foi de $71 \%$, mostrando que as estimativas baseadas na metodologia ER geraram estimativas bastante semelhantes às médias de duas repetições e às médias estimadas pela mesma metodologia a partir de uma única repetição. Entretanto, a rs entre as médias de duas repetições (BCCE) estimadas pela metodologia ER e as médias brutas para uma repetição foi mais baixa (55\%), mostrando que a metodologia ER pode melhorar as estimativas destas médias. 


\subsubsection{Metodologia AMMI dos experimentos em BCCE em 1999}

A análise AMMI permitiu selecionar o modelo AMMI $0\left(\hat{Y}_{g e}=\alpha_{g}+\beta_{e}\right)$, como ocorreu para os experimento em BA, o que pode ser explicado pela elevada $r_{s}$ entre os experimentos em BA e em BCCE (Tabelas 33 e 34). Podese considerar que, quando a análise AMMI seleciona o modelo AMMI 0 , a análise de ER foi mais informativa que a análise AMMI, pois os parâmetros apresentados pela ER permitiram, através da visualização dos $\beta$ e dos $\sigma_{d}^{2}$, mesmo sem a identificação de genótipos não adaptados ou instáveis, uma melhor compreensão do comportamento dos genótipos nos ambientes. Esta falta de informação proveniente do modelo AMMI 0 poderia ser solucionada pela adoção do modelo $A M M I$ 1, que geraria este tipo de informação; entretanto, isto poderia levar a erros de interpretação devido à utilização de ruídos como padrão.

Pelas tabelas 54 e 56, as $r_{s}$ entre médias estimadas pela análise AMMI para os experimentos em BA e em BCCE, foi de $75 \%$, diminuindo gradativamente até as médias ajustadas nos experimentos em BA ( $75 \%$ com as médias estimadas pela metodologia $\mathrm{AMMI}$ dos experimentos com uma repetição, $68 \%$ com as médias estimadas pela metodologia de ER para os experimentos com duas repetições, $51 \%$ com as médias estimadas pela metodologia de ER dos experimentos com uma repetição e com as médias dos experimentos com duas repetições e $43 \%$ com as médias dos experimentos com uma repetição). Portanto, quanto mais complexo o modelo menores ficaram as $r_{s}$ com as médias dos experimentos com uma repetição (BA); a utilização de duas repetições intensificou esse afastamento. 


\subsection{Experimentos em blocos aumentados (BA) em 2000}

No ambiente ESALQ-2 em 2000 ocorreu um ataque de lagartas (Anticarsia gemmatalis) após o florescimento, favorecendo a testemunha IAC100, resistente a insetos (Rossetto et al.,1989).

\subsubsection{Análise da variância (ANAVA) dos experimentos em BA em 2000}

Foram escolhidas aleatoriamente para a análise em BA em 2000 as segundas repetições nos ambientes Anhembi, ESALQ-1 e ESALQ-2 e a primeira repetição no ambiente Areão.

As ANAVAs individuais para os ambientes em 2000 analisadas em BA (Tabela 35) detectaram diferenças significativas apenas em ESALQ-2 (média de $2268 \mathrm{~kg} \mathrm{ha}^{-1}$ e $\mathrm{CV}=11 \%$ ) entre genótipos $(\mathrm{G})$ e em todas as fontes de variação do desdobramento de $G$ : linhagens $(L)$, testemunhas $(T)$ e linhagens versus testemunhas (LvsT). Em contraste, o ambiente Areão apresentou a menor média e o maior CV (1944 kg ha ${ }^{-1}$ e $22 \%$, respectivamente), não sendo possível encontrar diferenças significativas para nenhuma das fontes de variação estudadas.

O ambiente Anhembi apresentou a maior média (3517 $\left.\mathrm{kg} \mathrm{ha}^{-1}\right)$ e um CV considerado bom (12\%). Nesse ambiente, a ANAVA detectou diferenças significativas entre testemunhas e para LvsT (Tabela 35).

No ambiente ESALQ-1, com média de $2406 \mathrm{~kg}$ ha-1 e CV de 17\%, a ANAVA detectou diferenças entre genótipos e dentro dessa fonte de variação (linhagens e para o linhagens vs. testemunhas).

$\mathrm{Na}$ Tabela 36 observa-se que as linhagens selecionadas sempre produziram mais do que a melhor testemunha. $O$ teste de Dunnett contra a testemunha mais produtiva detectou diferenças significativas entre 'IAC-100' 
(3678 $\mathrm{kg} \mathrm{ha}^{-1}$ ) e Primavera (2713 $\mathrm{kg} \mathrm{ha}^{-1}$ ) no ambiente Anhembi e entre a linhagem USP-8-25 (3596 kg ha $\left.{ }^{-1}\right)$ e a testemunha Primavera (2234 kg ha $\left.{ }^{-1}\right)$ no ambiente ESALQ-2 (Tabela 36).

Pela Tabela 37, a análise conjunta para os experimentos em BA em 2000 possibilitou identificar diferenças significativas entre ambientes $(E)$, entre genótipos $(G)$ e para a interação GxE. Através do desdobramento foi possível verificar que as diferenças entre genótipos eram devidas a diferenças entre linhagens e ao contraste LvsT.

Como a GXE foi significativa, não se deve utilizar as médias dos genótipos visando selecionar linhagens com adaptação a todos os ambientes testados, pois a ordem de classificação das linhagens difere entre os ambientes. Realmente, a Tabela 36 mostra diferenças nas ordens de classificação das linhagens entre os locais / épocas; diferenças significativas entre linhagens e a melhor testemunha ocorreram apenas no ambiente ESALQ2. O teste de Dunnett entre as médias das linhagens no9s quatro locais / épocas e a melhor testemunha não detectou nenhum contraste significativo (Tabela 38).

\subsubsection{Metodologia de Eberhart \& Russell (1966) (ER) dos experimentos em BA em 2000}

De acordo com a Tabela 39, a ANAVA, segundo a metodologia ER, identificou diferenças significativas para todas as fontes de variação. A decomposição de GxE em $\mathrm{G}$ dentro de $\mathrm{E}$ foi altamente significativa mostrando que além dos genótipos apresentarem um comportamento diferencial nos diferentes ambientes, eles também apresentaram diferenças dentro dos ambientes.

O efeito de Ambientes Linear também foi significativo evidenciando que os ambientes influenciaram os genótipos linearmente. A interação GxE Linear 
significativa evidencou diferenças significativas entre os $\beta$ dos genótipos. A significância dos Desvios Combinados mostrou a existência de genótipos instáveis (Tabela 39).

Através da observação dos parâmetros $\beta$ e $\sigma_{d}^{2}$ (Tabela 40) foi possível identificar no grupo das linhagens mais produtivas $(p=20 \%)$, quatro linhagens instáveis: USP-11-15, USP-10-11, USP-11-12 e USP-11-46. Estas linhagens foram substituídas pelas linhagens USP-11-17, USP-4-8, USP10-18 e USP-8-6, consideradas produtivas e estáveis.

A média das correlçõs $\left(r_{s}\right)$ entre as médias brutas e as médias estimadas pela metodologia de ER para BA em 2000 foi de 59\% (Tabela 56).

\subsubsection{Metodologia AMMI dos experimentos em BA em 2000}

O modelo selecionado pela análise $\mathrm{AMMI}$ foi o modelo AMMMI 2 $\left(\hat{Y}_{g e}=\alpha_{g}+\beta_{e}+\lambda_{1} \gamma_{g 1} \delta_{e 1}+\lambda_{2} \gamma_{g 2} \delta_{e 2}\right)$ (Tabela 41). As médias das linhagens mais produtivas ( $\mathrm{p}=20 \%)$, os IPCA 1 e IPCA 2 e as médias estimadas para essas linhagens segundo o modelo AMMI 2 encontram-se na Tabela 42. Observa-se que as linhagens USP-11-12 e USP-11-46 foram consideradas instáveis para os dois parâmetros, enquanto que as linhagens USP-11-18 e USP-11-36 foram consideradas instáveis apenas pelo IPCA 1 e as linhagens USP-11-10 e USP11-15 foram consideradas instáveis pelo IPCA 2. Em substituição a estas linhagens, as linhagens produtivas e estáveis USP-11-17, USP-4-8, USP-8-6, USP-11-27, USP-5-1 e USP-5-5 foram colocadas no grupo das 16 linhagens selecionadas com base na análise AMMI dos experimentos em BA em 2000.

A análise gráfica através deveria ser realizada através de um gráfico em três dimensões para permitir a análise das médias do primeiro e do segundo IPCAs; entretanto, devido a maior facilidade para a interpretação, este gráfico foi substituído por dois biplots com as médias por IPCA 1 (Figura 3) e IPCA 1 
por IPCA 2 (Figura 4) que devem ser analisados simultaneamente. A Figura 3 explicita o relacionamento dos efeitos principais com a interação GxE , mas as conclusões a respeito da interação devem ser tiradas apenas após a observação da Figura 4, pois, sendo os IPCAs ortogonais entre si, a observação apenas do IPCA 1 pode considerar pontos próximos que em profundidade (considerando o IPCA 2) estariam distantes.

Os dois biplots (Figuras 3 e 4) revelam que a grande maioria dos genótipos foi considerada estável e que as testemunhas formaram um grupo compacto e estável. A testemunha IAC-100, resistente a insetos, embora bastante próxima das outras testemunhas ficou com o sinal negativo para os dois componentes principais demonstrando uma associação com o ambiente ESALQ-2, que sofreu com um ataque de lagartas.

$\mathrm{O}$ ambiente Anhembi, mais produtivo, também foi o ambiente mais estável, o que concorda com as observações de Whitehead \& Allen (1990) que consideram que, trabalhando com a metodologia de ER, os ambientes com baixo estresse oferecem uma maior probabilidade de selecionar linhagens superiores tanto para ambientes de baixo quanto de alto estresse. Para a análise da Figura 4, que envolveu apenas a GxE, os ambientes espalharam-se em todos os quadrantes o que indica que todos os ambientes geram informações importantes para a seleção de linhagens estáveis. O ambiente ESALQ-1 foi muito contrastante com o ambiente ESALQ-2 e o ambiente Areão com o ambiente Anhembi, porém em menor intensidade.

Pela tabela 56, as médias das correlações $\left(r_{s}\right)$ entre as médias estimadas pela análise AMMI e as médias brutas foram maiores que as $r_{s}$ entre as médias brutas e as estimadas pela metodologia de ER (69\% e 59\%, respectivamente), ambas relativamente semelhantes à $r_{s}$ entre as médias estimadas pela metodologia ER e a metodologia AMMI (60\%). 


\subsection{Experimentos em blocos casualizados subdivididos em conjuntos experimentais (BCCE) em 2000}

\subsubsection{Análise da variância (ANAVA) dos experimentos em BCCE em 2000}

Pela Tabela 43, as ANAVAS individuais para os experimentos em BCCE em 2000 detectaram diferenças significativas entre linhagens em todos os ambientes (Tabela 43). Em comparação com experimentos em BA (Tabela 35), os CVs diminuíram e as médias se mantiveram nos mesmos patamares, com exceção do ambiente ESALQ-2 onde a utilização das duas repetições elevou o CV de 11 para 21\%, muito provavelmente devido ao ataque de lagartas que foi mais desuniforme na primeira repetição (utilizada apenas para a análise em BCCE). Neste último ambiente, a análise em BCCE também diminuiu os níveis de significância. Em todos os outros ambientes, a análise em BCCE detectou maior número de efeitos significativos e aumentou a significância dos efeitos já detectados pela análise em BA.

Como na ANAVA em BA, o ambiente Anhembi foi o mais produtivo (3545 $\mathrm{kg} \mathrm{ha}^{-1}$ ), mas na ANAVA em BCCE, este ambiente também apresentou o menor CV (11\%). Neste ambiente foram detectadas diferenças significativas para todas as fontes de variação, exceto entre repetições.

O ambiente ESALQ-1 apresentou a segunda maior média e o segundo menor CV (2541 kg ha-1 e 15\%, respectivamente). Neste ambiente, a ANAVA detectou diferenças significativas entre repetições e entre genótipos (G). Na decomposição de $\mathrm{G}$ foi possível verificar que as diferenças foram devidas às diferenças entre linhagens (L) e ao contraste linhagens versus testemunhas (LvsT) (Tabela 43).

Para o experimento em BCCE foram detectadas diferenças significativas para todas as fontes de variação, exceto para LvsT no ambiente Areão (Tabela 43). A ANAVA neste ambiente analisado em BA não havia detectado diferenças para nenhuma fonte de variação (Tabela 35). 
No ambiente ESALQ-1 e para o experimento em BCCE foram detectadas diferenças entre as repetições (Tabela 43); para as outras fontes de variação, a ANAVA em BCCE aumentou o nível de significância relativamente ao experimento em BA (Tabelas 43 e 35).

Pela Tabela 44, o teste de Dunnett permitiu, pela maior precisão propiciada pelo BCCE, identificar em Anhembi a superioridade da testemunha IAC-100 (3735 kg ha ${ }^{-1}$ ) em relação às testemunhas IAC Foscarin-31 e Primavera (3161 e $2833 \mathrm{~kg} \mathrm{ha}^{-1}$ respectivamente). Permitiu ainda detectar a superioridade das linhagens USP-9-14 (3968 kg ha-1), USP-8-4 (3906 kg ha ${ }^{-1}$ ), USP-11-12 (3870 kg ha ${ }^{-1}$ ), USP-11-13 (3608 kg ha-1), USP-11-49 (3526 kg ha${ }^{1}$ ), USP-11-15 (3515 kg ha-1) e USP-11-6 (3508 $\left.\mathrm{kg} \mathrm{ha}^{-1}\right)$ em relação à testemunha mais produtiva IAS-5, com $2381 \mathrm{~kg} \mathrm{ha}^{-1}$ no ambiente ESALQ-1.

De acordo com a Tabela 45, a ANAVA conjunta permitiu, como na ANAVA em BA, observar que os efeitos de ambientes e de genótipos foram altamente significativos. O desdobramento permitiu verificar a existência de diferenças significativas entre linhagens e para LvsT. Ao contrário do que ocorreu na ANAVA em BA, a interação GxE foi não significativa, o que mais uma vez mostra que a falta de precisão provocada pelo delineamento em BA inflaciona a GxE na ANAVA conjunta dos experimentos em BA, o que não ocorreu nos experimentos em BCCE.

Embora a não significância da interação GxE permita a utilização das médias gerais dos genótipos para a seleção (Tabela 45), o teste de Dunnett não detectou nenhuma linhagem superior à testemunha mais produtiva (IAS-5, com $2535 \mathrm{~kg} \mathrm{ha}^{-1}$ ) (Tabela 46).

Apesar das discrepâncias ocasionadas no ambiente ESALQ-2 devido ao ataque de lagartas, fato que certamente ocasionou a $r_{s}$ mais baixa em todas as comparações entre experimentos em BA e BCCE (67\%, Tabela 55), a média das $r_{s}$ para o ano de 2000 ficou em patamar semelhante ao dos outros anos (79\%, Tabela 56). Provavelmente, houveram efeitos compensadores dos 
ambientes Anhembi e ESALQ-1, nos quais as $r_{\mathrm{s}}$ foram bastante altas (90 e 82\% respectivamente, Tabela 55).

Pela Tabela 56, a rs entre as médias dos experimentos com duas repetições (BCCE) e as médias do experimentos com uma repetição (BA) estimadas pelas metodologias de ER e AMMI foram respectivamente $60 \%$ e $61 \%$, mostrando que as estimativas das médias através destas duas metodologias causaram maiores mudanças na ordem de classificação dos genótipos do que a utilização de duas repetições.

\subsubsection{Metodologia de Eberhart \& Russell (1966) (ER) dos experimentos em BCCE em 2000}

A ANAVA proposta pela metodologia de ER dos experimentos em BCCE em 2000 detectou diferenças entre os genótipos dentro dos ambientes (Tabela 47) o que já havia sido verificado nas análise individuais (Tabelas 43 e 44); possibilitou ainda verificar que os ambientes influenciaram significativamente os genótipos (A Linear). Pela Tabela 48, a ANAVA proposta pela metodologia de ER não detectou diferenças entre os $\beta$ e nem entre os $\sigma_{d}^{2}$ para os experimentos em BCCE em 2000. Observa-se também na Tabela 48 que a análise dos parâmetros da metodologia ER não detectou nenhuma linhagem instável ou não adaptada, indicando que as variações encontradas na análise de ER dos experimentos em BA foram removidas pela maior precisão dos experimentos em BCCE.

Pela Tabela 56, a médias das $r_{s}$ entre as médias estimadas dos experimentos em BA e BCCE analisados pela metodologia ER foi $71 \%$. Era esperado que a $r_{s}$ entre as médias ajustadas do experimento em BA em BCCE fossem menores do que a entre os dois experimentos analisados pela metodologia de ER; entretanto, elas ficam no mesmo patamar (69 e 70\%, respectivamente). Esta distorção pode ser explicada pelo ataque de lagartas 
ocorrido no ambientes ESALQ-2, pois apenas neste ambiente a $r_{\mathrm{s}}$ entre as médias do experimento em BCCE (duas repetições) estimadas pela metodologia de ER e as médias brutas do experimento em BA (uma repetição) foi excepcionalmente alta (Tabela 55).

Pela Tabela 56, a média das $r_{s}$ entre as médias dos experimentos com duas repetições estimadas pela metodologia de ER e as do experimento com uma repetição estimadas pela metodologia $\mathrm{AMMI}$ foi de $70 \%$, portanto, no mesmo patamar que o encontrado entre a primeira e as médias brutas com uma ou com duas repetições.

\subsubsection{Metodologia AMMI dos experimentos em BCCE em 2000}

Pela Tabela 49, observa-se que foi selecionado o modelo AMMI 0 $\left(\hat{Y}_{g e}=\alpha_{g}+\beta_{e}\right)$. As médias e as estimativas para as médias nos ambientes em 2000 são apresentadas na Tabela 50, na qual se observa que as linhagens selecionadas produziram bem mais que a melhor testemunha.

Pela Tabela 56, a média das $r_{s}$ entre as médias estimadas pela metodologia AMMI para os experimentos em BCCE e as médias estimadas pela metodologia AMMI para os experimentos em BA foi de 75\%, menor apenas que a rs entre as médias estimadas pelas metodologias de ER e AMMI para os experimentos em BCCE (duas repetiçõs) que ficou em $80 \%$. A $r_{s}$ entre as

médias estimadas para o experimento com duas repetições (BCCE) estimada pela metodologia $\mathrm{AMMI}$ e as médias estimadas dos experimentos com uma repetição (BA) pela metodologia de ER foi $68 \%$, esta correlação cai levemente entre para as médias dos experimentos com duas repetições e as médias dos experimentos em BCCE estimadas por AMMI (66\%), e diminui ainda mais entre as médias dos experimentos uma repetição (BA) e repetições e as médias dos experimentos em BCCE estimadas por AMMI (60\%). A queda progressiva destas $r_{s}$ foi menos acentuada em 2000 do que nos outros anos. 


\subsection{ANAVA segundo a metodologia AMMI considerando conjuntamente os 12 ambientes}

A análise conjunta dos 12 ambientes em BCCE (Tabela 51) evidenciou que existem diferenças entre os ambientes e entre os genótipos testados, e que a interação GxE foi não significativa. Entretanto, como ressaltam Gauch Jr (1992) e Zobel et al. (1988), é comum a metodologia AMMI encontrar padrões significativos na GxE, mesmo com GxE não significativa. Assim, o modelo selecionado foi o modelo AMMI $2\left(\hat{Y}_{g e}=\alpha_{g}+\beta_{e}+\lambda_{1} \gamma_{g 1} \delta_{e 1}+\lambda_{2} \gamma_{g 2} \delta_{e 2}\right)$.

Através desse modelo foram geradas médias estimadas para todos os ambientes e métodos testados (Tabela 52); a seleção baseada nesse modelo possibilitou que, das 16 linhagens mais produtivas $(p=20 \%)$, apenas as linhagens USP-10-10, USP-9-14, USP-4-9, USP-11-19 e USP-11-27 fossem consideradas estáveis e produtivas. As linhagens USP-11-36, USP-11-44, USP8-5, USP-11-46, USP-11-33, USP-4-12, USP-11-17, USP-10-18, USP-11-41, USP-8-2 e USP-10-13, consideradas produtivas e estáveis foram, então, selecionadas para completar o grupo das 16 linhagens selecionadas.

A análise do biplot da Figura 5 mostra que a grande maioria das linhagens pode ser considerada estável; além disso o posicionamento destas em ângulo em relação ao IPCA 1 indica que a regressão é um bom modelo para o estudo do comportamento dessas linhagens (Gauch Jr, 1992). A observação da Figura 5 mostra ainda que as testemunhas formaram um grupo compacto, estável e menos produtivo que a média geral.

A observação da Figura 5 mostra também que o ambiente Anhembi formou um grupo contrastante em relação aos outros ambientes e que as linhagens mais produtivas tenderam a estarem associadas a este ambiente.

A Figura 6, que mostra apenas diferenças quanto à interação, mantêm o ambiente Anhembi como um grupo separado, mas os valores para o IPCA 2 
apresentam valores contrastantes para os anos 1998 e 2000; por esta razão, o ambiente Anhembi pode ser considerado o mais instável entre os ambientes analisados. Observa-se também na Figura 6, que algumas linhagens consideradas estáveis pelo IPCA 1 passaram a ser instáveis pelo IPCA 2, mas de uma maneira geral, a maioria das linhagens ainda ficou dentro dos limites de estabilidade.

A Tabela 52 apresenta os valores para o IPCA 1 e para o IPCA 2 e as médias estimadas para o modelo AMMI 2 para as 16 linhagens selecionadas $(p=20 \%)$ considerando-se os 12 ambientes. Essas médias estimadas foram utilizadas para comparar a eficiência relativa dos delineamentos experimentais e de tratamentos avaliados em se aproximar desse padrão.

\subsection{Correlações de Spearman $\left(r_{s}\right)$}

As Tabelas 53, 54 e 55 apresentam as $r_{s}$ entre as médias dos experimentos em BA e BCCE nos quatro locais / épocas de cultivo, as médias estimadas destes experimentos, submetidas às metodologias ER e AMMI, para os anos 1998, 1999 e 2000 e as médias estimadas pelo modelo AMMI 2 considerando os 12 ambientes.

Em todos os anos, as médias ajustadas dos experimentos em BA (médias BA) apresentaram a menor $r_{s}$ com as médias estimadas pelo modelo AMMI 2 para os 12 ambientes (padrão) (Tabela 56), sendo sempre menores (diferencial próximo a $10 \%$ ) que as $r_{s}$ entre as médias para os experimentos em BCCE (médias BCCE) e o padrão (Tabela 56) Este ganho de correlação entre as classificações, causado pela utilização de duas repetições, ao invés de uma, pode ser usado como uma medida para a comparação das médias estimadas pelas metodologias ER e AMMI.

Pela Tabela 56, nos anos 1998 e 2000, a r em relação ao padrão foram maiores para as médias BA estimadas pela metodologia ER (71\% em 1998 e 
$72 \%$ em 2000) do que as médias BCCE (66\% em 1998 e 65\% em 2000); entretanto em 1999, a $r_{\mathrm{s}}$ entre as médias BA estimadas por ER e o padrão (54\%) foi maior apenas que a $r_{s}$ entre médias BA e o padrão (49\%). Em 1998 a $r_{s}$ entre as médias BCCE segundo a metodologia ER e o padrão (66\%) foi menor que a $r_{s}$ entre as médias BA estimadas por ER e o padrão (71\%). Em 1999, a $r_{s}$ entre as médias BCCE segundo a metodologia ER e o padrão (69\%) foi maior que a $r_{s}$ entre as médias BA estimadas por ER e o padrão (54\%) (Tabela 56). Em 2000, as $r_{s}$ entre as médias BCCE estimadas por ER e 0 padrão, e entre as médias BA estimadas por ER e o padrão foram iguais (72\%).

Ainda pela Tabela 56, em 1998 as $r_{\mathrm{s}}$ entre as médias BA estimadas por ER e o padrão (71\%) foram menores apenas que a $r_{s}$ entre as médias BA estimadas por AMMI e o padrão (72\%). Em 1999, as $r_{s}$ entre as médias BA estimadas por AMMI e o padrão (78\%) foram mais altas que as $r_{s}$ entre 0 padrão e médias BCCE estimadas por ER (69\%), que entre o padrão e as médias BA estimadas por ER (54\%), e que entre o padrão e as médias BCCE (61\%). Por outro lado, em 2000,as $r_{s}$ entre médias BA estimadas por AMMI e padrão (70\%) foram menores que as $r_{\mathrm{s}}$ entre as médias BCCE estimadas por ER e o padrão (72\%) e que entre as médias BA estimadas por ER e o padrão (72\%).

As $r_{s}$ entre as médias BCCE estimadas por AMMI em 1998 e o padrão (64\%) foram melhores apenas que $r_{s}$ entre as médias BA e o padrão (57\%), enquanto que nos anos 1999 e 2000 ocorreu o esperado e, as $r_{s}$ entre as médias BCCE estimadas por AMMI e o padrão foram as mais altas (83\% em 1999 e $75 \%$ em 2000).

Considerando a média dos três anos foi possível verificar que as $r_{s}$ em relação ao padrão aumentaram à medida em que foram utilizadas duas repetições ao invés de uma, para todos os métodos (médias, ER e AMMI); e as $r_{s}$ também aumentam à medida em que se utilizou a metodologia ER em substituição às médias, e a metodologia AMMI em substituição a ER, para uma ou duas repetições (Tabela 57). 
A média das $r_{s}$ entre as médias BA estimadas por ER e o padrão (65\%) foi maior do que as médias das $r_{s}$ entre as médias BCCE e o padrão (64\%); a média das $r_{s}$ entre as médias BA estimadas por AMMI e o padrão (73\%) foi maior as médias das $r_{\mathrm{s}}$ entre as médias BCCE estimadas por ER e o padrão (69\%) (Tabela 57). 


\section{CONCLUSÕES}

Os resultados discutidos permitiram concluir que com o auxílio de delineamentos de tratamentos baseados em regressão linear (Eberhart \& Russell, 1966, ER) e em análise uni-multivariada (AMMI) foi possível eliminar parte dor ruído originado da falta de precisão das médias e que vem confundido com a interação genótipos $x$ ambientes $e$, consequentemente, aumentar a correlação com o padrão ideal (AMMI- 12 ambientes) e, assim, possibilitar a redução de duas para uma repetição nos experimentos intermediários, nas seguintes situações:

a) método AMMI ao invés de seleção baseada nas médias de duas repetições;

b) método ER (em dois dos três anos avaliados) ao invés da seleção baseada nas médias de duas repetições;

c) método AMMI (em dois dos três anos avaliados) ao invés de seleção baseada no ER. 
ANEXOS 
Tabela 1. Origem, genealogia e reação ao nematóide de cisto da soja (NCS) de 72 linhagens de soja

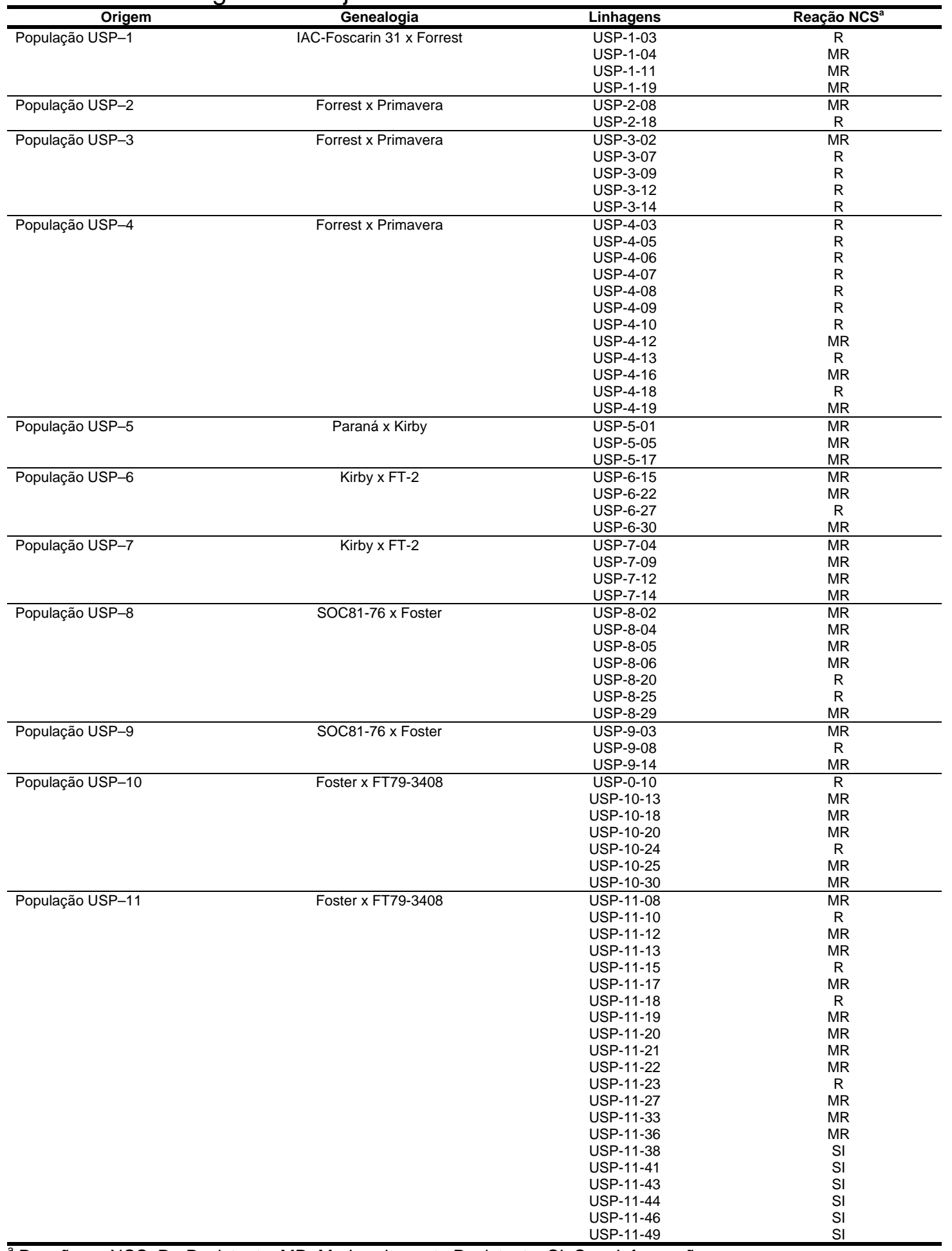

${ }^{a}$ Reação ao NCS: R= Resistente; MR: Moderadamente Resistente; SI: Sem Informação 
Tabela 2. Repetições do delineamento em blocos casualizados subdivididos em conjuntos experimentais tomadas aleatoriamente para as análises em blocos aumentados

\begin{tabular}{ccc}
\hline Anos & Ambientes & Repetição \\
\hline \multirow{3}{*}{1998} & Anhembi & 1 \\
& Areão & 2 \\
& ESALQ-1 & 2 \\
& ESALQ-2 & 1 \\
\hline \multirow{2}{*}{1999} & Anhembi & 2 \\
& Areão & 1 \\
& ESALQ-1 & 1 \\
& ESALQ-2 & 2 \\
\hline \multirow{2}{*}{2000} & Anhembi & 2 \\
& Areão & 1 \\
& ESALQ-1 & 2 \\
& ESALQ-2 & 2 \\
\hline
\end{tabular}


Tabela 3. Resumo das análises de variância para os experimentos em blocos aumentados em 1998

\begin{tabular}{|c|c|c|c|c|}
\hline $\mathbf{F V}$ & $\overline{G L}$ & QM & $\mathbf{F}$ & $\operatorname{Pr}<\mathrm{F}$ \\
\hline \multicolumn{5}{|l|}{ Anhembi } \\
\hline Blocos & 5 & 212176 & 1,49 & 0,2512 \\
\hline Genótipos & 75 & 615388 & 4,32 & 0,0014 \\
\hline Linhagens (L) & 71 & 635615 & 4,46 & 0,0012 \\
\hline Testemunhas $(T)$ & 3 & 265926 & 1,87 & 0,1785 \\
\hline L vs T & 1 & 92839 & 0,65 & 0,4321 \\
\hline Resíduo & 15 & 142419 & & \\
\hline \multicolumn{5}{|l|}{$\begin{array}{l}\text { Média }=2880,26^{\mathrm{a}} \\
\text { CV\% }=13^{\mathrm{b}}\end{array}$} \\
\hline \multicolumn{5}{|l|}{ Areão } \\
\hline Blocos & 5 & 305735 & 1,06 & 0,4179 \\
\hline Genótipos & 74 & 208363 & 0,73 & 0,8192 \\
\hline Linhagens (L) & 70 & 206323 & 0,72 & 0,8243 \\
\hline Testemunhas ( $\mathrm{T}$ ) & 3 & 134114 & 0,47 & 0,7097 \\
\hline L vs T & 1 & 578242 & 2,01 & 0,1764 \\
\hline Resíduo & 15 & 287208 & & \\
\hline \multicolumn{5}{|l|}{$\begin{array}{l}\text { Média = 2911,68 } \\
\text { CV\% }=18\end{array}$} \\
\hline \multicolumn{5}{|l|}{ ESALQ-1 } \\
\hline Blocos & 5 & 117726 & 0,35 & 0,8729 \\
\hline Genótipos & 74 & 282105 & 0,84 & 0,6977 \\
\hline Linhagens (L) & 70 & 257089 & 0,77 & 0,7744 \\
\hline Testemunhas $(T)$ & 3 & 761993 & 2,28 & 0,1212 \\
\hline L vs T & 1 & 681449 & 2,04 & 0,1739 \\
\hline Resíduo & 15 & 334324 & & \\
\hline \multicolumn{5}{|l|}{$\begin{array}{l}\text { Média = 2625,00 } \\
\text { CV\% }=22\end{array}$} \\
\hline \multicolumn{5}{|l|}{ ESALQ-2 } \\
\hline Blocos & 5 & 352798 & 1,31 & 0,3131 \\
\hline Genótipos & 75 & 408191 & 1,51 & 0,1869 \\
\hline Linhagens (L) & 71 & 312393 & 1,16 & 0,3949 \\
\hline Testemunhas (T) & 3 & 804184 & 2,98 & 0,0650 \\
\hline L vs T & 1 & 5388598 & 19,96 & 0,0005 \\
\hline Resíduo & 15 & 270020 & & \\
\hline $\begin{array}{l}\text { Média }=2901,10 \\
\text { CV\% }=18\end{array}$ & & & & \\
\hline
\end{tabular}


Tabela 4. Teste de Dunnett para as 16 linhagens mais produtivas e testemunhas contra a testemunha mais produtiva para os experimentos em blocos aumentados em 1998

\begin{tabular}{|c|c|c|c|c|c|c|c|c|c|c|c|}
\hline \multirow{2}{*}{\multicolumn{3}{|c|}{ Anhembi }} & \multicolumn{6}{|c|}{ Ambientes } & \multirow{2}{*}{\multicolumn{3}{|c|}{ ESALQ $2^{a}$ época }} \\
\hline & & & & Areão & & ESAL & $1^{a}$ époc & & & & \\
\hline Genótipos & Média & $\operatorname{Pr}<t$ & Genótipos & Média & $\mathrm{Pr}<\mathrm{t}$ & Genótipos & Média & $\operatorname{Pr}<\mathrm{t}$ & Genótipos & Média & $\operatorname{Pr}<\mathrm{t}$ \\
\hline \multicolumn{12}{|l|}{ Linhagens: } \\
\hline 04-05 & 4378 & 0,47 & $10-10$ & 3998 & 0,98 & 04-06 & 4350 & 0,82 & $06-27$ & 4670 & 0,36 \\
\hline $04-16$ & 4163 & 0,77 & $10-20$ & 3878 & 0,99 & 01-03 & 3807 & 0,99 & $10-24$ & 4300 & 0,73 \\
\hline 04-13 & 4148 & 0,79 & $11-41$ & 3643 & 1 & 04-05 & 3730 & 0,99 & $11-38$ & 4021 & 0,94 \\
\hline $10-13$ & 4145 & 0,80 & 04-12 & 3563 & 1 & $08-25$ & 3630 & 1 & $11-17$ & 3882 & 0,98 \\
\hline $11-38$ & 4072 & 0,88 & 09-08 & 3533 & 1 & $06-30$ & 3572 & 1 & 03-09 & 3815 & 0,99 \\
\hline 04-08 & 4041 & 0,91 & $06-27$ & 3531 & 1 & 03-09 & 3562 & 1 & $11-18$ & 3811 & 0,99 \\
\hline $08-25$ & 4003 & 0,94 & $11-10$ & 3463 & 1 & $11-46$ & 3434 & 1 & $11-08$ & 3792 & 0,99 \\
\hline $04-06$ & 3878 & 0,99 & $11-15$ & 3453 & 1 & $04-16$ & 3370 & 1 & $08-20$ & 3781 & 0,99 \\
\hline 04-09 & 3868 & 0,99 & $11-21$ & 3373 & 1 & $10-25$ & 3302 & 1 & $11-22$ & 3776 & 0,99 \\
\hline $08-20$ & 3867 & 0,99 & $07-14$ & 3368 & 1 & 04-18 & 3205 & 1 & $10-13$ & 3765 & 0,99 \\
\hline $11-27$ & 3836 & 1 & $08-25$ & 3333 & 1 & $04-12$ & 3200 & 1 & $11-41$ & 3746 & 0,99 \\
\hline 03-02 & 3710 & 1 & $11-38$ & 3328 & 1 & 04-09 & 3140 & 1 & $10-25$ & 3625 & 0,99 \\
\hline $11-13$ & 3682 & 1 & $11-27$ & 3308 & 1 & 04-19 & 3120 & 1 & $11-49$ & 3566 & 1 \\
\hline $11-18$ & 3647 & 1 & $11-19$ & 3303 & 1 & 03-12 & 3117 & 1 & $10-20$ & 3556 & 1 \\
\hline 04-19 & 3633 & 1 & $11-33$ & 3298 & 1 & $02-18$ & 3112 & 1 & 01-04 & 3541 & 1 \\
\hline $11-10$ & 3592 & 1 & $10-18$ & 3293 & 1 & $11-21$ & 3107 & 1 & $11-20$ & 3526 & 1 \\
\hline \multicolumn{12}{|c|}{ Testemunhas: } \\
\hline Foscarin & 3185 & padrão & Primavera & 2959 & padrão & Primavera & 2909 & padrão & Primavera & 2907 & padrão \\
\hline IAC-100 & 2982 & 1 & Foscarin & 2741 & 1 & IAC-100 & 2631 & 1 & IAC-100 & 2572 & 1 \\
\hline Primavera & 2870 & 1 & IAS-5 & 2671 & 1 & IAS-5 & 2281 & 0,92 & IAS-5 & 2372 & 0,96 \\
\hline IAS-5 & 2682 & 0,71 & IAC-100 & 2617 & 1 & Foscarin & 2113 & 0,66 & Foscarin & 2032 & 0,35 \\
\hline
\end{tabular}

Tabela 5. Análise de variância conjunta para os experimentos em blocos aumentados em 1998

\begin{tabular}{lrrrr}
\hline \multicolumn{1}{c}{ FV } & GL & QM & F & Pr > F \\
\hline Ambientes (E) & 3 & 1356147,69 & 3,56 & 0,0151 \\
Genótipos (G) & 75 & 483430,73 & 1,27 & 0,0946 \\
$\quad$ Linhagens (L) & 71 & 494653,00 & 1,30 & 0,0787 \\
$\quad$ Testemunhas (T) & 3 & 146737,00 & 0,39 & 0,7639 \\
$\quad$ L vs T & 1 & 668310,55 & 1,75 & 0,1868 \\
GxE & 223 & 381080,70 & 1,47 & 0,0381 \\
Erro médio & 60 & 258492,89 & & \\
\hline Média = 2861,35 & & & & \\
CV\% $=22^{\text {b }}$ & & & & \\
a Produtividade média em kg ha ${ }^{-1} ;$ & & &
\end{tabular}


Tabela 6.Teste de Dunnett para as 16 linhagens mais produtivas e testemunhas, contra a testemunha mais produtiva para a análise conjunta dos experimentos de quatro ambientes em blocos aumentados em 1998

\begin{tabular}{ccc}
\hline Genótipos & \multicolumn{2}{c}{ Parâmetros } \\
\cline { 2 - 3 } kg ha & Pr $>|\mathbf{t}|$ \\
\hline Linhagens: & 3642 & \\
$04-05$ & 3511 & 0,92 \\
$11-38$ & 3429 & 0,99 \\
$10-20$ & 3408 & 1 \\
$08-20$ & 3373 & 1 \\
$10-13$ & 3335 & 1 \\
$11-41$ & 3306 & 1 \\
$11-27$ & 3213 & 1 \\
$01-03$ & 3191 & 1 \\
$08-25$ & 3186 & 1 \\
$11-18$ & 3185 & 1 \\
$10-10$ & 3183 & 1 \\
$04-09$ & 3182 & 1 \\
$04-12$ & 3149 & 1 \\
$10-25$ & 3144 & 1 \\
$09-08$ & 3140 & 1 \\
$11-19$ & & 1 \\
\hline Testemunhas: & 2911 & padrão \\
Primavera & 2701 & 1 \\
IAC-100 & 2518 & 1 \\
Foscarin & 2502 & 1 \\
IAS-5 & &
\end{tabular}

${ }^{2}$ Produtividade média em $\mathrm{kg} \mathrm{ha}^{-1}$ 
Tabela 7. Análise de variância segundo a metodologia de Eberhart \& Russell (1966) para os experimentos delineados em blocos aumentados em 1998

\begin{tabular}{lrrcc}
\hline \multicolumn{1}{c}{ FV } & GL & QM & F & Pr>F \\
\hline Ambientes (E) & 3 & 1458910 & 3,78 & 0,0112 \\
Genótipos (G) & 75 & 459286 & 1,19 & 0,1664 \\
GxE & 225 & 385741 & 1,49 & 0,0338 \\
G dentro de E & 228 & 399862 & 1,55 & 0,0233 \\
E Linear & 1 & 4376730 & 16,93 & 0,0001 \\
$\quad$ GxE Linear & 75 & 338846 & 1,31 & 0,1390 \\
$\quad$ Desvios Combinados & 152 & 403805 & 1,56 & 0,0249 \\
Resíduo & 60 & 258493 & & \\
\hline
\end{tabular}

Tabela 8. Parâmetros e médias estimadas a partir do modelo de Eberhart \& Russell (1966) nos experimentos delineados em blocos aumentados em 1998 para 16 linhagens selecionadas $(p=20 \%)$ e com substituição de duas linhagens instáveis (08-25 e 04-16) por duas estáveis (11-33 e 11-21)

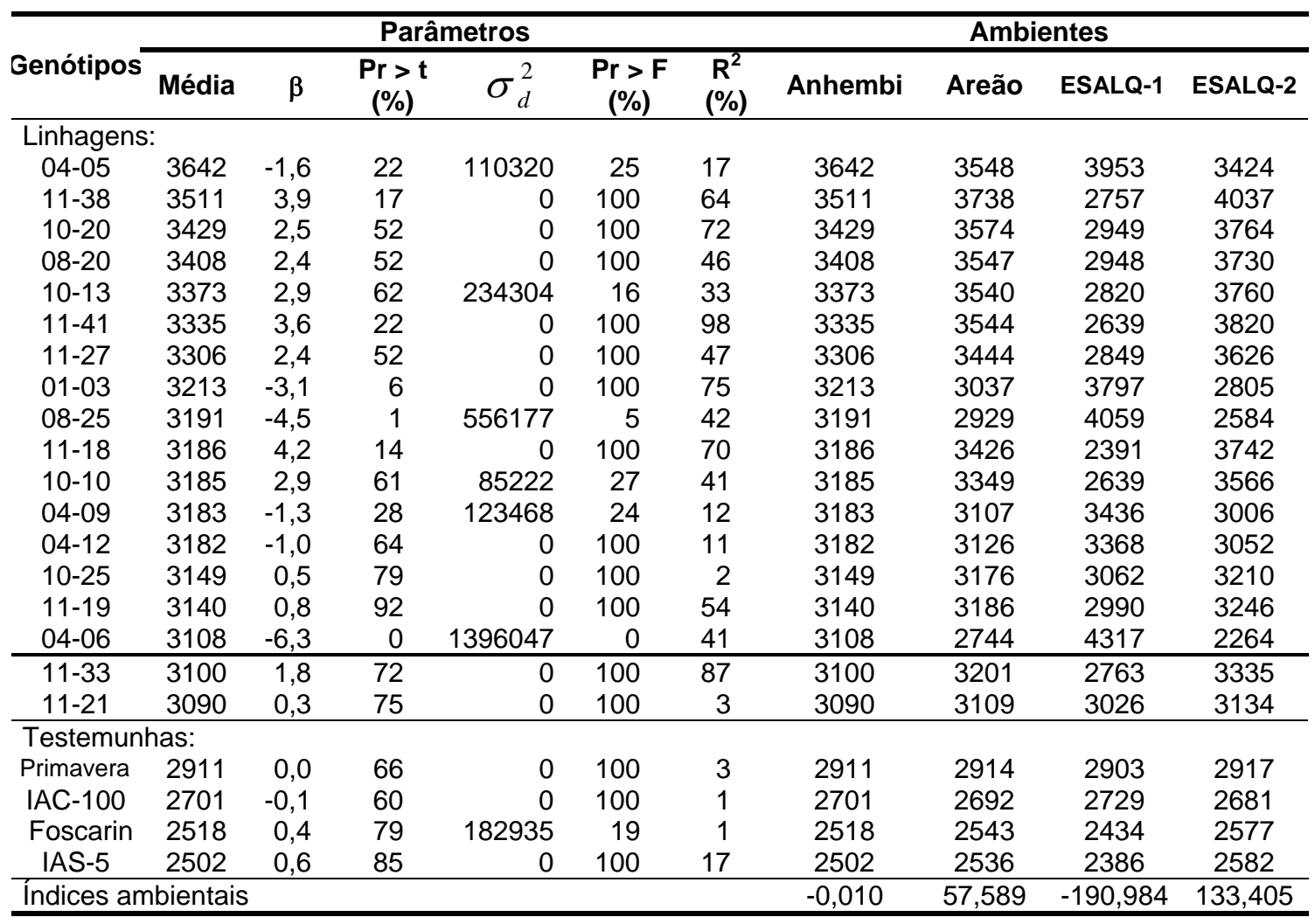


Tabela 9. Análise de variância segundo a metodologia AMMI dos experimentos em blocos aumentados em 1998

\begin{tabular}{lrrrc}
\hline \multicolumn{1}{c}{ FV } & GL & QM & F & Pr > F \\
\hline Ambientes (E) & 3 & 1458910 & 3,78 & 0,0112 \\
Genótipos (G) & 75 & 459286 & 1,19 & 0,1664 \\
G x E & 225 & 385741 & 1,49 & 0,0338 \\
$\quad$ AMMI 1 & 77 & 615529 & 2,38 & 0,0003 \\
$\quad$ Resíduo AMMI 1 & 148 & 266190 & 1,03 & 0,4584 \\
Resíduo & 60 & 258493 & - & - \\
\hline Média = 2860,91 & & & & \\
CV\% = 22 $^{\text {a }}$ & & & &
\end{tabular}


Tabela 10. Parâmetros e médias estimadas para a metodologia AMMI nos experimentos em blocos aumentados em 1998 para as 16 linhagens selecionadas $(p=20 \%)$ e com substituição de quatro linhagens instáveis (04-05, 08-25, 04-09 e 04-06) por quatro estáveis (11-33, 11-21, 11-15 e 9-8)

\begin{tabular}{ccrcccc}
\hline \multirow{2}{*}{ Genótipos } & \multicolumn{2}{c}{ Parâmetros AMMI 1 } & \multicolumn{4}{c}{ Médias estimadas } \\
\cline { 2 - 6 } Linhagens: & Médias & IPCA1 & Anhembi & Areão & ESALQ-1 & ESALQ-2 \\
04-05 & 3642 & 12,03 & 4421 & 3475 & 3477 & 3194 \\
$11-38$ & 3511 & 3,07 & 3710 & 3511 & 3327 & 3496 \\
$10-20$ & 3429 & $-1,52$ & 3331 & 3515 & 3235 & 3636 \\
$08-20$ & 3408 & 3,44 & 3631 & 3402 & 3225 & 3376 \\
$10-13$ & 3373 & 6,61 & 3801 & 3308 & 3196 & 3187 \\
$11-41$ & 3335 & $-2,82$ & 3152 & 3445 & 3138 & 3604 \\
$11-27$ & 3306 & 5,15 & 3640 & 3268 & 3126 & 3191 \\
$01-03$ & 3213 & 6,08 & 3607 & 3157 & 3035 & 3053 \\
$08-25$ & 3191 & 18,34 & 4379 & 2906 & 3039 & 2438 \\
$11-18$ & 3186 & 1,38 & 3276 & 3218 & 2998 & 3253 \\
$10-10$ & 3185 & $-6,66$ & 2753 & 3367 & 2979 & 3640 \\
$04-09$ & 3183 & 12,03 & 3962 & 3016 & 3018 & 2736 \\
$04-12$ & 3182 & 5,58 & 3543 & 3135 & 3003 & 3046 \\
$10-25$ & 3149 & $-6,37$ & 2737 & 3326 & 2945 & 3591 \\
$11-19$ & 3140 & $-1,17$ & 3064 & 3220 & 2947 & 3330 \\
$04-06$ & 3108 & 14,90 & 4073 & 2888 & 2949 & 2522 \\
\hline $11-33$ & 3100 & 0,13 & 3108 & 3155 & 2909 & 3227 \\
$11-21$ & 3090 & $-3,21$ & 2882 & 3207 & 2892 & 3378 \\
$11-15$ & 3087 & 1,67 & 3195 & 3114 & 2900 & 3140 \\
09-08 & 3072 & $-0,04$ & 3069 & 3130 & 2880 & 3207 \\
\hline Testemunhas: & & & & & & \\
Foscarin & 2518 & 10,11 & 3173 & 2387 & 2349 & 2163 \\
IAC-100 & 2701 & 4,90 & 3018 & 2667 & 2520 & 2597 \\
IAS-5 & 2502 & 3,22 & 2710 & 2499 & 2318 & 2479 \\
Primavera & 2911 & 0,67 & 2954 & 2956 & 2722 & 3013 \\
\hline Ambientes: & & & & & \\
Anhembi & 2861 & 64,79 & & & & \\
Areão & 2918 & $-18,65$ & & & & \\
ESALQ-1 & 2670 & 2,17 & & & & \\
ESALQ-2 & 2994 & $-48,31$ & & & & \\
\hline
\end{tabular}


Tabela 11. Análise de variância para os experimentos em blocos casualizados subdivididos em conjuntos experimentais em 1998

\begin{tabular}{|c|c|c|c|c|}
\hline FV & GL & $\overline{Q M}$ & $\mathbf{F}$ & $\operatorname{Pr}<F$ \\
\hline \multicolumn{5}{|l|}{ Anhembi } \\
\hline Repetições (R) & 1 & 65892 & 0,24 & 0,6287 \\
\hline Conjuntos / R & 10 & 465373 & 1,66 & 0,1002 \\
\hline Genótipos & 75 & 788406 & 2,81 & $<0,0001$ \\
\hline Linhagens (L) & 71 & 805831 & 2,88 & $<0,0001$ \\
\hline Testemunhas $(\mathrm{T})$ & 3 & 530837 & 1,89 & 0,1352 \\
\hline L vs T & 1 & 280716 & 1,00 & 0,3192 \\
\hline Resíduo & 102 & 280143 & & \\
\hline \multicolumn{5}{|l|}{ Média $=2870,93^{\mathrm{a}}$} \\
\hline \multicolumn{5}{|l|}{$\mathrm{CV} \%=18^{\mathrm{b}}$} \\
\hline \multicolumn{5}{|l|}{ Areão } \\
\hline Repetições (R) & 1 & 14822 & 0,05 & 0,8321 \\
\hline Conjuntos / R & 10 & 537349 & 1,64 & 0,1063 \\
\hline Genótipos & 74 & 282007 & 0,86 & 0,7536 \\
\hline Linhagens (L) & 70 & 253602 & 0,77 & 0,8745 \\
\hline Testemunhas ( $\mathrm{T}$ ) & 3 & 449244 & 1,37 & 0,2564 \\
\hline L vs T & 1 & 1821131 & 5,55 & 0,0204 \\
\hline Resíduo & $10 \overline{3}$ & 328137 & & \\
\hline \multicolumn{5}{|l|}{$\begin{array}{l}\text { Média = 2881,69 } \\
\text { CV\% }=20\end{array}$} \\
\hline \multicolumn{5}{|l|}{ ESALQ-1 } \\
\hline Repetições (R) & 1 & 162397 & 0,63 & 0,4296 \\
\hline Conjuntos / R & 10 & 195363 & 0,76 & 0,6700 \\
\hline Genótipos & 75 & 372047 & 1,44 & 0,0429 \\
\hline Linhagens (L) & 71 & 345421 & 1,34 & 0,0882 \\
\hline Testemunhas $(\mathrm{T})$ & 3 & 1108331 & 4,29 & 0,0068 \\
\hline L vs T & 1 & 128380 & 0,50 & 0,4824 \\
\hline Resíduo & 103 & 258288 & & \\
\hline \multicolumn{5}{|l|}{$\begin{array}{l}\text { Média = 2592,67 } \\
\text { CV\% = } 20\end{array}$} \\
\hline \multicolumn{5}{|l|}{ ESALQ-2 } \\
\hline Repetições & 1 & 110637 & 0,45 & 0,5058 \\
\hline Conjuntos / R & 10 & 277559 & 1,12 & 0,3560 \\
\hline Genótipos & 75 & 456380 & 1,84 & 0,0022 \\
\hline Linhagens (L) & 71 & 324206 & 1,31 & 0,1085 \\
\hline Testemunhas $(T)$ & 3 & 458098 & 1,85 & 0,1437 \\
\hline L vs T & 1 & 7902541 & 31,85 & $<0,0001$ \\
\hline Resíduo & 100 & 248147 & & \\
\hline \multicolumn{5}{|l|}{ Média = 2933,24 } \\
\hline
\end{tabular}


Tabela 12. Teste de Dunnett para as 16 linhagens mais produtivas $(p=20 \%)$ e testemunhas contra a testemunha mais produtiva para os experimentos em blocos casualizados subdivididos em conjuntos experimentais em 1998

\begin{tabular}{|c|c|c|c|c|c|c|c|c|c|c|c|}
\hline \multicolumn{12}{|c|}{ Ambientes } \\
\hline \multicolumn{3}{|c|}{ Anhembi } & \multicolumn{3}{|c|}{ Areão } & \multicolumn{3}{|c|}{ ESALQ-1 } & \multicolumn{3}{|c|}{ ESALQ-2 } \\
\hline Genótipos & Média & $\mathrm{Pr}<\mathrm{t}$ & Genótipos & Média & $\operatorname{Pr}<t$ & Genótipos & Média & $\mathrm{Pr}<\mathrm{t}$ & Genótipos & Média & $\mathrm{Pr}<\mathrm{t}$ \\
\hline \multicolumn{12}{|l|}{ Linhagens: } \\
\hline $11-38$ & 4500 & 0,13 & 04-09 & 3893 & 0,89 & 04-06 & 4270 & 0,68 & $06-27$ & 4347 & 0,02 \\
\hline 04-10 & 4013 & 0,92 & 07-12 & 3803 & 0,96 & $09-08$ & 3535 & 1 & 11-17 & 3686 & 0,83 \\
\hline $04-16$ & 4012 & 0,92 & $10-10$ & 3763 & 0,98 & $11-17$ & 3369 & 1 & $11-38$ & 3652 & 0,88 \\
\hline $04-06$ & 3834 & 0,99 & $11-38$ & 3755 & 0,98 & $01-03$ & 3280 & 1 & $11-49$ & 3635 & 0,91 \\
\hline 04-05 & 3752 & 0,99 & $08-25$ & 3620 & 0,99 & 04-05 & 3270 & 1 & $05-05$ & 3614 & 0,93 \\
\hline $11-43$ & 3683 & 1 & 04-12 & 3533 & 1 & 04-19 & 3258 & 1 & $11-20$ & 3609 & 0,94 \\
\hline $11-21$ & 3655 & 1 & 04-19 & 3533 & 1 & $05-17$ & 3214 & 1 & $11-15$ & 3577 & 0,96 \\
\hline $04-13$ & 3634 & 1 & 04-03 & 3445 & 1 & $02-18$ & 3191 & 1 & $10-25$ & 3565 & 0,97 \\
\hline $08-20$ & 3630 & 1 & $09-14$ & 3393 & 1 & 04-08 & 3142 & 1 & $11-27$ & 3533 & 0,98 \\
\hline $11-49$ & 3625 & 1 & $07-14$ & 3338 & 1 & $08-04$ & 3119 & 1 & $11-12$ & 3523 & 0,98 \\
\hline $08-04$ & 3600 & 1 & $11-27$ & 3297 & 1 & 04-09 & 3098 & 1 & $11-22$ & 3490 & 0,99 \\
\hline $11-13$ & 3595 & 1 & $11-10$ & 3243 & 1 & $11-20$ & 3095 & 1 & $11-46$ & 3464 & 0,99 \\
\hline 04-08 & 3590 & 1 & $11-20$ & 3243 & 1 & 03-09 & 3083 & 1 & $10-13$ & 3460 & 0,99 \\
\hline $11-27$ & 3500 & 1 & $10-24$ & 3227 & 1 & $10-18$ & 3024 & 1 & $05-01$ & 3459 & 0,99 \\
\hline $10-30$ & 3495 & 1 & $05-05$ & 3206 & 1 & $11-46$ & 3009 & 1 & $09-03$ & 3452 & 0,99 \\
\hline $03-02$ & 3468 & 1 & 04-05 & 3198 & 1 & $10-24$ & 2954 & 1 & $08-29$ & 3447 & 0,99 \\
\hline \multicolumn{12}{|c|}{ Testemunhas: } \\
\hline Foscarin & 3123 & padrão & IAC-100 & 2900 & padrão & Primaveré & 2940 & padrão & Primaverá & 2782 & padrão \\
\hline IAC-100 & 3075 & 1 & IAS-5 & 2828 & 1 & IAC-100 & 2585 & 0,99 & IAC-100 & 2604 & 1 \\
\hline IAS-5 & 2788 & 0,99 & Foscarin & 2582 & 1 & IAS-5 & 2509 & 0,90 & IAS-5 & 2485 & 0,99 \\
\hline Primavera & 2697 & 0,94 & Primavera & 2494 & 0,99 & Foscarin & 2200 & 0,04 & Foscarin & 2318 & 0,76 \\
\hline
\end{tabular}

Tabela 13. Análise de variância conjunta para os experimentos em blocos casualizados subdivididos em conjuntos experimentais em 1998

\begin{tabular}{lrrrr}
\hline \multicolumn{1}{c}{ FV } & GL & QM & F & Pr > F \\
\hline Ambientes (E) & 3 & 2042205 & 7,36 & 0,0001 \\
Genótipos (G) & 75 & 331743 & 1,19 & 0,1617 \\
$\quad$ Linhagens (L) & 71 & 342518 & 1,23 & 0,1269 \\
$\quad$ Testemunhas (T) & 3 & 41027 & 0,15 & 0,9310 \\
$\quad$ L vs T & 1 & 415428 & 1,50 & 0,2225 \\
GxE & 224 & 277613 & 1,00 & 0,5111 \\
Resíduo & 408 & 278900 & & \\
\hline Média = 2843,02 & & & & \\
CV\% = 19 & & & & \\
${ }^{\text {a }}$ Produtividade média kg ha & & &
\end{tabular}


Tabela 14. Teste de Dunnett para as 16 linhagens mais produtivas $(p=20 \%)$ e testemunhas contra a testemunha mais produtiva para os experimentos em blocos casualizados subdivididos em conjuntos experimentais em 1998

\begin{tabular}{ccc}
\hline Genótipos & \multicolumn{2}{c}{ Parâmetros } \\
\cline { 2 - 3 } kg ha & $\mathbf{P r}>|\mathbf{t}|$ \\
\hline Linhagens: & 3573 & 0,60 \\
$11-38$ & 3366 & 0,97 \\
$04-06$ & 3282 & 0.99 \\
$04-05$ & 3275 & 0,99 \\
$11-27$ & 3273 & 0,99 \\
$04-09$ & 3238 & 0,99 \\
$09-08$ & 3179 & 1 \\
$04-10$ & 3162 & 1 \\
$11-17$ & 3130 & 1 \\
$11-20$ & 3118 & 1 \\
$04-12$ & 3084 & 1 \\
$11-12$ & 3073 & 1 \\
$10-10$ & 3046 & 1 \\
$11-21$ & 3037 & 1 \\
$08-04$ & 3031 & 1 \\
$04-19$ & 3013 & 1 \\
$11-41$ & & \\
IAC-100 & 2791 & padrão \\
Primavera & 2728 & 1 \\
IAS-5 & 2653 & 1 \\
Foscarin & 2556 &
\end{tabular}

a Produtividade média $\mathrm{kg} \mathrm{ha}^{-1}$

Tabela 15. Análise de variância segundo a metodologia de Eberhart \& Russell (1966) nos experimentos delineados em blocos casualizados subdivididos em conjuntos experimentais em 1998

\begin{tabular}{lrrrr}
\hline \multicolumn{1}{c}{ FV } & GL & QM & \multicolumn{1}{c}{ F } & Pr>F \\
\hline Ambientes (E) & 3 & 2102402 & 7,45 & 0,0001 \\
Genótipos (G) & 75 & 314618 & 1,12 & 0,2695 \\
GxE & 225 & 282088 & 1,01 & 0,4570 \\
G dentro de E & 228 & 306039 & 1,10 & 0,2096 \\
$\quad$ E Linear & 1 & 6307206 & 22,61 & 0,0001 \\
$\quad$ GxE Linear & 75 & 214637 & 0,77 & 0,9173 \\
$\quad$ Desvios Combinados & 152 & 311658 & 1,12 & 0,1969 \\
Resíduo & 408 & 139450 & & \\
\hline
\end{tabular}


Tabela 16. Parâmetros e médias estimadas a partir do modelo de Eberhart \& Russell (1966) nos experimentos delineados em blocos casualizados subdivididos em conjuntos experimentais em 1998

\begin{tabular}{|c|c|c|c|c|c|c|c|c|c|c|}
\hline \multirow{2}{*}{ Genótipos } & \multicolumn{6}{|c|}{ Parâmetros } & \multicolumn{4}{|c|}{ Ambientes } \\
\hline & Média & $\beta$ & $\begin{array}{c}\mathrm{Pr}>\mathrm{t} \\
(\%)\end{array}$ & $\sigma_{d}^{2}$ & $\begin{array}{r}\mathrm{Pr}>\mathrm{F} \\
(\%)\end{array}$ & $\begin{array}{c}R^{2} \\
(\%)\end{array}$ & Anhembi & Areão & ESALQ-1 & ESALQ-2 \\
\hline \multicolumn{11}{|l|}{ Linhagens: } \\
\hline $11-38$ & 3572 & 3,5 & 6 & 521340 & 1 & 43 & 3543 & 3821 & 2791 & 4136 \\
\hline 04-06 & 3361 & $-4,0$ & 0 & 328706 & 4 & 58 & 3397 & 3076 & 4260 & 2714 \\
\hline 04-05 & 3282 & $-0,8$ & 16 & 15471 & 33 & 15 & 3289 & 3223 & 3468 & 3148 \\
\hline $11-27$ & 3275 & 1,9 & 51 & 0 & 100 & 78 & 3259 & 3410 & 2852 & 3581 \\
\hline 04-09 & 3268 & $-0,3$ & 67 & 293010 & 5 & 1 & 3271 & 3249 & 3332 & 3223 \\
\hline $09-08$ & 3237 & $-1,3$ & 7 & 0 & 100 & 48 & 3249 & 3142 & 3539 & 3020 \\
\hline 04-10 & 3178 & 1,5 & 72 & 382549 & 2 & 15 & 3166 & 3284 & 2848 & 3417 \\
\hline $11-17$ & 3162 & 0,0 & 55 & 189839 & 10 & 0 & 3162 & 3162 & 3163 & 3162 \\
\hline $11-20$ & 3130 & 1,2 & 87 & 78151 & 21 & 21 & 3120 & 3217 & 2860 & 3326 \\
\hline 04-12 & 3119 & 1,2 & 87 & 0 & 100 & 32 & 3108 & 3206 & 2846 & 3316 \\
\hline $11-12$ & 3083 & 1,8 & 57 & 0 & 100 & 53 & 3068 & 3210 & 2687 & 3370 \\
\hline $10-10$ & 3072 & 2,8 & 16 & 34681 & 29 & 65 & 3048 & 3274 & 2442 & 3528 \\
\hline $11-21$ & 3046 & 1,9 & 51 & 122566 & 15 & 37 & 3029 & 3184 & 2612 & 3359 \\
\hline $08-04$ & 3036 & $-0,5$ & 24 & 505354 & 1 & 2 & 3041 & 3000 & 3153 & 2953 \\
\hline 04-19 & 3027 & $-1,8$ & 3 & 211637 & 8 & 27 & 3043 & 2899 & 3431 & 2736 \\
\hline $11-41$ & 3012 & 1,8 & 56 & 0 & 100 & 76 & 2997 & 3140 & 2612 & 3302 \\
\hline $03-02$ & 3011 & 0,4 & 65 & 3752 & 36 & 5 & 3008 & 3041 & 2919 & 3076 \\
\hline $11-33$ & 3005 & 0,3 & 58 & 0 & 100 & 7 & 3003 & 3024 & 2946 & 3047 \\
\hline $10-30$ & 2986 & 0,1 & 52 & 41580 & 27 & 0 & 2986 & 2992 & 2969 & 2999 \\
\hline $11-19$ & 2981 & 1,9 & 52 & 0 & 100 & 84 & 2967 & 3123 & 2541 & 3294 \\
\hline $10-13$ & 2980 & 2,5 & 24 & 0 & 100 & 98 & 2962 & 3164 & 2408 & 3385 \\
\hline \multicolumn{11}{|c|}{ Testemunhas: } \\
\hline IAC-100 & 2790 & 0,3 & 57 & 0 & 100 & 3 & 2789 & 2809 & 2733 & 2832 \\
\hline Primavera & 2728 & $-0,7$ & 20 & 0 & 100 & 36 & 2734 & 2680 & 2880 & 2619 \\
\hline IAS-5 & 2652 & 0,2 & 55 & 0 & 100 & 3 & 2651 & 2667 & 2608 & 2685 \\
\hline Foscarin & 2556 & 0,5 & 68 & 103974 & 18 & 4 & 2552 & 2590 & 2451 & 2632 \\
\hline \multicolumn{4}{|c|}{ Índices ambientais } & & & & $-8,752$ & 71,726 & $-225,75$ & 162,78 \\
\hline
\end{tabular}

Tabela 17. Análise de variância segundo a metodologia AMMI dos experimentos em blocos casualizados subdivididos em conjuntos experimentais em 1998 pelo modelo AMMI 1

\begin{tabular}{lrrrr}
\hline \multicolumn{1}{c}{ FV } & GL & QM & F & Pr>F \\
\hline Ambientes (E) & 3 & 2102402 & 7,45 & $<0,0001$ \\
Genótipos (G) & 75 & 314618 & 1,12 & 0,2695 \\
GxE & 225 & 282088 & 1,36 & 0,0430 \\
AMMI 1 & 77 & 430651 & 1,54 & 0,0043 \\
$\quad$ Resíduo AMMI 1 & 148 & 204795 & 0,73 & 0,9859 \\
Resíduo & 408 & 278900 & & \\
\hline
\end{tabular}

Média $=2843,26^{\mathrm{a}}$

$\mathrm{CV} \%=19^{\mathrm{b}}$

${ }^{\text {a Produtividade média kg ha }}$

${ }^{\mathrm{b}}$ Coeficiente de variação 
Tabela 18. Parâmetros e médias estimadas para a metodologia AMMI dos experimentos em blocos casualizados subdivididos em conjuntos experimentais em 1998, Modelo AMMI 1, para as 16 linhagens selecionadas $(p=20 \%)$ e com substituição de duas linhagens instáveis (11-38 e 04-10) por duas estáveis (03-02 e 11-33)

\begin{tabular}{ccccccc}
\hline \multirow{2}{*}{ Genótipos } & \multicolumn{2}{c}{ Parâmetros AMMI 1 } & \multicolumn{3}{l}{ Médias estimadas } \\
\cline { 2 - 7 } & Médias & IPCA1 & Anhembi & Areão & ESALQ-1 & ESALQ-2 \\
\hline Linhagens: & & & & & & \\
11-38 & 3573 & 12,92 & 4399 & 4397 & 3432 & 3167 \\
$04-06$ & 3366 & 8,60 & 3901 & 3912 & 3297 & 3020 \\
$04-05$ & 3282 & 8,43 & 3816 & 3817 & 3215 & 2938 \\
$11-27$ & 3276 & 2,84 & 3451 & 3451 & 3302 & 3009 \\
$04-09$ & 3273 & 5,19 & 3606 & 3599 & 3260 & 2974 \\
$09-08$ & 3238 & 3,72 & 3466 & 3470 & 3249 & 2959 \\
$04-10$ & 3179 & 11,68 & 3920 & 3923 & 3059 & 2790 \\
$11-17$ & 3162 & $-3,17$ & 2946 & 2951 & 3288 & 2979 \\
$11-20$ & 3130 & $-8,58$ & 2570 & 2571 & 3346 & 3022 \\
$04-12$ & 3119 & 2,74 & 3290 & 3288 & 3146 & 2854 \\
$11-12$ & 3084 & 2,43 & 3230 & 3232 & 3117 & 2823 \\
$10-10$ & 3073 & $-3,21$ & 2864 & 2859 & 3199 & 2890 \\
$11-21$ & 3046 & 8,65 & 3595 & 3595 & 2976 & 2699 \\
$08-04$ & 3037 & 7,74 & 3521 & 3528 & 2982 & 2703 \\
$04-19$ & 3031 & 4,18 & 3298 & 3292 & 3035 & 2746 \\
11-41 & 3013 & 2,83 & 3188 & 3188 & 3039 & 2747 \\
\hline $03-02$ & 3011 & 7,35 & 3476 & 3476 & 2963 & 2682 \\
11-33 & 3005 & 3,57 & 3226 & 3228 & 3019 & 2728 \\
\hline Testemunhas: & & & & & & \\
IAC-100 & 2791 & 5,16 & 3117 & 3116 & 2779 & 2493 \\
Primavera & 2728 & 0,19 & 2731 & 2733 & 2798 & 2499 \\
IAS-5 & 2653 & 3,04 & 2842 & 2841 & 2675 & 2383 \\
Foscarin & 2556 & 9,22 & 3142 & 3142 & 2477 & 2202 \\
\hline Ambientes: & & & & & \\
ESALQ-2 & 3004 & $-33,96$ & & & & \\
Areão & 2916 & $-16,56$ & & & & \\
Anhembi & 2836 & 64,34 & & & & \\
ESALQ-1 & 2616 & $-13,82$ & & & & \\
\hline
\end{tabular}


Tabela 19. Análise de variância para os experimentos em blocos aumentados em 1999

\begin{tabular}{|c|c|c|c|c|}
\hline FV & $\mathbf{G L}$ & QM & $\mathrm{F}$ & $\operatorname{Pr}<F$ \\
\hline \multicolumn{5}{|l|}{ Anhembi } \\
\hline Blocos & 5 & 435980 & 2,20 & 0,1089 \\
\hline Genótipos & 75 & 463401 & 2,54 & 0,0340 \\
\hline Linhagens (L) & 71 & 422868 & 2,13 & 0,0514 \\
\hline Testemunhas $(\mathrm{T})$ & 3 & 90870 & 0,46 & 0,7154 \\
\hline L vs T & 1 & 4458844 & 22,49 & 0,0003 \\
\hline Resíduo & 15 & 198279 & & \\
\hline \multicolumn{5}{|l|}{$\begin{array}{l}\text { Média }=3731,41^{\mathrm{a}} \\
\mathrm{CV} \%=12^{\mathrm{b}}\end{array}$} \\
\hline \multicolumn{5}{|l|}{ Areão } \\
\hline Blocos & 5 & 103389 & 0,67 & 0,6502 \\
\hline Genótipos & 75 & 274398 & 1,79 & 0,1040 \\
\hline Linhagens (L) & 71 & 223105 & 1,45 & 0,2128 \\
\hline Testemunhas $(T)$ & 3 & 445886 & 2,90 & 0,0694 \\
\hline L vs T & 1 & 3401701 & 22,14 & 0,0003 \\
\hline Resíduo & 15 & 153615 & & \\
\hline \multicolumn{5}{|l|}{$\begin{array}{l}\text { Média = 1539,38 } \\
\text { CV\% }=25\end{array}$} \\
\hline \multicolumn{5}{|l|}{ ESALQ-1 } \\
\hline Blocos & 5 & 328599 & 1,73 & 0,1894 \\
\hline Genótipos & 75 & 293481 & 1,54 & 0,1753 \\
\hline Linhagens (L) & 71 & 299727 & 1,57 & 0,1640 \\
\hline Testemunhas $(\mathrm{T})$ & 3 & 213164 & 1,12 & 0,3724 \\
\hline L vs T & 1 & 91022 & 0,48 & 0,4999 \\
\hline Resíduo & 15 & 190406 & & \\
\hline \multicolumn{5}{|l|}{$\begin{array}{l}\text { Média = 2319,17 } \\
\text { CV\% }=19\end{array}$} \\
\hline \multicolumn{5}{|l|}{ ESALQ- 2} \\
\hline Blocos & 5 & 109895 & 0,31 & 0,8998 \\
\hline Genótipos & 70 & 297709 & 0,83 & 0,7028 \\
\hline Linhagens (L) & 66 & 271082 & 0,76 & 0,7751 \\
\hline Testemunhas (T) & 3 & 141011 & 0,39 & 0,7592 \\
\hline L vs T & 1 & 2428044 & 6,79 & 0,0218 \\
\hline Resíduo & 15 & 270020 & & \\
\hline $\begin{array}{l}\text { Média }=2485,79 \\
\text { CV\% }=24\end{array}$ & & & & \\
\hline
\end{tabular}

a Produtividade média $\mathrm{kg} \mathrm{ha}^{-1}$ para este ambiente no respectivo ano agrícola

${ }^{\mathrm{b}}$ Coeficiente de variação 
Tabela 20. Teste de Dunnett para as 16 linhagens mais produtivas $(p=20 \%)$ e testemunhas a contra testemunha mais produtiva para os experimentos em blocos aumentados em 1999

\begin{tabular}{|c|c|c|c|c|c|c|c|c|c|c|c|}
\hline \multicolumn{12}{|c|}{ Ambientes } \\
\hline \multicolumn{3}{|c|}{ Anhembi } & \multicolumn{3}{|c|}{ Areão } & \multicolumn{3}{|c|}{ ESALQ-1 } & \multicolumn{3}{|c|}{ ESALQ-2 } \\
\hline Genótipos & Média & $\operatorname{Pr}<\mathrm{t}$ & Genótipos & Média & Pr $<\mathrm{t}$ & Genótipos & Média & $\operatorname{Pr}<t$ & Genótipos & Média & Pr $<\mathrm{t}$ \\
\hline \multicolumn{12}{|l|}{ Linhagens: } \\
\hline 04-19 & 3737 & 0,89 & $10-10$ & 3085 & 0,18 & $11-19$ & 3730 & 0,69 & 04-19 & 3737 & 0,89 \\
\hline $11-46$ & 3635 & 0,94 & 09-14 & 2950 & 0,29 & $11-13$ & 3568 & 0,87 & $11-46$ & 3635 & 0,94 \\
\hline 04-06 & 3572 & 0,96 & 04-09 & 2748 & 0,53 & $11-36$ & 3368 & 0,98 & 04-06 & 3572 & 0,96 \\
\hline 08-02 & 3517 & 0,98 & $11-27$ & 2515 & 0,84 & $11-21$ & 3258 & 1 & $08-02$ & 3517 & 0,98 \\
\hline $10-18$ & 3504 & 0,98 & 04-05 & 2403 & 0,94 & 04-08 & 3047 & 1 & $10-18$ & 3504 & 0,98 \\
\hline $11-43$ & 3490 & 0,98 & $08-20$ & 2362 & 0,96 & $11-46$ & 3016 & 1 & $11-43$ & 3490 & 0,98 \\
\hline $08-20$ & 3432 & 0,99 & $07-14$ & 2358 & 0,96 & $09-03$ & 2998 & 1 & $08-20$ & 3432 & 0,99 \\
\hline 08-04 & 3285 & 1 & $11-18$ & 2315 & 0,98 & $11-17$ & 2973 & 1 & 08-04 & 3285 & 1 \\
\hline $10-10$ & 3221 & 1 & $11-15$ & 2255 & 0,99 & $08-25$ & 2926 & 1 & $10-10$ & 3221 & 1 \\
\hline $01-11$ & 3159 & 1 & $05-05$ & 2187 & 1 & $11-41$ & 2920 & 1 & $01-11$ & 3159 & 1 \\
\hline $11-33$ & 3141 & 1 & $11-44$ & 2113 & 1 & $11-08$ & 2883 & 1 & $11-33$ & 3141 & 1 \\
\hline $08-05$ & 3099 & 1 & 05-01 & 2112 & 1 & $10-10$ & 2878 & 1 & 08-05 & 3099 & 1 \\
\hline 09-03 & 3059 & 1 & 08-05 & 2058 & 1 & 09-14 & 2863 & 1 & 09-03 & 3059 & 1 \\
\hline $11-19$ & 3056 & 1 & $10-30$ & 2053 & 1 & 04-19 & 2812 & 1 & $11-19$ & 3056 & 1 \\
\hline $11-44$ & 3055 & 1 & $10-13$ & 2038 & 1 & 01-04 & 2803 & 1 & $11-44$ & 3055 & 1 \\
\hline 03-02 & 2972 & 1 & $11-13$ & 1970 & 1 & 05-05 & 2797 & 1 & 03-02 & 2972 & 1 \\
\hline \multicolumn{12}{|c|}{ Testemunhas: } \\
\hline IAS-5 & 2375 & padrão & Foscarin & 1553 & padrão & IAS-5 & 2530 & padrão & IAS-5 & 2375 & padrão \\
\hline Primavera & 2287 & 1 & IAS-5 & 1262 & 1 & Primavera & 2257 & 1 & Primavera & 2287 & 1 \\
\hline IAC-100 & 2228 & 1 & Primavera & 1141 & 0,94 & IAC-C & 2184 & 1 & IAC-100 & 2228 & 1 \\
\hline Foscarin & 1985 & 1 & IAC-100 & 898 & 0,36 & FOSCA & 2093 & 0,97 & Foscarin & 1985 & 1 \\
\hline
\end{tabular}

Tabela 21. Análise de variância conjunta para os experimentos delineados em blocos aumentados em 1999

\begin{tabular}{lrrrr}
\hline \multicolumn{1}{c}{ FV } & GL & \multicolumn{1}{c}{ QM } & F & Pr $>$ F \\
\hline Ambientes (E) & 3 & 64189710 & 250,26 & $<0,0001$ \\
Genótipos (G) & 75 & 647355 & 2,52 & $<0,0001$ \\
GxE & 220 & 256488 & 1,16 & 0,2503 \\
$\quad$ Linhagens (L) & 71 & 656457 & 2,56 & $<0,0001$ \\
$\quad$ Testemunhas (T) & 3 & 39650 & 0,15 & 0,9267 \\
$\quad$ L vs T & 1 & 1795074 & 7,00 & 0,0087 \\
Resíduo & 58 & 220391 & & \\
\hline
\end{tabular}

Média $=2592,64^{\mathrm{a}}$

$\mathrm{CV} \%=20^{\mathrm{b}}$

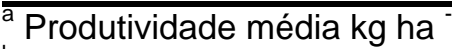

${ }^{\text {b }}$ Coeficiente de variação 
Tabela 22. Teste de Dunnett para as 16 linhagens mais produtivas $(p=20 \%)$ e testemunhas contra a testemunha mais produtiva para a análise conjunta dos experimentos em blocos aumentados em 1999

\begin{tabular}{ccc}
\hline \multirow{2}{*}{ Genótipos } & \multicolumn{2}{c}{ Parâmetros } \\
\cline { 2 - 3 } Linhagens & $\mathbf{P r}>|\mathbf{t}|$ \\
$10-10$ & 3540 & 0,05 \\
$08-02$ & 3358 & 0,19 \\
$11-46$ & 3230 & 0,40 \\
$11-21$ & 3193 & 0,47 \\
$08-20$ & 3165 & 0,53 \\
$08-05$ & 3159 & 0,55 \\
$09-14$ & 3124 & 0,63 \\
$10-18$ & 3036 & 0,82 \\
$04-19$ & 2996 & 0,90 \\
$11-36$ & 2994 & 0,90 \\
$11-44$ & 2991 & 0,90 \\
$11-13$ & 2985 & 0,91 \\
$04-10$ & 2984 & 0,91 \\
$11-41$ & 2983 & 0,97 \\
$04-06$ & 2965 & 0,94 \\
$04-09$ & 2956 & 0,95 \\
\hline IAS-5 & & \\
Primavera & 2381 & padrão \\
Foscarin & 2303 & 1 \\
IAC-100 & 2218 & 1 \\
\hline Testemunhas: & 2153 & 1 \\
\hline
\end{tabular}

a Produtividade média $\mathrm{kg} \mathrm{ha}^{-1}$

Tabela 23. Análise de variância segundo a metodologia de Eberhart \& Russell (1966) para os experimentos delineados em blocos aumentados em 1999

\begin{tabular}{lrrrr}
\hline \multicolumn{1}{c}{ FV } & GL & \multicolumn{1}{c}{ QM } & F & Pr>F \\
\hline Ambientes (E) & 3 & 64183950 & 253,02 & 0,0001 \\
Genótipos (G) & 75 & 638704 & 2,52 & 0,0001 \\
GxE & 225 & 253672 & 1,15 & 0,2665 \\
G dentro de E & 228 & 1094859 & 4,97 & 0,0001 \\
$\quad$ E Linear & 1 & 192551851 & 873,68 & 0,0001 \\
$\quad$ GxE Linear & 75 & 245999 & 1,12 & 0,3332 \\
$\quad$ Desvios Combinados & 152 & 254119 & 1,15 & 0,2706 \\
Resíduo & 58 & 220391 & & \\
\hline
\end{tabular}


Tabela 24. Parâmetros e médias estimadas a partir do modelo de Eberhart \& Russell (1966) para os experimentos delineados em blocos aumentados em 1999

\begin{tabular}{|c|c|c|c|c|c|c|c|c|c|c|}
\hline \multirow[b]{2}{*}{ Genótipos } & \multicolumn{6}{|c|}{ Parâmetros } & \multicolumn{4}{|c|}{ Estimativas } \\
\hline & Média & $\beta$ & $\begin{array}{r}P r>t \\
(\%)\end{array}$ & $\sigma_{d}^{2}$ & $\begin{array}{c}\mathrm{Pr}>\mathrm{F} \\
(\%)\end{array}$ & $\begin{array}{l}R^{2} \\
(\%)\end{array}$ & Anhembi & Areão & ESALQ-1 & ESALQ-2 \\
\hline \multicolumn{11}{|l|}{ Linhagens: } \\
\hline $10-10$ & 3540 & 0,9 & 85 & 55146 & 29 & 80 & 4709 & 2627 & 3295 & 3530 \\
\hline $08-02$ & 3358 & 1,8 & 1 & 0 & 100 & 99 & 5529 & 1661 & 2904 & 3340 \\
\hline $11-46$ & 3230 & 1,1 & 66 & 0 & 100 & 91 & 4631 & 2134 & 2936 & 3218 \\
\hline $11-21$ & 3193 & 1,6 & 5 & 21370 & 34 & 93 & 5158 & 1656 & 2781 & 3176 \\
\hline $08-20$ & 3165 & 1,0 & 96 & 0 & 100 & 89 & 4382 & 2212 & 2909 & 3154 \\
\hline 08-05 & 3159 & 1,6 & 6 & 40484 & 31 & 92 & 5085 & 1652 & 2755 & 3142 \\
\hline $09-14$ & 3124 & 0,7 & 24 & 190102 & 16 & 57 & 3934 & 2491 & 2954 & 3117 \\
\hline $10-18$ & 3036 & 1,8 & 1 & 0 & 100 & 96 & 5301 & 1265 & 2562 & 3017 \\
\hline $04-19$ & 2996 & 1,0 & $9 \overline{9}$ & 240464 & 13 & 73 & 4232 & 2029 & 2737 & 2985 \\
\hline $11-36$ & 2994 & 1,5 & 7 & 247652 & 13 & 86 & 4890 & 1512 & 2597 & 2978 \\
\hline $11-44$ & 2991 & 1,0 & 92 & 0 & 100 & 97 & 4266 & 1994 & 2724 & 2980 \\
\hline $11-13$ & 2985 & 0,7 & 61 & 208084 & 15 & 62 & 3902 & 2269 & 2793 & 2977 \\
\hline $04-10$ & 2984 & 1,3 & 66 & 0 & 100 & 98 & 4573 & 1741 & 2650 & 2970 \\
\hline $04-06$ & 2965 & 1,0 & 86 & 35310 & 32 & 82 & 4141 & 2045 & 2718 & 2954 \\
\hline 04-09 & 2956 & 0,8 & 55 & 234161 & 14 & 65 & 3968 & 2165 & 2744 & 2948 \\
\hline 05-01 & 2950 & 1,1 & 75 & 0 & 100 & 95 & 4305 & 1890 & 2666 & 2938 \\
\hline \multicolumn{11}{|c|}{ Testemunhas: } \\
\hline IAS-5 & 2381 & 0,9 & 71 & 0 & 100 & 90 & 3482 & 1521 & 2151 & 2372 \\
\hline Primavera & 2303 & 1,0 & 87 & 0 & 100 & 97 & 3598 & 1290 & 2032 & 2292 \\
\hline Foscarin & 2218 & 0,8 & 56 & 0 & 100 & 96 & 3168 & 1476 & 2019 & 2210 \\
\hline IAC-100 & 2153 & 1,0 & 90 & 0 & 100 & 94 & 3436 & 1150 & 1884 & 2142 \\
\hline \multicolumn{7}{|c|}{ Índices ambientais } & 1237,18 & $-967,28$ & $-259,26$ & $-10,63$ \\
\hline
\end{tabular}

Tabela 25. Análise de variância segundo a metodologia AMMI dos experimentos em blocos aumentados em 1999, modelo AMMI 0

\begin{tabular}{lrrrr}
\hline \multicolumn{1}{c}{ FV } & GL & \multicolumn{1}{c}{ QM } & F & Pr $>$ F \\
\hline Ambientes (E) & 3 & 64183950 & 253,02 & $<0,0001$ \\
Genótipos (G) & 75 & 638704 & 2,52 & $<0,0001$ \\
GxE & 225 & 253672 & 1,15 & 0,2665 \\
Resíduo & 58 & 220391 & & \\
\hline
\end{tabular}

Média $=2592,46^{\mathrm{a}}$

$\mathrm{CV} \%=19^{\mathrm{b}}$

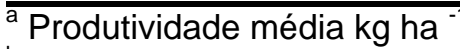

${ }^{\text {b }}$ Coeficiente de variação 
Tabela 26. Parâmetros e médias estimadas para a metodologia AMMI nos experimentos dispostos em blocos aumentados em 1999, modelo AMMI 0

\begin{tabular}{cccccc}
\hline \multirow{2}{*}{ Genótipos } & $\begin{array}{c}\text { Parâmetros } \\
\text { AMMI 0 }\end{array}$ & \multicolumn{4}{c}{ Médias estimadas } \\
\cline { 2 - 6 } & Médias & Anhembi & Areão & ESALQ-1 & ESALQ-2 \\
\hline Linhagens: & & & & & \\
$10-10$ & 3540 & 4777 & 2573 & 3281 & 3530 \\
$08-02$ & 3358 & 4596 & 2391 & 3099 & 3348 \\
$11-46$ & 3230 & 4467 & 2262 & 2970 & 3219 \\
$11-21$ & 3193 & 4430 & 2225 & 2933 & 3182 \\
$08-20$ & 3165 & 4402 & 2197 & 2905 & 3154 \\
$08-05$ & 3159 & 4396 & 2191 & 2899 & 3148 \\
$09-14$ & 3124 & 4361 & 2157 & 2865 & 3113 \\
$10-18$ & 3036 & 4273 & 2069 & 2777 & 3026 \\
$04-19$ & 2996 & 4233 & 2029 & 2737 & 2985 \\
$11-36$ & 2994 & 4231 & 2027 & 2735 & 2983 \\
$11-44$ & 2991 & 4228 & 2024 & 2732 & 2980 \\
$11-13$ & 2985 & 4222 & 2018 & 2726 & 2975 \\
$04-10$ & 2984 & 4221 & 2016 & 2724 & 2973 \\
$04-06$ & 2965 & 4202 & 1997 & 2705 & 2954 \\
$04-09$ & 2956 & 4193 & 1989 & 2697 & 2946 \\
$05-01$ & 2950 & 4187 & 1982 & 2690 & 2939 \\
\hline Testemunhas: & & & & & \\
IAS-5 & 2381 & 3619 & 1414 & 2122 & 2371 \\
Primavera & 2303 & 3540 & 1336 & 2044 & 2293 \\
Foscarin & 2218 & 3455 & 1251 & 1959 & 2208 \\
IAC-100 & 2153 & 3390 & 1186 & 1894 & 2142 \\
\hline Ambientes: & 3830 & & & & \\
Anhembi & 385 & & & & \\
ESALQ-2 & 2582 & & & & \\
ESALQ-1 & 2333 & & & & \\
Areão & 1625 & & & & \\
\hline
\end{tabular}


Tabela 27. Análise de variância para os experimentos em blocos casualizados subdivididos em conjuntos experimentais em 1999

\begin{tabular}{|c|c|c|c|c|}
\hline FV & $\mathbf{G L}$ & QM & $F$ & $P r<F$ \\
\hline \multicolumn{5}{|l|}{ Anhembi } \\
\hline Repetições (R) & 1 & 884011 & 3,76 & 0,0554 \\
\hline Conjuntos / R & 10 & 397438 & 1,69 & 0,0935 \\
\hline Genótipos & 75 & 575962 & 2,45 & $<0,0001$ \\
\hline Linhagens (L) & 71 & 427645 & 1,82 & 0,0029 \\
\hline Testemunhas (T) & 3 & 253770 & 1,08 & 0,3617 \\
\hline L vs T & 1 & 11713609 & 49,79 & $<0,0001$ \\
\hline Resíduo & 100 & 235260 & & \\
\hline \multicolumn{5}{|l|}{$\begin{array}{l}\text { Média }=3672,14^{\mathrm{a}} \\
\text { CV\% }=13^{\mathrm{b}}\end{array}$} \\
\hline \multicolumn{5}{|l|}{ Areão } \\
\hline Repetições (R) & 1 & 652750 & 3,82 & 0,0534 \\
\hline Conjuntos / R & 10 & 152347 & 0,89 & 0,5442 \\
\hline Genótipos & 75 & 355462 & 2,08 & 0,0003 \\
\hline Linhagens (L) & 71 & 274388 & 1,60 & 0,0136 \\
\hline Testemunhas ( $\mathrm{T}$ ) & 3 & 1460505 & 8,54 & $<0,0001$ \\
\hline L vs T & 1 & 2796559 & 16,36 & 0,0001 \\
\hline Resíduo & 105 & 170980 & & \\
\hline \multicolumn{5}{|l|}{$\begin{array}{l}\text { Média }=1597,68 \\
\text { CV\% }=26\end{array}$} \\
\hline \multicolumn{5}{|l|}{ ESALQ-1 } \\
\hline Repetições (R) & 1 & 2549560 & 11,78 & 0,0009 \\
\hline Conjuntos / R & 10 & 386135 & 1,78 & 0,0724 \\
\hline Genótipos & 75 & 326155 & 1,51 & 0,0263 \\
\hline Linhagens (L) & 71 & 308887 & 1,43 & 0,0485 \\
\hline Testemunhas (T) & 3 & 831751 & 3,84 & 0,0118 \\
\hline L vs T & 1 & 35391 & 0,16 & 0,6868 \\
\hline Resíduo & 105 & 216472 & & \\
\hline \multicolumn{5}{|l|}{$\begin{array}{l}\text { Média }=2203,93 \\
\text { CV\% }=21\end{array}$} \\
\hline \multicolumn{5}{|l|}{ ESALQ-2 } \\
\hline Repetições (R) & 1 & 1150 & 0,00 & 0,9454 \\
\hline Conjuntos / R & 10 & 709300 & 2,91 & 0,0031 \\
\hline Genótipos & 75 & 389405 & 1,60 & 0,0149 \\
\hline Linhagens (L) & 71 & 375045 & 1,54 & 0,0242 \\
\hline Testemunhas ( $\mathrm{T}$ ) & 3 & 278743 & 1,14 & 0,3356 \\
\hline L vs T & 1 & 1423857 & 5,84 & 0,0175 \\
\hline Resíduo & 98 & 243838 & & \\
\hline $\begin{array}{l}\text { Média }=2487,11 \\
\text { CV\% }=20\end{array}$ & & & & \\
\hline
\end{tabular}


Tabela 28. Teste de Dunnett para as 16 linhagens mais produtivas $(p=20 \%)$ e testemunhas contra a testemunha mais produtiva para os experimentos em blocos casualizados subdivididos em conjuntos experimentais em 1999

\begin{tabular}{|c|c|c|c|c|c|c|c|c|c|c|c|}
\hline \multicolumn{12}{|c|}{ Ambientes } \\
\hline \multicolumn{3}{|c|}{ Anhembi } & \multicolumn{3}{|c|}{ Areão } & \multicolumn{3}{|c|}{ ESALQ-1 } & \multicolumn{3}{|c|}{ ESALQ-2 } \\
\hline Genótipos & Média & $\operatorname{Pr}<t$ & Genótipos & Média & $\operatorname{Pr}<t$ & Genótipos & Média & $P r<t$ & Genótipos & Média & $\operatorname{Pr}<t$ \\
\hline \multicolumn{12}{|l|}{ Linhagens: } \\
\hline $08-02$ & 4779 & 0,08 & $10-10$ & 2777 & 0,20 & $11-21$ & 2975 & 1 & $10-18$ & 3407 & 0,83 \\
\hline 08-05 & 4653 & 0,13 & 04-09 & 2409 & 0,96 & $11-19$ & 2874 & 1 & 04-16 & 3392 & 0,86 \\
\hline $10-10$ & 4570 & 0,30 & $11-15$ & 2407 & 0,96 & $11-13$ & 2852 & 1 & $04-05$ & 3302 & 0,96 \\
\hline $11-21$ & 4543 & 0,35 & $11-18$ & 2330 & 0,99 & $11-23$ & 2757 & 1 & $11-36$ & 3279 & 0,97 \\
\hline $11-38$ & 4451 & 0,42 & $11-27$ & 2285 & 1 & $04-12$ & 2733 & 1 & $11-38$ & 3278 & 1 \\
\hline $11-36$ & 4433 & 0,56 & $09-14$ & 2240 & 1 & $11-08$ & 2680 & 1 & 04-09 & 3197 & 1 \\
\hline 04-05 & 4428 & 0,47 & $11-13$ & 2230 & 1 & 04-19 & 2654 & 1 & $11-46$ & 3166 & 1 \\
\hline $10-18$ & 4393 & 0,54 & $11-33$ & 2190 & 1 & $11-44$ & 2625 & 1 & 01-11 & 3155 & 1 \\
\hline $11-08$ & 4390 & 0,65 & $08-20$ & 2137 & 1 & $10-18$ & 2615 & 1 & 04-12 & 3150 & 1 \\
\hline $04-10$ & 4358 & 0,62 & $07-14$ & 2100 & 1 & $04-16$ & 2593 & 1 & $09-03$ & 3122 & 1 \\
\hline 08-04 & 4319 & 0,71 & 04-05 & 2039 & 1 & $11-17$ & 2587 & 1 & $11-18$ & 3089 & 1 \\
\hline $11-27$ & 4300 & 0,82 & 08-04 & 1996 & 1 & $11-41$ & 2577 & 1 & $11-12$ & 3038 & 1 \\
\hline $09-08$ & 4259 & 0,82 & $06-30$ & 1996 & 1 & $02-18$ & 2560 & 1 & $07-12$ & 3027 & 1 \\
\hline $11-41$ & 4256 & 0,83 & $11-44$ & 1986 & 1 & $08-05$ & 2543 & 1 & $04-03$ & 3011 & 1 \\
\hline $11-46$ & 4209 & 0,90 & 01-03 & 1975 & 1 & $04-13$ & 2539 & 1 & $11-43$ & 3009 & 1 \\
\hline 04-09 & 4200 & 0,91 & $04-12$ & 1942 & 1 & $11-46$ & 2527 & 1 & $11-44$ & 3004 & 1 \\
\hline \multicolumn{12}{|c|}{ Testemunhas: } \\
\hline Primavera & 3374 & padrão & Foscarin & 1748 & padrão & IAS-5 & 2547 & padrão & IAC-100 & 2510 & padrão \\
\hline IAS-5 & 3262 & 1 & IAS-5 & 1511 & 1 & Primavera & 2198 & 0,98 & IAS-5 & 2408 & 1 \\
\hline IAC-100 & 3206 & 1 & Primavera & 1378 & 0,83 & IAC-100 & 1993 & 0,24 & Primavera & 2256 & 1 \\
\hline Foscarin & 3011 & 0,99 & IAC-100 & 918 & 0,00 & Foscarin & 1985 & 0,22 & Foscarin & 2154 & 0,99 \\
\hline
\end{tabular}

Tabela 29. Análise de variância conjunta para os experimentos em blocos casualizados subdivididos em conjuntos experimentais em 1999

\begin{tabular}{lrrrr}
\hline \multicolumn{1}{c}{ FV } & GL & \multicolumn{1}{c}{ QM } & \multicolumn{1}{c}{ F } & Pr $>$ F \\
\hline Ambientes (E) & 3 & 61672265 & 461,05 & $<0,0001$ \\
Genótipos (G) & 75 & 477973 & 3,57 & $<0,0001$ \\
$\quad$ Linhagens (L) & 71 & 486001 & 3,63 & $<0,0001$ \\
$\quad$ Testemunhas (T) & 3 & 55782 & 0,42 & 0,7410 \\
$\quad$ L vs T & 1 & 1174540 & 8,78 & 0,0034 \\
GxE & 225 & 133764 & 0,62 & 1,0000 \\
Resíduo & 406 & 279599 & & \\
\hline
\end{tabular}

Média $=2542,31^{\mathrm{a}}$

$\mathrm{CV} \%=14^{\mathrm{b}}$

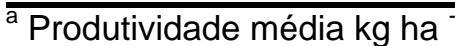

${ }^{\mathrm{b}}$ Coeficiente de variação 
Tabela 30. Teste de Dunnett para as 16 linhagens mais produtivas $(p=20 \%)$ e testemunhas, contra a testemunha mais produtiva, para os experimentos em blocos casualizados subdivididos em conjuntos experimentais em 1999

\begin{tabular}{ccc}
\hline \multirow{2}{*}{ Genótipos } & \multicolumn{2}{c}{ Parâmetros } \\
\cline { 2 - 3 } Linhagens: & Pr $>$ |t $\mid$ \\
$10-10$ & 3204 & 0,10 \\
$04-09$ & 3032 & 0,43 \\
$10-18$ & 2995 & 0,53 \\
$11-13$ & 2990 & 0,55 \\
$04-05$ & 2957 & 0,66 \\
$04-12$ & 2949 & 0,68 \\
$08-05$ & 2945 & 0,70 \\
$04-10$ & 2930 & 0,74 \\
$11-44$ & 2927 & 0,75 \\
$11-15$ & 2926 & 0,76 \\
$11-21$ & 2925 & 0,76 \\
$11-46$ & 2920 & 0,77 \\
$11-38$ & 2909 & 0,81 \\
$11-18$ & 2897 & 0,84 \\
$04-16$ & 2896 & 0,84 \\
$09-14$ & 2891 & 0,86 \\
IAS-5 & & padrão \\
Primavera & 2432 & 1 \\
Foscarin & 2301 & 1 \\
IAC-100 & 2224 & 1 \\
\hline Testemunhas: & 2157 &
\end{tabular}

\footnotetext{
${ }^{a}$ Produtividade média $\mathrm{kg} \mathrm{ha}^{-1}$
} 
Tabela 31. Análise de variância segundo a metodologia de Eberhart \& Russell (1966) para os experimentos delineados em blocos casualizados subdivididos em conjuntos experimentais em 1999

\begin{tabular}{lrrrr}
\hline \multicolumn{1}{c}{ FV } & GL & \multicolumn{1}{c}{ QM } & \multicolumn{1}{c}{$\mathbf{F}$} & Pr>F \\
\hline Ambientes (E) & 3 & 61672264 & 461,05 & $<0,0001$ \\
Genótipos (G) & 75 & 477973 & 3,57 & $<0,0001$ \\
GxE & 225 & 133764 & 0,48 & 1,0000 \\
G dentro de E & 228 & 943481 & 3,37 & $<0,0001$ \\
E Linear & 1 & 185016794 & 661,72 & $<0,0001$ \\
$\quad$ GxE Linear & 75 & 100409 & 0,36 & 1,0000 \\
$\quad$ Desvios Combinados & 152 & 148462 & 0,53 & 1,0000 \\
Resíduo & 406 & 139800 & & \\
\hline
\end{tabular}

Tabela 32. Parâmetros e médias estimadas a partir do modelo de Eberhart \& Russell (1966), para os experimentos em blocos casualizados subdivididos em conjuntos experimentais, em 1999

\begin{tabular}{|c|c|c|c|c|c|c|c|c|c|c|}
\hline \multirow[b]{2}{*}{ Genótipos } & \multicolumn{6}{|c|}{ Parâmetros } & \multicolumn{4}{|c|}{ Ambientes } \\
\hline & Média & $\beta$ & $\begin{array}{c}\mathrm{Pr}> \\
\mathrm{t} \\
(\%)\end{array}$ & $\sigma_{d}^{2}$ & $\begin{array}{c}\mathrm{Pr}>\mathrm{F} \\
(\%)\end{array}$ & $\begin{array}{l}R^{2} \\
(\%)\end{array}$ & Anhembi & Areão & ESALQ-1 & ESALQ-2 \\
\hline \multicolumn{11}{|l|}{ Linhagens: } \\
\hline $10-10$ & 3204 & 1,0 & 83 & 69829 & 22 & 84 & 4382 & 2358 & 2888 & 3189 \\
\hline 04-09 & 3032 & 0,9 & 73 & 0 & 100 & 90 & 4168 & 2215 & 2727 & 3017 \\
\hline $10-18$ & 2995 & 1,3 & 24 & 14223 & 33 & 93 & 4582 & 1855 & 2570 & 2975 \\
\hline $11-13$ & 2990 & 0,8 & 52 & 0 & 100 & 98 & 4032 & 2241 & 2710 & 2976 \\
\hline $04-05$ & 2957 & 1,2 & 60 & 61893 & 24 & 90 & 4447 & 1887 & 2558 & 2938 \\
\hline 04-12 & 2949 & 0,9 & 72 & 0 & 100 & 95 & 4082 & 2134 & 2645 & 2934 \\
\hline $08-05$ & 2945 & 1,3 & 14 & 0 & 100 & 100 & 4614 & 1745 & 2497 & 2923 \\
\hline $04-10$ & 2930 & 1,2 & 53 & 0 & 100 & 100 & 4359 & 1904 & 2547 & 2912 \\
\hline $11-44$ & 2927 & 1,0 & 92 & 0 & 100 & 99 & 4138 & 2057 & 2602 & 2912 \\
\hline $11-15$ & 2926 & 0,9 & 59 & 0 & 100 & 91 & 4001 & 2154 & 2638 & 2912 \\
\hline $11-21$ & 2925 & 1,4 & 12 & 43800 & 27 & 93 & 4624 & 1705 & 2470 & 2903 \\
\hline $11-46$ & 2920 & 1,1 & 61 & 0 & 100 & 97 & 4313 & 1920 & 2547 & 2902 \\
\hline $11-38$ & 2909 & 1,3 & 21 & 5181 & 36 & 93 & 4516 & 1754 & 2478 & 2888 \\
\hline $11-18$ & 2897 & 0,9 & 77 & 50994 & 26 & 85 & 4047 & 2070 & 2588 & 2882 \\
\hline 04-16 & 2896 & 0,9 & 56 & 52559 & 25 & 82 & 3960 & 2132 & 2611 & 2882 \\
\hline 09-14 & 2891 & 0,8 & 54 & 0 & 100 & 98 & 3908 & 2160 & 2618 & 2878 \\
\hline \multicolumn{11}{|c|}{ Testemunhas: } \\
\hline IAS-5 & 2432 & 0,7 & 28 & 0 & 100 & 87 & 3351,9 & 1771 & 2185 & 2420 \\
\hline Primavera & 2301 & 0,9 & 67 & 0 & 100 & 97 & 3412,2 & 1502 & 2003 & 2287 \\
\hline Foscarin & 2224 & 0,6 & 10 & 0 & 100 & 99 & 2976,1 & 1684 & 2023 & 2215 \\
\hline IAC-100 & 2157 & 1,0 & 98 & 21133 & 32 & 88 & 3402,4 & 1262 & 1823 & 2141 \\
\hline \multicolumn{7}{|c|}{ Índices ambientais } & 1237,91 & $-889,61$ & $-332,18$ & $-16,11$ \\
\hline
\end{tabular}


Tabela 33. Análise de variância segundo a metodologia AMMI dos experimentos em blocos casualizados subdivididos em conjuntos experimentais em 1999, modelo AMMI 0

\begin{tabular}{lrrrr}
\hline \multicolumn{1}{c}{ FV } & GL & QM & F & Pr>F \\
\hline Ambientes (E) & 3 & 61672265 & 461,05 & $<0,0001$ \\
Genótipos (G) & 75 & 477973 & 3,57 & $<0,0001$ \\
GxE & 225 & 133764 & 0,48 & 0,9999 \\
Resíduo & 406 & 279599 & & \\
\hline
\end{tabular}

Média $=2542,31^{\mathrm{a}}$

$\mathrm{CV} \%=14^{\mathrm{b}}$

a Produtividade média kg ha ${ }^{-1}$

${ }^{\mathrm{b}}$ Coeficiente de variação

Tabela 34. Parâmetros e médias estimadas para a metodologia AMMI dos experimentos em blocos casualizados subdivididos em conjuntos experimentais em 1999, modelo AMMI 0

\begin{tabular}{|c|c|c|c|c|c|}
\hline \multirow{2}{*}{ Genótipos } & \multirow{2}{*}{$\begin{array}{c}\text { Parâmetros } \\
\text { AMMI } 0 \\
\text { Médias }\end{array}$} & \multicolumn{4}{|c|}{ Médias estimadas } \\
\hline & & Anhembi & Areão & ESALQ-1 & ESALQ-2 \\
\hline \multicolumn{6}{|l|}{ Linhagens: } \\
\hline $10-10$ & 3204 & 4442 & 2314 & 2872 & 3188 \\
\hline 04-09 & 3032 & 4270 & 2142 & 2700 & 3016 \\
\hline $10-18$ & 2995 & 4233 & 2106 & 2663 & 2979 \\
\hline $11-13$ & 2990 & 4228 & 2100 & 2658 & 2974 \\
\hline 04-05 & 2957 & 4195 & 2068 & 2625 & 2941 \\
\hline 04-12 & 2949 & 4187 & 2059 & 2616 & 2932 \\
\hline 08-05 & 2945 & 4183 & 2055 & 2613 & 2929 \\
\hline 04-10 & 2930 & 4168 & 2041 & 2598 & 2914 \\
\hline $11-44$ & 2927 & 4165 & 2038 & 2595 & 2911 \\
\hline $11-15$ & 2926 & 4164 & 2036 & 2594 & 2910 \\
\hline $11-21$ & 2925 & 4163 & 2036 & 2593 & 2909 \\
\hline $11-46$ & 2920 & 4158 & 2031 & 2588 & 2904 \\
\hline $11-38$ & 2909 & 4147 & 2019 & 2577 & 2893 \\
\hline $11-18$ & 2897 & 4134 & 2007 & 2564 & 2880 \\
\hline 04-16 & 2896 & 4134 & 2006 & 2564 & 2880 \\
\hline $09-14$ & 2891 & 4129 & 2001 & 2559 & 2875 \\
\hline \multicolumn{6}{|l|}{ Testemunhas: } \\
\hline IAS-5 & 2432 & 3670 & 1542 & 2100 & 2416 \\
\hline Primavera & 2301 & 3539 & 1412 & 1969 & 2285 \\
\hline Foscarin & 2224 & 3462 & 1335 & 1892 & 2208 \\
\hline IAC-100 & 2157 & 3395 & 1267 & 1825 & 2141 \\
\hline \multicolumn{6}{|l|}{ Ambientes: } \\
\hline Anhembi & 3780 & & & & \\
\hline ESALQ-2 & 2526 & & & & \\
\hline ESALQ-1 & 2210 & & & & \\
\hline Areão & 1653 & & & & \\
\hline
\end{tabular}


Tabela 35. Análise de variância para os experimentos em blocos aumentados em 2000

\begin{tabular}{|c|c|c|c|c|}
\hline FV & $\overline{G L}$ & $\overline{Q M}$ & $\bar{F}$ & $\mathrm{Pr}<\mathrm{F}$ \\
\hline \multicolumn{5}{|l|}{ Anhembi } \\
\hline Blocos & 5 & 82430 & 0,46 & 0,7973 \\
\hline Genótipos & 75 & 370065 & 2,08 & 0,0634 \\
\hline Linhagens (L) & 71 & 320473 & 1,80 & 0,1099 \\
\hline Testemunhas ( $\mathrm{T}$ ) & 3 & 960200 & 5,40 & 0,0112 \\
\hline L vs T & 1 & 2140022 & 12,02 & 0,0038 \\
\hline Resíduo & 14 & 177978 & & \\
\hline \multicolumn{5}{|l|}{$\begin{array}{l}\text { Média }=3516,63^{\mathrm{a}} \\
\mathrm{CV} \%=12^{\mathrm{b}}\end{array}$} \\
\hline \multicolumn{5}{|l|}{ Areão } \\
\hline Blocos & 5 & 373074 & 2,04 & 0,1313 \\
\hline Genótipos & 74 & 236261 & 1,29 & 0,3000 \\
\hline Linhagens (L) & 70 & 245043 & 1,34 & 0,2715 \\
\hline Testemunhas (T) & 3 & 103424 & 0,56 & 0,6466 \\
\hline L vs T & 1 & 15999 & 0,09 & 0,7716 \\
\hline Resíduo & 15 & 183164 & & \\
\hline \multicolumn{5}{|l|}{$\begin{array}{l}\text { Média = 1944,45 } \\
\text { CV\% }=22\end{array}$} \\
\hline \multicolumn{5}{|l|}{ ESALQ-1 } \\
\hline Blocos & 5 & 551893 & 0,35 & 0,8734 \\
\hline Genótipos & 73 & 430350 & 2,71 & 0,0172 \\
\hline Linhagens (L) & 69 & 374055 & 2,35 & 0,0336 \\
\hline Testemunhas (T) & 3 & 199087 & 1,25 & 0,3262 \\
\hline L vs T & 1 & 5112955 & 32,15 & $<0,0001$ \\
\hline Resíduo & 15 & 159041 & & \\
\hline \multicolumn{5}{|l|}{$\begin{array}{l}\text { Média = 2406,44 } \\
\text { CV\% }=17\end{array}$} \\
\hline \multicolumn{5}{|l|}{ ESALQ-2 } \\
\hline Blocos & 5 & 270530 & 4,44 & 0,0110 \\
\hline Genótipos & 75 & 291956 & 4,80 & 0,0008 \\
\hline Linhagens (L) & 71 & 280323 & 4,61 & 0,0010 \\
\hline Testemunhas (T) & 3 & 281307 & 4,62 & 0,0176 \\
\hline L vs T & 1 & 1149823 & 18,89 & 0,0006 \\
\hline Resíduo & 15 & 60863 & & \\
\hline $\begin{array}{l}\text { Média = 2268,31 } \\
\text { CV\% }=11\end{array}$ & & & & \\
\hline
\end{tabular}


Tabela 36. Teste de Dunnett para as 16 linhagens mais produtivas $(p=20 \%)$ e testemunhas contra a testemunha mais produtiva para os experimentos em blocos aumentados em 2000

\begin{tabular}{|c|c|c|c|c|c|c|c|c|c|c|c|}
\hline \multicolumn{12}{|c|}{ Ambientes } \\
\hline \multicolumn{3}{|c|}{ Anhembi } & \multicolumn{3}{|c|}{ Areão } & \multicolumn{3}{|c|}{ ESALQ-1 } & \multicolumn{3}{|c|}{ ESALQ-2 } \\
\hline Genótipos & Média & $\operatorname{Pr}<t$ & Genótipos & Média & $\operatorname{Pr}<t$ & Genótipos & Média & $\operatorname{Pr}<t$ & Genótipos & Média & $\mathrm{Pr}<\mathrm{t}$ \\
\hline \multicolumn{12}{|l|}{ Linhagens: } \\
\hline $08-20$ & 4601 & 0,93 & $11-10$ & 3162 & 0,83 & $10-24$ & 3930 & 0,09 & $08-25$ & 3596 & 0,02 \\
\hline $11-36$ & 4534 & 0,97 & $11-18$ & 3126 & 0,87 & $11-13$ & 3920 & 0,10 & $11-46$ & 3341 & 0,08 \\
\hline 04-06 & 4501 & 0,98 & $10-10$ & 2812 & 1 & $11-15$ & 3874 & 0,11 & 04-06 & 3338 & 0,08 \\
\hline $07-12$ & 4480 & 0,98 & $11-20$ & 2811 & 1 & $11-12$ & 3836 & 0,13 & $09-14$ & 3311 & 0,09 \\
\hline $11-22$ & 4450 & 0,99 & $11-36$ & 2721 & 1 & $11-46$ & 3672 & 0,24 & $11-10$ & 3290 & 0,11 \\
\hline $11-17$ & 4429 & 0,99 & $09-14$ & 2642 & 1 & $11-08$ & 3590 & 0,31 & $11-38$ & 3244 & 0,14 \\
\hline $11-41$ & 4395 & 1 & 04-18 & 2566 & 1 & 08-04 & 3545 & 0,36 & $08-05$ & 3243 & 0,14 \\
\hline $10-18$ & 4335 & 1 & 04-06 & 2441 & 1 & $11-49$ & 3465 & 0,45 & $10-18$ & 3236 & 0,15 \\
\hline $08-04$ & 4314 & 1 & $11-19$ & 2397 & 1 & 04-09 & 3399 & 0,54 & $08-29$ & 3188 & 0,19 \\
\hline $09-14$ & 4271 & 1 & $02-08$ & 2386 & 1 & $04-13$ & 3299 & 0,67 & 09-08 & 3166 & 0,22 \\
\hline $09-08$ & 4240 & 1 & 04-05 & 2382 & 1 & $09-14$ & 3284 & 0,69 & $08-06$ & 3080 & 0,34 \\
\hline $11-10$ & 4235 & 1 & $06-22$ & 2371 & 1 & $11-27$ & 3237 & 0,76 & $11-12$ & 3030 & 0,44 \\
\hline $11-38$ & 4224 & 1 & $04-03$ & 2358 & 1 & $11-18$ & 3230 & 0,76 & $01-04$ & 2930 & 0,65 \\
\hline $11-13$ & 4164 & 1 & $04-07$ & 2356 & 1 & $11-33$ & 3217 & 0,78 & $11-22$ & 2900 & 0,72 \\
\hline $11-19$ & 4140 & 1 & $11-15$ & 2327 & 1 & 04-08 & 3216 & 0,78 & 05-01 & 2893 & 0,73 \\
\hline $11-21$ & 4120 & 1 & $03-12$ & 2326 & 1 & $10-10$ & 3124 & 0,88 & $11-08$ & 2854 & 0,81 \\
\hline \multicolumn{12}{|c|}{ Testemunhas: } \\
\hline IAC-100 & 3678 & padrão & IAS-5 & 2113 & padrão & IAS-5 & 2195 & padrão & Primavera & 2234 & padrão \\
\hline IAS-5 & 3343 & 1 & Foscarin & 1878 & 1 & Foscarin & 2122 & 1 & IAC-100 & 2188 & 1 \\
\hline Foscarin & 3260 & 0,98 & Primavera & 1869 & 1 & Primavera & 1909 & 1 & IAS-5 & 2133 & 1 \\
\hline Primavera & 2713 & 0,07 & IAC-100 & 1818 & 1 & IAC-100 & 1803 & 0,97 & Foscarin & 1760 & 0,18 \\
\hline
\end{tabular}

Tabela 37. Análise de variância conjunta para os experimentos delineados em blocos aumentados em 2000

\begin{tabular}{lrrrr}
\hline \multicolumn{1}{c}{ FV } & GL & \multicolumn{1}{c}{ QM } & F & Pr $>$ F \\
\hline Ambientes (E) & 3 & 37350499 & 136,36 & $<0,0001$ \\
Genótipos (G) & 75 & 663258 & 2,42 & $<0,0001$ \\
$\quad$ Linhagens (L) & 71 & 679973 & 2,48 & $<0,0001$ \\
$\quad$ Testemunhas (T) & 3 & 55660 & 0,20 & 0,8941 \\
$\quad$ L vs T & 1 & 1309695 & 4,78 & 0,0298 \\
GxE & 222 & 273915 & 1,89 & 0,0022 \\
Resíduo & 59 & 144707 & & \\
\hline
\end{tabular}

Média $=2593,48^{\mathrm{a}}$

$\mathrm{CV} \%=20^{\mathrm{b}}$

${ }^{\text {a Produtividade média kg ha }}$

${ }^{\mathrm{b}}$ Coeficiente de variação 
Tabela 38. Teste de Dunnett para as 16 linhagens mais produtivas $(p=20 \%)$ e testemunhas contra a testemunha mais produtiva, para a análise conjunta dos experimentos em blocos aumentados em 2000

\begin{tabular}{ccc}
\hline Genótipos & \multicolumn{3}{c}{ Parâmetros } \\
\cline { 2 - 3 } Linhagens: & kg $\mathbf{~}^{\mathbf{- 1 a}}$ & $\mathbf{P r} \mathbf{| t}$ \\
09-14 & 3377 & 0,30 \\
$11-10$ & 3348 & 0,35 \\
$04-06$ & 3280 & 0,48 \\
$11-18$ & 3214 & 0,62 \\
$11-08$ & 3183 & 0,69 \\
$08-25$ & 3163 & 0,74 \\
$08-04$ & 3142 & 0,78 \\
$10-10$ & 3129 & 0,81 \\
$11-38$ & 3117 & 0,83 \\
$11-15$ & 3107 & 0,85 \\
$11-19$ & 3033 & 0,95 \\
$08-29$ & 3029 & 0,96 \\
$11-49$ & 3019 & 0,97 \\
$11-36$ & 2988 & 0,98 \\
$11-12$ & 2966 & 0,99 \\
$11-46$ & 2959 & 0,99 \\
\hline IAS-5 & & \\
IAC-100 & 2446 & padrão \\
Foscarin & 2372 & 1 \\
Primavera & 2255 & 1 \\
\hline Testemunhas: & 2181 & 1 \\
\hline a & & \\
\hline
\end{tabular}

${ }^{a}$ Produtividade média $\mathrm{kg} \mathrm{ha}^{-1}$ 
Tabela 39. Análise de variância segundo a metodologia de Eberhart \& Russell (1966) para os experimentos delineados em blocos aumentados em 2000

\begin{tabular}{lrrrr}
\hline \multicolumn{1}{c}{ FV } & GL & \multicolumn{1}{c}{ QM } & \multicolumn{1}{c}{ F } & \multicolumn{1}{c}{ Pr>F } \\
\hline Ambientes (E) & 3 & 37457615 & 138,12 & $<0,0001$ \\
Genótipos (G) & 75 & 660437 & 2,44 & $<0,0001$ \\
GxE & 225 & 271203 & 1,87 & 0,0025 \\
G dentro de E & 228 & 760498 & 5,26 & $<0,0001$ \\
$\quad$ E Linear & 1 & 112372846 & 776,56 & $<0,0001$ \\
$\quad$ GxE Linear & 75 & 245203 & 1,69 & 0,0182 \\
$\quad$ Desvios Combinados & 152 & 280464 & 1,94 & 0,0022 \\
Resíduo & 59 & 144707 & & \\
\hline
\end{tabular}

Tabela 40. Parâmetros e médias estimadas a partir do modelo de Eberhart \& Russell (1966) para os experimentos delineados em blocos aumentados em 2000

\begin{tabular}{|c|c|c|c|c|c|c|c|c|c|c|}
\hline \multirow[b]{2}{*}{ Genótipos } & \multicolumn{6}{|c|}{ Parâmetros } & \multicolumn{4}{|c|}{ Ambientes } \\
\hline & Médias & $\beta$ & $\begin{array}{c}\text { Pr }>t \\
(\%)\end{array}$ & $\sigma_{d}^{2}$ & $\begin{array}{c}\mathrm{Pr}>\mathrm{F} \\
(\%)\end{array}$ & $\begin{array}{c}R^{2} \\
(\%)\end{array}$ & Anhembi & Areão & ESALQ-1 & ESALQ-2 \\
\hline \multicolumn{11}{|l|}{ Linhagens: } \\
\hline $09-14$ & 3377 & 0,9 & 83 & 0 & 100 & 96 & 4307 & 2775 & 3305 & 3122 \\
\hline $11-10$ & 3348 & 0,7 & 62 & 90139 & 21 & 62 & 4063 & 2885 & 3293 & 3152 \\
\hline 04-06 & 3280 & 1,2 & 54 & 0 & 100 & 89 & 4468 & 2511 & 3188 & 2954 \\
\hline $11-18$ & 3214 & 0,8 & 52 & 121216 & 17 & 62 & 3981 & 2718 & 3155 & 3004 \\
\hline $11-08$ & 3183 & 0,9 & 86 & 17294 & 33 & 80 & 4123 & 2574 & 3110 & 2925 \\
\hline $08-25$ & 3163 & 0,7 & 58 & 185916 & 11 & 55 & 3901 & 2685 & 3106 & 2960 \\
\hline $08-04$ & 3142 & 1,3 & 65 & 28769 & 31 & 88 & 4431 & 2307 & 3042 & 2788 \\
\hline $10-10$ & 3129 & 0,8 & 56 & 0 & 100 & 87 & 3935 & 2608 & 3067 & 2908 \\
\hline $11-38$ & 3117 & 1,1 & 69 & 0 & 100 & 87 & 4237 & 2391 & 3030 & 2809 \\
\hline $11-15$ & 3107 & 0,8 & 53 & 318282 & 5 & 51 & 3902 & 2592 & 3046 & 2889 \\
\hline $11-19$ & 3033 & 1,1 & 82 & 0 & 100 & 97 & 4095 & 2346 & 2951 & 2742 \\
\hline $08-29$ & 3029 & 1,1 & 87 & 23083 & 32 & 83 & 4073 & 2354 & 2949 & 2743 \\
\hline $11-49$ & 3019 & 1,1 & 72 & 110691 & 18 & 78 & 4126 & 2303 & 2934 & 2716 \\
\hline $10-11$ & 2988 & 1,4 & 20 & 605595 & 1 & 66 & 4382 & 2085 & 2880 & 2605 \\
\hline $11-12$ & 2966 & 1,5 & 14 & 1046447 & 0 & 57 & 4420 & 2024 & 2853 & 2566 \\
\hline $11-46$ & 2959 & 1,3 & 27 & 1192623 & 0 & 50 & 4297 & 2092 & 2856 & 2592 \\
\hline $11-17$ & 2939 & 1,5 & 14 & 0 & 100 & 98 & 4386 & 2002 & 2827 & 2542 \\
\hline $04-08$ & 2916 & 0,9 & 74 & 0 & 100 & 87 & 3804 & 2341 & 2848 & 2672 \\
\hline $10-18$ & 2892 & 1,5 & 12 & 266428 & 7 & 80 & 4372 & 1933 & 2777 & 2485 \\
\hline $08-06$ & 2864 & 1,2 & 63 & 92119 & 20 & 81 & 4010 & 2122 & 2776 & 2550 \\
\hline \multicolumn{11}{|c|}{ Testemunhas } \\
\hline IAS-5 & 2446 & 0,8 & 57 & 0 & 100 & 92 & 3257 & 1920 & 2383 & 2223 \\
\hline IAC-100 & 2372 & 1,2 & 57 & 9239 & 35 & 87 & 3544 & 1613 & 2281 & 2050 \\
\hline Foscarin & 2255 & 0,9 & 83 & 0 & 100 & 92 & 3184 & 1653 & 2183 & 2000 \\
\hline Primavera & 2181 & 0,5 & 11 & 0 & 100 & 80 & 2674 & 1862 & 2143 & 2046 \\
\hline \multicolumn{4}{|c|}{ Índices ambientais } & & & & 992,44 & $-642,97$ & $-76,82$ & $-272,65$ \\
\hline
\end{tabular}


Tabela 41. Análise de variância segundo a metodologia AMMI dos experimentos em blocos aumentados em 2000, modelo AMMI 2

\begin{tabular}{lrrrr}
\hline \multicolumn{1}{c}{ FV } & GL & \multicolumn{1}{c}{ QM } & \multicolumn{1}{c}{ F } & Pr $>$ F \\
\hline Ambientes (E) & 3 & 37458515 & 138,12 & $<0,0001$ \\
Genótipos (G) & 75 & 660441 & 2,44 & $<0,0001$ \\
GxE & 225 & 271199 & 1,87 & 0,0025 \\
$\quad$ AMMI 1 & 77 & 336372 & 2,32 & 0,0005 \\
$\quad$ AMMI 2 & 75 & 283220 & 1,96 & 0,0040 \\
$\quad$ Resíduo GxE & 73 & 190105 & 1,31 & 0,1396 \\
Resíduo & 59 & 144707 & & \\
\hline Média = 2590,84 & & & & \\
CV\% $=20^{\text {b }}$ & & & & \\
a $^{\text {arodutividade média kg ha }}{ }^{-1}$ &
\end{tabular}


Tabela 42. Parâmetros e médias estimadas das linhagens mais produtivas $(p=20 \%)$ para a metodologia AMMI nos experimentos dispostos em blocos aumentados em 2000, Modelo AMMI 2

\begin{tabular}{|c|c|c|c|c|c|c|c|}
\hline \multirow{2}{*}{ Genótipos } & \multicolumn{3}{|c|}{ Parâmetros AMMI 2} & \multicolumn{4}{|c|}{ Médias estimadas } \\
\hline & Médias & IPCA1 & IPCA2 & Anhembi & Areão & ESALQ-1 & ESALQ-2 \\
\hline \multicolumn{8}{|l|}{ Linhagens: } \\
\hline $09-14$ & 3377 & $-2,08$ & $-0,53$ & 4423 & 2648 & 3236 & 3200 \\
\hline $11-10$ & 3348 & 1,47 & $-11,14$ & 4277 & 3164 & 2693 & 3259 \\
\hline 04-06 & 3280 & $-6,91$ & $-4,23$ & 4445 & 2438 & 2858 & 3378 \\
\hline $11-18$ & 3214 & 10,53 & $-0,64$ & 3928 & 3119 & 3280 & 2531 \\
\hline $11-08$ & 3183 & 0,89 & 7,53 & 4169 & 2324 & 3529 & 2711 \\
\hline $08-25$ & 3163 & $-6,66$ & $-0,99$ & 4329 & 2222 & 2921 & 3180 \\
\hline $08-04$ & 3142 & 0,05 & 9,75 & 4155 & 2164 & 3594 & 2655 \\
\hline $10-10$ & 3129 & 6,19 & $-0,44$ & 3958 & 2811 & 3132 & 2617 \\
\hline $11-38$ & 3117 & $-7,13$ & $-2,90$ & 4291 & 2219 & 2764 & 3195 \\
\hline $11-15$ & 3107 & 5,92 & 12,17 & 3971 & 2339 & 3788 & 2330 \\
\hline $11-19$ & 3033 & $-1,81$ & $-2,72$ & 4067 & 2394 & 2779 & 2893 \\
\hline $08-29$ & 3029 & $-6,88$ & 1,00 & 4206 & 2008 & 2892 & 3012 \\
\hline $11-49$ & 3019 & 4,97 & 8,95 & 3901 & 2315 & 3510 & 2352 \\
\hline $11-36$ & 2988 & 10,34 & 5,04 & 3720 & 2687 & 3357 & 2189 \\
\hline $11-12$ & 2966 & $-12,39$ & 19,30 & 4329 & 1037 & 3726 & 2771 \\
\hline $11-46$ & 2959 & $-15,15$ & 16,17 & 4388 & 1001 & 3504 & 2944 \\
\hline $11-17$ & 2939 & $-6,38$ & $-0,99$ & 4098 & 2012 & 2702 & 2946 \\
\hline 04-08 & 2916 & 2,38 & 5,35 & 3858 & 2207 & 3169 & 2431 \\
\hline 08-06 & 2864 & $-9,09$ & 1,64 & 4100 & 1711 & 2724 & 2922 \\
\hline $11-27$ & 2840 & $-1,30$ & 7,41 & 3884 & 1876 & 3143 & 2459 \\
\hline 05-01 & 2840 & $-4,06$ & $-3,94$ & 3930 & 2130 & 2482 & 2816 \\
\hline $05-05$ & 2822 & $-2,86$ & $-2,74$ & 3884 & 2131 & 2549 & 2725 \\
\hline \multicolumn{8}{|l|}{ Testemunhas: } \\
\hline IAS-5 & 2446 & 3,28 & $-4,22$ & 3342 & 2112 & 2195 & 2133 \\
\hline IAC-100 & 2372 & $-3,07$ & $-6,71$ & 3430 & 1808 & 1880 & 2370 \\
\hline Foscarin & 2255 & 4,12 & $-1,60$ & 3135 & 1873 & 2160 & 1851 \\
\hline PRIMA & 2181 & 2,41 & $-6,54$ & 3096 & 1885 & 1791 & 1955 \\
\hline \multicolumn{8}{|l|}{ Ambientes: } \\
\hline Anhembi & 3583 & $-26,36$ & 2,27 & & & & \\
\hline ESALQ-1 & 2514 & 16,75 & 54,14 & & & & \\
\hline ESALQ-2 & 2318 & $-40,29$ & $-21,82$ & & & & \\
\hline Areão & 1948 & 49,91 & $-34,59$ & & & & \\
\hline
\end{tabular}


Tabela 43. Análise de variância para os experimentos em blocos casualizados subdivididos em conjuntos experimentais em 2000

\begin{tabular}{|c|c|c|c|c|}
\hline FV & $\mathbf{G L}$ & QM & $\mathbf{F}$ & $\mathrm{Pr}<\mathrm{F}$ \\
\hline \multicolumn{5}{|l|}{ Anhembi } \\
\hline Repetições (R) & 1 & 173952 & 1,16 & 0,2837 \\
\hline Conjuntos / R & 10 & 1088823 & 7,27 & $<0,0001$ \\
\hline Genótipos & 75 & 750435 & 5,01 & $<0,0001$ \\
\hline Linhagens (L) & 71 & 648905 & 4,33 & $<0,0001$ \\
\hline Testemunhas (T) & 3 & 1666540 & 11,12 & $<0,0001$ \\
\hline L vs T & 1 & 5308222 & 35,43 & $<0,0001$ \\
\hline Resíduo & 104 & 149818 & & \\
\hline \multicolumn{5}{|l|}{$\begin{array}{l}\text { Média }=3544,95^{\mathrm{a}} \\
\mathrm{CV} \%=11^{\mathrm{b}}\end{array}$} \\
\hline \multicolumn{5}{|l|}{ Areão } \\
\hline Repetições (R) & 1 & 12502711 & 70,72 & $<0,0001$ \\
\hline Conjuntos / R & 10 & 388285 & 2,20 & 0,0236 \\
\hline Genótipos & 75 & 276254 & 1,56 & $0,017 \varepsilon$ \\
\hline Linhagens (L) & 71 & 265411 & 1,50 & 0,0295 \\
\hline Testemunhas (T) & 3 & 510626 & 2,89 & 0,0391 \\
\hline L vs T & 1 & 348427 & 1,97 & 0,1634 \\
\hline Resíduo & 103 & 176792 & & \\
\hline \multicolumn{5}{|l|}{$\begin{array}{l}\text { Média }=2203,41 \\
\text { CV\% }=19\end{array}$} \\
\hline \multicolumn{5}{|l|}{ ESALQ-1 } \\
\hline Repetições (R) & 1 & 3256201 & 21,90 & $<0,0001$ \\
\hline Conjuntos / R & 10 & 60605 & 0,41 & 0,9402 \\
\hline Genótipos & 75 & 557085 & 3,75 & $<0,0001$ \\
\hline Linhagens (L) & 71 & 473060 & 3,18 & $<0,0001$ \\
\hline Testemunhas (T) & 3 & 249326 & 1,68 & 0,1767 \\
\hline L vs T & 1 & 7031739 & 47,29 & $<0,0001$ \\
\hline Resíduo & 101 & 148679 & & \\
\hline \multicolumn{5}{|l|}{$\begin{array}{l}\text { Média }=2541,12 \\
\text { CV\% }=15\end{array}$} \\
\hline \multicolumn{5}{|l|}{ ESALQ-2 } \\
\hline Repetições (R) & 1 & 1024117, & 5,05 & 0,0267 \\
\hline Conjuntos / R & 10 & 981781, & 4,84 & $<0,0001$ \\
\hline Genótipos & 75 & 332596 & 1,64 & 0,0096 \\
\hline Linhagens (L) & 71 & 300098 & 1,48 & 0,0335 \\
\hline Testemunhas (T) & 3 & 506401 & 2,50 & 0,0637 \\
\hline L vs T & 1 & 2118541 & 10,45 & 0,0016 \\
\hline Resíduo & 105 & 202703 & & \\
\hline $\begin{array}{l}\text { Média }=2195,27 \\
\text { CV\% }=21\end{array}$ & & & & \\
\hline
\end{tabular}


Tabela 44. Teste de Dunnett para as 16 linhagens mais produtivas $(p=20 \%)$ e testemunhas contra a testemunha mais produtiva para os experimentos em blocos casualizados subdivididos em conjuntos experimentais em 2000

\begin{tabular}{|c|c|c|c|c|c|c|c|c|c|c|c|}
\hline \multicolumn{12}{|c|}{ Ambientes } \\
\hline \multicolumn{3}{|c|}{ Anhembi } & \multicolumn{3}{|c|}{ Areão } & \multicolumn{3}{|c|}{ ESALQ-1 } & \multicolumn{3}{|c|}{ ESALQ-2 } \\
\hline Genótipos & Médias & $\operatorname{Pr}<t$ & Genótipos & Médias & $\operatorname{Pr}<\mathrm{t}$ & Genótipos & Médias & $\mathrm{Pr}<\mathrm{t}$ & Genótipos & Médias & $\mathrm{Pr}<\mathrm{t}$ \\
\hline \multicolumn{12}{|l|}{ Linhagens: } \\
\hline $08-20$ & 4768 & 0,11 & $11-19$ & 3621 & 0,77 & $10-24$ & 3968 & 0,00 & 09-14 & 3303 & 0,13 \\
\hline $11-19$ & 4544 & 0,55 & $11-27$ & 3585 & 0,84 & $08-04$ & 3906 & 0,00 & $11-22$ & 3111 & 0,45 \\
\hline $11-12$ & 4537 & 0,57 & $09-14$ & 3411 & 0,97 & $11-12$ & 3870 & 0,00 & $11-38$ & 2935 & 0,85 \\
\hline $08-04$ & 4458 & 0,78 & $11-12$ & 3321 & 0,99 & $11-13$ & 3608 & 0,02 & $04-06$ & 2885 & 0,92 \\
\hline $11-21$ & 4435 & 0,85 & $11-15$ & 3251 & 1 & $11-49$ & 3526 & 0,04 & $11-19$ & 2854 & 0,95 \\
\hline $11-22$ & 4422 & 0,86 & $04-12$ & 3221 & 1 & $11-15$ & 3515 & 0,04 & $10-13$ & 2848 & 0,96 \\
\hline $11-36$ & 4383 & 0,93 & $11-38$ & 3220 & 1 & $11-08$ & 3508 & 0,05 & $11-15$ & 2846 & 0,96 \\
\hline $11-18$ & 4366 & 0,95 & $10-13$ & 3181 & 1 & $04-13$ & 3422 & 0,10 & 04-16 & 2813 & 0,98 \\
\hline $11-08$ & 4331 & 0,98 & $08-02$ & 3171 & 1 & $11-18$ & 3333 & 0,21 & $10-10$ & 2761 & 1 \\
\hline $04-06$ & 4300 & 0,99 & $04-06$ & 3166 & 1 & $11-46$ & 3318 & 0,24 & $08-29$ & 2725 & 1 \\
\hline $11-13$ & 4286 & 0,99 & 04-08 & 2971 & 1 & $11-41$ & 3265 & 0,35 & $11-44$ & 2722 & 1 \\
\hline $11-15$ & 4259 & 1 & $11-41$ & 2926 & 1 & $04-03$ & 3253 & 0,38 & $08-04$ & 2702 & 1 \\
\hline $09-14$ & 4251 & 1 & $02-18$ & 2880 & 1 & $11-27$ & 3253 & 0,38 & $11-10$ & 2679 & 1 \\
\hline $10-10$ & 4249 & 1 & $10-25$ & 2880 & 1 & $11-38$ & 3238 & 0,41 & $11-18$ & 2587 & 1 \\
\hline $10-18$ & 4217 & 1 & 05-05 & 2876 & 1 & $11-33$ & 3223 & 0,45 & $08-25$ & 2578 & 1 \\
\hline $10-30$ & 4149 & 1 & $04-03$ & 2855 & 1 & $11-23$ & 3155 & 0,64 & $09-03$ & 2558 & 1 \\
\hline \multicolumn{12}{|c|}{ Testemunhas: } \\
\hline IAC-100 & 3735 & padrão & IAS-5 & 2668 & padrão & IAS-5 & 2381 & padrão & IAC-100 & 2128 & padrão \\
\hline IAS-5 & 3279 & 0,26 & Primavera & 2509 & 1 & Foscarin & 2252 & 1 & Primavera & 2127 & 1 \\
\hline Foscarin & 3161 & 0,04 & Foscarin & 2178 & 0,71 & IAC-100 & 2130 & 1 & IAS-5 & 2092 & 1 \\
\hline Primavera & 2833 & 0,00 & IAC-100 & 2013 & 0,28 & Primavera & 2041 & 0,88 & Foscarin & 1706 & 0,75 \\
\hline
\end{tabular}

Tabela 45. Análise de variância conjunta para os experimentos em blocos casualizados subdivididos em conjuntos experimentais em 2000

\begin{tabular}{lrrrr}
\hline \multicolumn{1}{c}{ FV } & GL & \multicolumn{1}{c}{ QM } & \multicolumn{1}{c}{ F } & Pr $>$ F \\
\hline Ambientes (E) & 3 & 32466124 & 202,41 & $<0,0001$ \\
Genótipos (G) & 75 & 591430 & 3,69 & $<0,0001$ \\
$\quad$ Linhagens (L) & 71 & 603551 & 3,76 & $<0,0001$ \\
$\quad$ Testemunhas (T) & 3 & 63017, & 0,39 & 0,7582 \\
L vs T & 1 & 1316045 & 8,20 & 0,0046 \\
GxE & 225 & 160400 & 0,95 & 0,6802 \\
Resíduo & 413 & 169712 & & \\
\hline
\end{tabular}

Média $=2678,78^{\mathrm{a}}$

$\mathrm{CV} \%=15^{\mathrm{b}}$

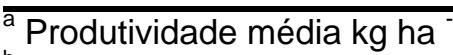

${ }^{\mathrm{b}}$ Coeficiente de variação 
Tabela 46. Teste de Dunnett para as 16 linhagens mais produtivas $(p=20 \%)$ e testemunhas, contra a testemunha mais produtiva, para os experimentos em blocos casualizados subdivididos em conjuntos experimentais em 2000

\begin{tabular}{|c|c|c|}
\hline \multirow{2}{*}{ Genótipos } & \multicolumn{2}{|c|}{ Parâmetros } \\
\hline & $\mathrm{kg} \mathrm{ha}^{-1 a}$ & $\operatorname{Pr}>|t|$ \\
\hline \multicolumn{3}{|l|}{ Linhagens: } \\
\hline 09-14 & 3366 & 0,12 \\
\hline 08-04 & 3360 & 0,13 \\
\hline $11-15$ & 3352 & 0,13 \\
\hline $11-18$ & 3309 & 0,19 \\
\hline $11-19$ & 3297 & 0,21 \\
\hline $11-12$ & 3219 & 0,36 \\
\hline $11-22$ & 3218 & 0,36 \\
\hline $11-38$ & 3214 & 0,37 \\
\hline $11-08$ & 3141 & 0,57 \\
\hline $10-10$ & 3129 & 0,60 \\
\hline 04-06 & 3096 & 0,70 \\
\hline 04-03 & 3065 & 0,79 \\
\hline $11-36$ & 3061 & 0,80 \\
\hline $11-10$ & 3059 & 0,80 \\
\hline $11-49$ & 3053 & 0,82 \\
\hline $04-16$ & 3031 & 0,87 \\
\hline \multicolumn{3}{|l|}{ Testemunhas: } \\
\hline IAS-5 & 2535 & padrão \\
\hline IAC-100 & 2477 & 1 \\
\hline Primavera & 2299 & 1 \\
\hline Foscarin & 2287 & 1 \\
\hline
\end{tabular}

\footnotetext{
${ }^{a}$ Produtividade média $\mathrm{kg} \mathrm{ha}^{-1}$
} 
Tabela 47. Análise de variância segundo a metodologia de Eberhart \& Russell (1966) para os experimentos em blocos casualizados subdivididos em conjuntos experimentais em 2000

\begin{tabular}{lrrrr}
\hline \multicolumn{1}{c}{ FV } & GL & \multicolumn{1}{c}{ QM } & \multicolumn{1}{c}{ F } & \multicolumn{1}{c}{ Pr>F } \\
\hline Ambientes (E) & 3 & 32466124 & 202,41 & $<0,0001$ \\
Genótipos (G) & 75 & 591430 & 3,69 & $<0,0001$ \\
GxE & 225 & 160400 & 0,95 & 0,6802 \\
G dentro de E & 228 & 585475 & 3,45 & $<0,0001$ \\
$\quad$ E Linear & 1 & 97398371 & 573,90 & $<0,0001$ \\
$\quad$ GxE Linear & 75 & 198184 & 1,17 & 0,1764 \\
$\quad$ Desvios Combinados & 152 & 139646 & 0,82 & 0,9206 \\
Resíduo & 413 & 84856 & & \\
\hline
\end{tabular}

Tabela 48. Parâmetros e médias estimadas a partir do modelo de Eberhart \& Russell (1966), para os experimentos em blocos casualizados subdivididos em conjuntos experimentais em 2000

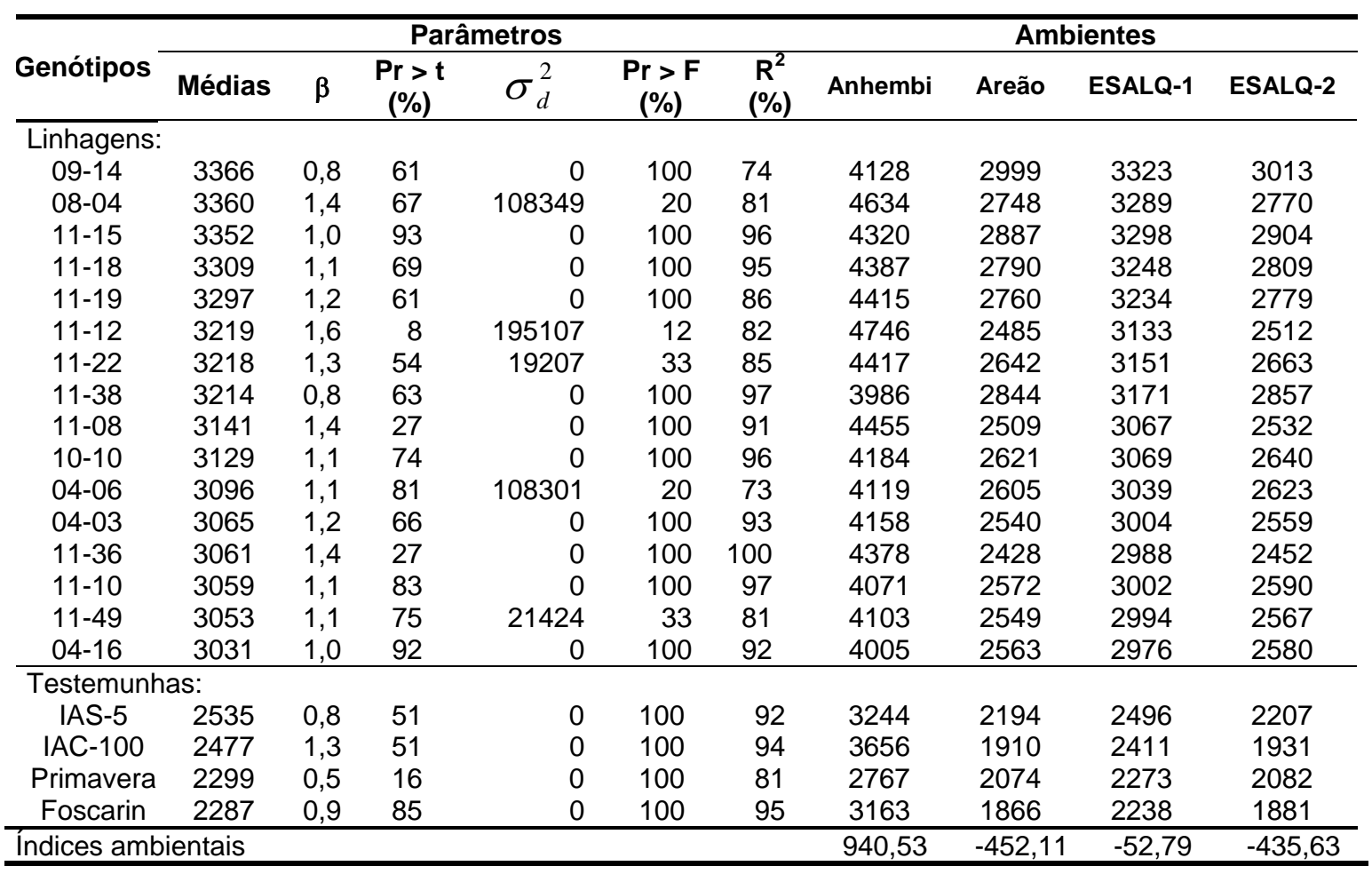


Tabela 49. Análise de variância segundo a metodologia AMMI dos experimentos em blocos casualizados subdivididos em conjuntos experimentais em 2000, modelo AMMI 0

\begin{tabular}{lrrrr}
\hline \multicolumn{1}{c}{ FV } & \multicolumn{1}{c}{ GL } & \multicolumn{1}{c}{ QM } & \multicolumn{1}{c}{ F } & \multicolumn{1}{c}{ Pr>F } \\
\hline Ambientes (E) & 3 & 32466124 & 202,41 & $<0,0001$ \\
Genótipos (G) & 75 & 591430 & 3,69 & $<0,0001$ \\
GxE & 225 & 160400 & 0,95 & 0,6802 \\
Resíduo & 413 & 169712 & & \\
\hline
\end{tabular}

Média $=2678,79^{\mathrm{a}}$

$\mathrm{CV} \%=15^{\mathrm{b}}$

${ }^{2}$ Produtividade média kg ha ${ }^{-1}$

${ }^{\mathrm{b}}$ Coeficiente de variação 
Tabela 50. Parâmetros e médias estimadas para a metodologia AMMI dos experimentos em blocos casualizados subdivididos em conjuntos experimentais em 2000, modelo AMMI 0

\begin{tabular}{|c|c|c|c|c|c|}
\hline \multirow{2}{*}{ Genótipos } & \multirow{2}{*}{$\begin{array}{c}\text { Parâmetros } \\
\text { AMMI } 0 \\
\text { Médias }\end{array}$} & \multicolumn{4}{|c|}{ Médias estimadas } \\
\hline & & Anhembi & Areão & ESALQ-1 & ESALQ-2 \\
\hline \multicolumn{6}{|l|}{ Linhagens: } \\
\hline $09-14$ & 3366 & 4306 & 2913 & 3313 & 2930 \\
\hline $08-04$ & 3360 & 4301 & 2908 & 3307 & 2924 \\
\hline $11-15$ & 3352 & 4293 & 2900 & 3300 & 2917 \\
\hline $11-18$ & 3309 & 4249 & 2857 & 3256 & 2873 \\
\hline $11-19$ & 3297 & 4238 & 2845 & 3244 & 2862 \\
\hline $11-12$ & 3219 & 4160 & 2767 & 3166 & 2783 \\
\hline $11-22$ & 3218 & 4159 & 2766 & 3166 & 2783 \\
\hline $11-38$ & 3214 & 4155 & 2762 & 3162 & 2779 \\
\hline $11-08$ & 3141 & 4081 & 2689 & 3088 & 2705 \\
\hline $10-10$ & 3129 & 4069 & 2677 & 3076 & 2693 \\
\hline 04-06 & 3096 & 4037 & 2644 & 3044 & 2661 \\
\hline 04-03 & 3065 & 4006 & 2613 & 3013 & 2630 \\
\hline $11-36$ & 3061 & 4002 & 2609 & 3009 & 2626 \\
\hline $11-10$ & 3059 & 4000 & 2607 & 3006 & 2623 \\
\hline $11-49$ & 3053 & 3994 & 2601 & 3000 & 2618 \\
\hline 04-16 & 3031 & 3972 & 2579 & 2978 & 2596 \\
\hline \multicolumn{6}{|l|}{ Testemunhas: } \\
\hline IAS-5 & 2535 & 3476 & 2083 & 2483 & 2100 \\
\hline IAC-100 & 2477 & 3418 & 2025 & 2425 & 2042 \\
\hline Primavera & 2299 & 3240 & 1847 & 2246 & 1863 \\
\hline Foscarin & 2287 & 3227 & 1835 & 2234 & 1851 \\
\hline \multicolumn{6}{|l|}{ Ambientes: } \\
\hline Anhembi & 3619 & & & & \\
\hline ESALQ-2 & 2626 & & & & \\
\hline ESALQ-1 & 2243 & & & & \\
\hline Areão & 2227 & & & & \\
\hline
\end{tabular}


Tabela 51. Análise de variância segundo a metodologia AMMI considerando conjuntamente os 12 ambientes, modelo AMMI 2

\begin{tabular}{lrrrr}
\hline \multicolumn{1}{c}{ FV } & GL & \multicolumn{1}{c}{ QM } & \multicolumn{1}{c}{ F } & Pr $>$ F \\
\hline Ambientes (E) & 11 & 27502650 & 143,59 & $<0,0001$ \\
Genótipos (G) & 75 & 1005856 & 5,25 & $<0,0001$ \\
GxE & 825 & 191538 & 0,87 & 0,9879 \\
AMMI 1 & 85 & 446270 & 2,02 & $<0,0001$ \\
$\quad$ AMMI 2 & 83 & 289166 & 1,31 & 0,0376 \\
$\quad$ Resíduo AMMI 2 & 657 & 146249 & 0,66 & 1,0000 \\
Resíduo & 1229 & 221308 & & \\
\hline
\end{tabular}

Média $=2688,12^{\mathrm{a}}$

$\mathrm{CV} \%=16^{\mathrm{b}}$

${ }^{2}$ Produtividade média kg ha ${ }^{-1}$

${ }^{\mathrm{b}}$ Coeficiente de variação 
Tabela 52. Médias gerais, estimativas de parâmetros IPCA 1 e IPCA 2 e médias estimadas através do modelo AMMI 2 para genótipos nos 12 ambientes avaliados

\begin{tabular}{|c|c|c|c|c|c|c|c|c|c|c|c|c|c|c|c|}
\hline \multirow{3}{*}{ Genótipos } & \multirow{3}{*}{ Médias } & \multirow{3}{*}{ IPCA1 } & \multirow{3}{*}{ IPCA2 } & \multicolumn{12}{|c|}{ Médias estimadas } \\
\hline & & & & \multicolumn{4}{|c|}{ Ano 1998} & \multicolumn{4}{|c|}{ Ano 1999} & \multicolumn{4}{|c|}{ Ano 2000} \\
\hline & & & & Anhembi & Areão & ESALQ-1 & ESALQ-2 & Anhembi & Areão & ESALQ-1 & ESALQ-2 & Anhembi & Areão & ESALQ-1 & ESALQ-2 \\
\hline \multicolumn{15}{|l|}{ Linhagens: } & \\
\hline $\begin{array}{l}11-38 \\
10-10\end{array}$ & 3232 & 11,49 & $-0,51$ & 3974 & 3191 & 2854 & 3232 & 4420 & 2108 & 2708 & 3064 & 4480 & 2665 & 3398 & 2691 \\
\hline $\begin{array}{c}10-10 \\
9-14\end{array}$ & 3135 & $-1,87$ & $-7,95$ & 2916 & 3379 & 2758 & 3678 & 4241 & 2170 & 2581 & 2977 & 4186 & 2676 & 3295 & 2766 \\
\hline $9-14$ & 3074 & 4,69 & $-2,62$ & 3367 & 3186 & 2760 & 3324 & 4214 & 2022 & 2549 & 2910 & 4189 & 2566 & 3190 & 2611 \\
\hline $8-4$ & 3060 & 12,90 & $-6,85$ & 3707 & 2958 & 2389 & 3132 & 4283 & 1961 & 2470 & 2892 & 4475 & 2466 & 3440 & 2545 \\
\hline $4-9$ & 3046 & 1,40 & 7,44 & 3478 & 3275 & 3247 & 3187 & 4123 & 1957 & 2636 & 2883 & 3863 & 2589 & 2787 & 2543 \\
\hline $11-18$ & 3045 & 7,90 & $-12,33$ & 3223 & 3043 & 2246 & 3390 & 4247 & 2028 & 2414 & 2882 & 4445 & 2488 & 3516 & 2618 \\
\hline $11-15$ & 3040 & 9,39 & $-17,83$ & 3125 & 2982 & 1965 & 3454 & 4275 & 2047 & 2348 & 2878 & 4597 & 2458 & 3713 & 2638 \\
\hline $11-19$ & 3029 & 2,91 & $-5,02$ & 3172 & 3173 & 2672 & 3367 & 4163 & 2004 & 2491 & 2867 & 4141 & 2532 & 3177 & 2595 \\
\hline $11-12$ & 3021 & 9,23 & $-11,24$ & 3323 & 2990 & 2248 & 3294 & 4230 & 1982 & 2399 & 2857 & 4431 & 2453 & 3474 & 2571 \\
\hline $11-27$ & 2999 & 3,22 & $-1,94$ & 3266 & 3139 & 2751 & 3259 & 4127 & 1950 & 2488 & 2836 & 4067 & 2502 & 3067 & 2538 \\
\hline $4-6$ & 2996 & 4,69 & 17,19 & 3959 & 3184 & 3581 & 2813 & 4062 & 1807 & 2684 & 2828 & 3677 & 2528 & 2459 & 2386 \\
\hline $4-16$ & 2961 & 14,96 & 7,02 & 4110 & 2874 & 2823 & 2719 & 4150 & 1764 & 2501 & 2790 & 4141 & 2381 & 2956 & 2341 \\
\hline $4-10$ & 2954 & 10,65 & 3,51 & 3789 & 2948 & 2779 & 2890 & 4120 & 1809 & 2476 & 2785 & 4092 & 2403 & 2972 & 2390 \\
\hline $11-22$ & 2934 & $-0,79$ & $-11,69$ & 2675 & 3138 & 2385 & 3509 & 4061 & 1980 & 2342 & 2776 & 4085 & 2457 & 3219 & 2577 \\
\hline $11-13$ & 2933 & 14,02 & $-1,81$ & 3776 & 2825 & 2435 & 2883 & 4147 & 1796 & 2386 & 2763 & 4277 & 2339 & 3187 & 2377 \\
\hline $4-5$ & 2932 & 1,99 & 13,81 & 3616 & 3169 & 3411 & 2912 & 3989 & 1791 & 2587 & 2765 & 3622 & 2481 & 2470 & 2374 \\
\hline $11-36$ & 2915 & 2,22 & $-6,70$ & 2971 & 3066 & 2500 & 3304 & 4049 & 1905 & 2361 & 2753 & 4046 & 2420 & 3103 & 2497 \\
\hline $11-44$ & 2905 & 3,98 & $-1,84$ & 3207 & 3033 & 2655 & 3145 & 4036 & 1849 & 2394 & 2741 & 3980 & 2403 & 2973 & 2438 \\
\hline 08-05 & 2884 & 2,59 & 0,98 & 3201 & 3056 & 2790 & 3106 & 3994 & 1821 & 2407 & 2720 & 3864 & 2401 & 2839 & 2409 \\
\hline $11-46$ & 2870 & $-5,26$ & $-8,08$ & 2484 & 3190 & 2581 & 3501 & 3949 & 1930 & 2329 & 2714 & 3831 & 2441 & 2964 & 2528 \\
\hline $11-33$ & 2867 & 5,10 & $-0,46$ & 3272 & 2975 & 2650 & 3048 & 4003 & 1794 & 2366 & 2703 & 3944 & 2359 & 2914 & 2381 \\
\hline 04-12 & 2865 & $-4,36$ & 9,82 & 3089 & 3232 & 3323 & 3106 & 3886 & 1801 & 2502 & 2703 & 3474 & 2463 & 2415 & 2390 \\
\hline $11-17$ & 2853 & $-2,28$ & 4,16 & 3010 & 3150 & 3016 & 3149 & 3911 & 1808 & 2425 & 2691 & 3636 & 2420 & 2618 & 2399 \\
\hline $10-18$ & 2845 & $-1,18$ & $-6,18$ & 2737 & 3078 & 2537 & 3321 & 3950 & 1860 & 2309 & 2686 & 3875 & 2382 & 2955 & 2454 \\
\hline $11-41$ & 2839 & 6,94 & $-5,19$ & 3194 & 2886 & 2372 & 3063 & 4007 & 1782 & 2284 & 2675 & 4064 & 2304 & 3067 & 2369 \\
\hline $08-02$ & 2817 & $-1,73$ & $-7,43$ & 2640 & 3058 & 2469 & 3335 & 3923 & 1844 & 2271 & 2659 & 3859 & 2357 & 2956 & 2440 \\
\hline \multirow{2}{*}{\multicolumn{16}{|c|}{ Testemunhas: }} \\
\hline & & & & & & & & & & & & & & & \\
\hline $\begin{array}{l}\text { IAS-5 } \\
\text { IAC-100 }\end{array}$ & $\begin{array}{l}2540 \\
2475\end{array}$ & $\begin{array}{r}-0,04 \\
4,15\end{array}$ & $\begin{array}{l}5,67 \\
6,52\end{array}$ & $\begin{array}{l}2850 \\
3047\end{array}$ & $\begin{array}{l}2793 \\
2634\end{array}$ & $\begin{array}{l}2706 \\
2586\end{array}$ & $\begin{array}{l}2750 \\
2541\end{array}$ & $\begin{array}{l}3611 \\
3576\end{array}$ & $\begin{array}{l}1470 \\
1364\end{array}$ & $\begin{array}{l}2117 \\
2049\end{array}$ & $\begin{array}{l}2377 \\
2309\end{array}$ & $\begin{array}{l}3353 \\
3376 \\
3376\end{array}$ & 2091 & 2304 & 2058 \\
\hline $\begin{array}{l}\text { TAC-100 } \\
\text { Primavera }\end{array}$ & $\begin{array}{l}2475 \\
2443\end{array}$ & $\begin{array}{r}4,15 \\
-4,93\end{array}$ & $\begin{array}{r}6,52 \\
10,42\end{array}$ & $\begin{array}{l}3047 \\
2655\end{array}$ & $\begin{array}{l}2634 \\
2827\end{array}$ & $\begin{array}{l}2586 \\
2944\end{array}$ & $\begin{array}{l}2541 \\
2687\end{array}$ & $\begin{array}{l}3576 \\
3456\end{array}$ & $\begin{array}{l}1364 \\
1379\end{array}$ & $\begin{array}{l}2049 \\
2088\end{array}$ & $\begin{array}{l}2309 \\
2281\end{array}$ & $\begin{array}{l}3376 \\
3022 \\
3022\end{array}$ & 2047 & 2281 & 1948 \\
\hline $\begin{array}{l}\text { Foscarin } \\
\text { Fonter }\end{array}$ & 2356 & $\begin{array}{r}-4,93 \\
5,59 \\
\end{array}$ & $\begin{array}{r}r 0,42 \\
6,06 \\
\end{array}$ & $\begin{array}{l}2655 \\
2984 \\
\end{array}$ & 2476 & 2398 & 2394 & $\begin{array}{l}5456 \\
3472\end{array}$ & 1238 & 1917 & $\begin{array}{l}2281 \\
2189\end{array}$ & $\begin{array}{l}3022 \\
3313\end{array}$ & 1855 & $\begin{array}{l}1961 \\
2213\end{array}$ & 1821 \\
\hline \multicolumn{16}{|l|}{ Ambientes: } \\
\hline Anhembi 99 & 3780 & 8,23 & $-3,96$ & & & & & & & & & & & & \\
\hline Anhembi 00 & 3619 & 26,58 & $-21,58$ & & & & & & & & & & & & \\
\hline ESALQ-2 98 & 3008 & $-29,47$ & $-21,89$ & & & & & & & & & & & & \\
\hline Areão 98 & 2915 & $-23,12$ & $\begin{array}{r}5,30 \\
3,25\end{array}$ & & & & & & & & & & & & \\
\hline $\begin{array}{l}\text { Anhembi } 988 \\
\text { FSAI }\end{array}$ & 2836 & 53,17 & & & & & & & & & & & & & \\
\hline $\begin{array}{l}\text { ESALQ-1 } 00 \\
\text { ESALO-1 } 98\end{array}$ & $\begin{array}{l}2626 \\
2619\end{array}$ & $\begin{array}{r}18,01 \\
-25,28\end{array}$ & $\begin{array}{r}-30,92 \\
42,17\end{array}$ & & & & & & & & & & & & \\
\hline ESALQ-2 99 & 2526 & $\begin{array}{r}-20,60 \\
0,69\end{array}$ & $-1,15$ & & & & & & & & & & & & \\
\hline ESALQ-2 00 & 2243 & $-8,50$ & $-6,52$ & & & & & & & & & & & & \\
\hline Areão 00 & 2227 & $-8,88$ & 2,64 & & & & & & & & & & & & \\
\hline ESALQ-1 99 & 2210 & $-3,23$ & $\begin{array}{l}10,47 \\
582\end{array}$ & & & & & & & & & & & & \\
\hline $\begin{array}{l}\text { Areấo } 99 \\
\text { MÉDIA }\end{array}$ & $\frac{1653}{2689}$ & $-8,19$ & $-5,82$ & & & & & & & & & & & & \\
\hline
\end{tabular}


Tabela 53. Correlações de Spearman (acima da diagonal) e os respectivos níveis de significância (abaixo da diagonal) entre as médias dos experimentos em $\mathrm{BA}^{\mathrm{a}}$ (uma repetição) e em $\mathrm{BCCE}^{\mathrm{b}}$ (duas repetições), médias estimadas através das metodologias de $E R^{c}$ e $A M M I$ e as médias estimadas pela análise AMMI para os 12 ambientes em 1998

\begin{tabular}{|c|c|c|c|c|c|c|c|c|}
\hline \multirow{3}{*}{\multicolumn{2}{|c|}{$\begin{array}{l}1998 \\
\text { ANHEMBI }\end{array}$}} & \multicolumn{6}{|c|}{ Modelos } & \multirow{3}{*}{$\begin{array}{c}\text { AMMI } 12 \\
\text { AMB }^{d}\end{array}$} \\
\hline & & \multicolumn{2}{|c|}{ Médias } & \multicolumn{2}{|c|}{ ER } & \multicolumn{2}{|c|}{ AMMI } & \\
\hline & & $\mathrm{BA}^{\mathrm{a}}$ & $\mathrm{BCCE}^{\mathrm{b}}$ & BA & BCCE & $\mathrm{BA}$ & BCCE & \\
\hline \multirow{2}{*}{ Médias } & BA & 1 & 0,74 & 0,80 & 0,70 & 0,73 & 0,59 & 0,73 \\
\hline & BCCE & 0,0001 & 1 & 0,80 & 0,75 & 0,79 & 0,61 & 0,82 \\
\hline \multirow{2}{*}{ ER } & BA & 0,0001 & 0,0001 & 1 & 0,86 & 0,92 & 0,69 & 0,87 \\
\hline & BCCE & 0,0001 & 0,0001 & 0,0001 & 1 & 0,76 & 0,72 & 0,75 \\
\hline \multirow{2}{*}{ AMMI } & BA & 0,0001 & 0,0001 & 0,0001 & 0,0001 & 1 & 0,69 & 0,92 \\
\hline & BCCE & 0,0001 & 0,0001 & 0,0001 & 0,0001 & 0,0001 & 1 & 0,69 \\
\hline \multicolumn{2}{|c|}{ AMMI 12 AMB } & 0,0001 & 0,0001 & 0,0001 & 0,0001 & 0,0001 & 0,0001 & 1 \\
\hline 1998 & & \multicolumn{6}{|c|}{ Modelos } & \\
\hline \multirow{2}{*}{\multicolumn{2}{|c|}{ AREÃO }} & \multicolumn{2}{|c|}{ Médias } & \multicolumn{2}{|c|}{ ER } & \multicolumn{2}{|c|}{ AMMI } & AMMI 12 \\
\hline & & BA & BCCE & BA & BCCE & BA & BCCE & AMB \\
\hline \multirow{2}{*}{ Médias } & $\mathrm{BA}$ & 1 & 0,73 & 0,66 & 0,52 & 0,57 & 0,24 & 0,58 \\
\hline & BCCE & 0,0001 & 1 & 0,52 & 0,73 & 0,60 & 0,47 & 0,69 \\
\hline \multirow{2}{*}{$\begin{array}{l}\text { Eberhart } \\
\text { Russell }\end{array}$} & BA & 0,0001 & 0,0001 & 1 & 0,78 & 0,78 & 0,40 & 0,50 \\
\hline & BCCE & 0,0001 & 0,0001 & 0,0001 & 1 & 0,74 & 0,63 & 0,58 \\
\hline \multirow{2}{*}{ AMMI } & BA & 0,0001 & 0,0001 & 0,0001 & 0,0001 & 1 & 0,64 & 0,62 \\
\hline & BCCE & 0,0692 & 0,0002 & 0,0018 & 0,0001 & 0,0001 & 1 & 0,52 \\
\hline \multicolumn{2}{|c|}{ AMMI 12 AMB } & 0,0001 & 0,0001 & 0,0001 & 0,0001 & 0,0001 & 0,0001 & 1 \\
\hline 1998 & & \multicolumn{6}{|c|}{ Modelos } & \\
\hline \multirow{2}{*}{\multicolumn{2}{|c|}{ ESALQ-1 }} & \multicolumn{2}{|c|}{ Médias } & \multicolumn{2}{|c|}{ ER } & \multicolumn{2}{|c|}{ AMMI } & AMMI 12 \\
\hline & & BA & BCCE & BA & BCCE & $\mathrm{BA}$ & BCCE & AMB \\
\hline \multirow{2}{*}{ Médias } & $\mathrm{BA}$ & 1 & 0,71 & 0,67 & 0,56 & 0,70 & 0,17 & 0,49 \\
\hline & BCCE & 0,0001 & 1 & 0,70 & 0,74 & 0,73 & 0,26 & 0,54 \\
\hline Eberhart & BA & 0,0001 & 0,0001 & 1 & 0,86 & 0,81 & 0,30 & 0,79 \\
\hline Russell & BCCE & 0,0001 & 0,0001 & 0,0001 & 1 & 0,77 & 0,39 & 0,65 \\
\hline & $\mathrm{BA}$ & 0,0001 & 0,0001 & 0,0001 & 0,0001 & 1 & 0,41 & 0,64 \\
\hline & BCCE & 0,2199 & 0,0528 & 0,0232 & 0,003 & 0,0018 & 1 & 0,47 \\
\hline AMMI 12 & AMB & 0,0001 & 0,0001 & 0,0001 & 0,0001 & 0,0001 & 0,0002 & 1 \\
\hline 1998 & & & & & delos & & & \\
\hline ESALQ-2 & & Mé & dias & & & & & AMMI 12 \\
\hline & & BA & BCCE & BA & BCCE & BA & BCCE & AMB \\
\hline & $\mathrm{BA}$ & 1 & 0,88 & 0,71 & 0,70 & 0,68 & 0,55 & 0,49 \\
\hline s & BCCE & 0,0001 & 1 & 0,66 & 0,79 & 0,73 & 0,62 & 0,59 \\
\hline Eberhart & BA & 0,0001 & 0,0001 & 1 & 0,88 & 0,87 & 0,72 & 0,67 \\
\hline Russell & BCCE & 0,0001 & 0,0001 & 0,0001 & 1 & 0,87 & 0,77 & 0,70 \\
\hline AMMI & BA & 0,0001 & 0,0001 & 0,0001 & 0,0001 & 1 & 0,74 & 0,69 \\
\hline Rivivivi & BCCE & 0,0001 & 0,0001 & 0,0001 & 0,0001 & 0,0001 & 1 & 0,88 \\
\hline AMMI 12 & - AMB & 0,0001 & 0,0001 & 0,0001 & 0,0001 & 0,0001 & 0,0001 & 1 \\
\hline
\end{tabular}


Tabela 54. Correlações de Spearman (acima da diagonal) e os respectivos níveis de significância (abaixo da diagonal) entre as médias dos experimentos em $\mathrm{BA}^{\mathrm{a}}$ (uma repetição) e em $\mathrm{BCCE}^{\mathrm{b}}$ (duas repetições), médias estimadas através das metodologias de $\mathrm{ER}^{\mathrm{C}}$ e $\mathrm{AMMI}$ e as médias estimadas pela análise AMMI para os 12 ambientes em 1999

\begin{tabular}{|c|c|c|c|c|c|c|c|c|}
\hline \multirow{3}{*}{\multicolumn{2}{|c|}{$\begin{array}{l}1999 \\
\text { ANHEMBI }\end{array}$}} & \multicolumn{6}{|c|}{ Modelos } & \multirow{3}{*}{$\begin{array}{c}\text { AMMI } 12 \\
\text { AMB }^{d}\end{array}$} \\
\hline & & \multicolumn{2}{|c|}{ Médias } & \multicolumn{2}{|c|}{ ER } & \multicolumn{2}{|c|}{ AMMI } & \\
\hline & & $\mathrm{BAa}$ & $\mathrm{BCCE}^{\mathrm{b}}$ & BA & BCCE & $\mathrm{BA}$ & BCCE & \\
\hline \multirow{2}{*}{ Médias } & BA & 1 & 0,72 & 0,51 & 0,51 & 0,46 & 0,49 & 0,48 \\
\hline & BCCE & 0,0001 & 1 & 0,49 & 0,75 & 0,72 & 0,50 & 0,62 \\
\hline Eberhart & $\mathrm{BA}$ & 0,0001 & 0,0001 & 1 & 0,61 & 0,58 & 0,45 & 0,48 \\
\hline Russell & BCCE & 0,0001 & 0,0001 & 0,0001 & 1 & 0,78 & 0,69 & 0,65 \\
\hline \multirow{2}{*}{ AMMI } & BA & 0,0003 & 0,0001 & 0,0001 & 0,0001 & 1 & 0,68 & 0,70 \\
\hline & BCCE & 0,0001 & 0,0001 & 0,0005 & 0,0001 & 0,0001 & 1 & 0,78 \\
\hline \multicolumn{2}{|c|}{ AMMI 12 AMB } & 0,0002 & 0,0001 & 0,0002 & 0,0001 & 0,0001 & 0,0001 & 1 \\
\hline 1999 & & \multicolumn{6}{|c|}{ Modelos } & \\
\hline \multirow{2}{*}{ AREÃO } & & \multicolumn{2}{|c|}{ Médias } & \multicolumn{2}{|c|}{ ER } & \multicolumn{2}{|c|}{ AMMI } & AMMI 12 \\
\hline & & BA & BCCE & BA & BCCE & BA & BCCE & AMB \\
\hline \multirow{2}{*}{ Médias } & $\mathrm{BA}$ & 1 & 0,78 & 0,38 & 0,45 & 0,48 & 0,29 & 0,29 \\
\hline & BCCE & 0,0001 & 1 & 0,46 & 0,72 & 0,64 & 0,47 & 0,56 \\
\hline Eberhart & $\mathrm{BA}$ & 0,0034 & 0,0003 & 1 & 0,68 & 0,70 & 0,49 & 0,46 \\
\hline Russell & BCCE & 0,0005 & 0,0001 & 0,0001 & 1 & 0,73 & 0,61 & 0,60 \\
\hline \multirow{2}{*}{ AMMI } & $\mathrm{BA}$ & 0,0001 & 0,0001 & 0,0001 & 0,0001 & 1 & 0,74 & 0,76 \\
\hline & BCCE & 0,0304 & 0,0002 & 0,0001 & 0,0001 & 0,0001 & 1 & 0,87 \\
\hline \multicolumn{2}{|c|}{ AMMI 12 AMB } & 0,0267 & 0,0001 & 0,0003 & 0,0001 & 0,0001 & 0,0001 & 1 \\
\hline 1999 & & \multicolumn{6}{|c|}{ Modelos } & \\
\hline \multirow{2}{*}{\multicolumn{2}{|c|}{ ESALQ-1 }} & \multicolumn{2}{|c|}{ Médias } & \multicolumn{2}{|c|}{ ER } & \multicolumn{2}{|c|}{ AMMI } & AMMI 12 \\
\hline & & $\mathrm{BA}$ & BCCE & $\mathrm{BA}$ & BCCE & $\mathrm{BA}$ & BCCE & AMB \\
\hline \multirow{2}{*}{ Médias } & $\mathrm{BA}$ & 1 & 0,77 & 0,46 & 0,49 & 0,49 & 0,37 & 0,47 \\
\hline & BCCE & 0,0001 & 1 & 0,50 & 0,62 & 0,63 & 0,51 & 0,54 \\
\hline Eberhart & BA & 0,0004 & 0,0001 & 1 & 0,74 & 0,63 & 0,43 & 0,41 \\
\hline Russell & BCCE & 0,0001 & 0,0001 & 0,0001 & 1 & 0,77 & 0,62 & 0,64 \\
\hline \multirow[b]{2}{*}{ AMMI } & $\mathrm{BA}$ & 0,0001 & 0,0001 & 0,0001 & 0,0001 & 1 & 0,68 & 0,81 \\
\hline & BCCE & 0,0045 & 0,0001 & 0,0009 & 0,0001 & 0,0001 & 1 & 0,81 \\
\hline \multicolumn{2}{|c|}{ AMMI 12 AMB } & 0,0003 & 0,0001 & 0,0017 & 0,0001 & 0,0001 & 0,0001 & 1 \\
\hline 1999 & & & & & delos & & & \\
\hline ESALO-2 & & Mé & ias & & & & & AMMI 12 \\
\hline ESALQ-2 & & BA & BCCE & BA & BCCE & $\mathrm{BA}$ & BCCE & AMB \\
\hline Médi & $\mathrm{BA}$ & 1 & 0,89 & 0,83 & 0,75 & 0,66 & 0,56 & 0,72 \\
\hline Miedias & BCCE & 0,0001 & 1 & 0,78 & 0,77 & 0,64 & 0,55 & 0,72 \\
\hline Eberhart & BA & 0,0001 & 0,0001 & 1 & 0,92 & 0,79 & 0,68 & 0,79 \\
\hline Russell & BCCE & 0,0001 & 0,0001 & 0,0001 & 1 & 0,78 & 0,78 & 0,84 \\
\hline AMMI & BA & 0,0001 & 0,0001 & 0,0001 & 0,0001 & 1 & 0,90 & 0,86 \\
\hline AIVIIVI & BCCE & 0,0001 & 0,0001 & 0,0001 & 0,0001 & 0,0001 & 1 & 0,87 \\
\hline AMMI 12 & $2 \mathrm{AMB}$ & 0,0001 & 0,0001 & 0,0001 & 0,0001 & 0,0001 & 0,0001 & 1 \\
\hline
\end{tabular}


Tabela 55. Correlações de Spearman (acima da diagonal) e os respectivos níveis de significância (abaixo da diagonal) entre as médias dos experimentos em $\mathrm{BA}^{\mathrm{a}}$ (uma repetição) e em $\mathrm{BCCE}^{\mathrm{b}}$ (duas repetições), médias estimadas através das metodologias de $\mathrm{ER}^{\mathrm{C}}$ e $\mathrm{AMMI}$ e as médias estimadas pela análise AMMI para os 12 ambientes em 2000

\begin{tabular}{|c|c|c|c|c|c|c|c|c|}
\hline \multirow{3}{*}{\multicolumn{2}{|c|}{2000}} & \multicolumn{6}{|c|}{ Modelos } & \multirow{3}{*}{$\begin{array}{l}\text { AMMI } 12 \\
\text { AMB }^{d}\end{array}$} \\
\hline & & \multicolumn{2}{|c|}{ Médias } & \multicolumn{2}{|c|}{ ER } & \multicolumn{2}{|c|}{ AMMI } & \\
\hline & & BAa & BCCE $^{b}$ & BA & BCCE & BA & BCCE & \\
\hline \multirow{2}{*}{ Médias } & $\mathrm{BA}$ & 1 & 0,90 & 0,67 & 0,75 & 0,75 & 0,68 & 0,58 \\
\hline & BCCE & 0,0001 & 1 & 0,59 & 0,78 & 0,72 & 0,69 & 0,68 \\
\hline Eberhart & BA & 0,0001 & 0,0001 & 1 & 0,70 & 0,67 & 0,72 & 0,70 \\
\hline Russell & BCCE & 0,0001 & 0,0001 & 0,0001 & 1 & 0,79 & 0,84 & 0,78 \\
\hline \multirow{2}{*}{ AMMI } & $\mathrm{BA}$ & 0,0001 & 0,0001 & 0,0001 & 0,0001 & 1 & 0,79 & 0,67 \\
\hline & BCCE & 0,0001 & 0,0001 & 0,0001 & 0,0001 & 0,0001 & 1 & 0,70 \\
\hline \multicolumn{2}{|c|}{ AMMI 12 AMB } & 0,0001 & 0,0001 & 0,0001 & 0,0001 & 0,0001 & 0,0001 & 1 \\
\hline 2000 & & \multicolumn{6}{|c|}{ Modelos } & \\
\hline \multirow{2}{*}{\multicolumn{2}{|c|}{ AREÃo }} & \multicolumn{2}{|c|}{ Médias } & \multicolumn{2}{|c|}{ ER } & \multicolumn{2}{|c|}{ AMMI } & AMMI 12 \\
\hline & & $\mathrm{BA}$ & BCCE & $\mathrm{BA}$ & BCCE & $\mathrm{BA}$ & BCCE & AMB \\
\hline \multirow{2}{*}{ Médias } & BA & 1 & 0,78 & 0,47 & 0,60 & 0,66 & 0,43 & 0,54 \\
\hline & BCCE & 0,0001 & 1 & 0,43 & 0,48 & 0,56 & 0,47 & 0,53 \\
\hline Eberhart & $\mathrm{BA}$ & 0,0007 & 0,0007 & 1 & 0,75 & 0,63 & 0,68 & 0,71 \\
\hline Russell & BCCE & 0,0001 & 0,0001 & 0,0001 & 1 & 0,61 & 0,72 & 0,70 \\
\hline \multirow{2}{*}{ AMMI } & BA & 0,0001 & 0,0001 & 0,0001 & 0,0001 & 1 & 0,71 & 0,78 \\
\hline & BCCE & 0,0009 & 0,0002 & 0,0001 & 0,0001 & 0,0001 & 1 & 0,77 \\
\hline \multicolumn{2}{|c|}{ AMMI 12 AMB } & 0,0001 & 0,0001 & 0,0001 & 0,0001 & 0,0001 & 0,0001 & 1 \\
\hline 2000 & & \multicolumn{6}{|c|}{ Modelos } & \\
\hline \multirow{2}{*}{\multicolumn{2}{|c|}{ ESALQ-1 }} & \multicolumn{2}{|c|}{ Médias } & \multicolumn{2}{|c|}{ ER } & \multicolumn{2}{|c|}{ AMMI } & AMMI 12 \\
\hline & & BA & BCCE & BA & BCCE & $\mathrm{BA}$ & BCCE & AMB \\
\hline \multirow{2}{*}{ Médias } & $\mathrm{BA}$ & 1 & 0,82 & 0,56 & 0,63 & 0,62 & 0,64 & 0,57 \\
\hline & BCCE & 0,0001 & 1 & 0,52 & 0,80 & 0,51 & 0,74 & 0,63 \\
\hline Eberhart & $\mathrm{BA}$ & 0,0001 & 0,0001 & 1 & 0,67 & 0,49 & 0,61 & 0,72 \\
\hline Russell & BCCE & 0,0001 & 0,0001 & 0,0001 & 1 & 0,59 & 0,91 & 0,77 \\
\hline \multirow{2}{*}{ AMMI } & $\mathrm{BA}$ & 0,0001 & 0,0001 & 0,0001 & 0,0001 & 1 & 0,65 & 0,57 \\
\hline & BCCE & 0,0001 & 0,0001 & 0,0001 & 0,0001 & 0,0001 & 1 & 0,71 \\
\hline \multicolumn{2}{|c|}{ AMMI 12 AMB } & 0,0001 & 0,0001 & 0,0001 & 0,0001 & 0,0001 & 0,0001 & 1 \\
\hline 2000 & & & & & delos & & & \\
\hline ESAIO-1 & & Mé & dias & & $R$ & & & AMMI 12 \\
\hline ESALQ-1 & & $\mathrm{BA}$ & BCCE & $\mathrm{BA}$ & BCCE & $\mathrm{BA}$ & BCCE & AMB \\
\hline & BA & 1 & 0,67 & 0,68 & 0,81 & 0,71 & 0,65 & 0,55 \\
\hline Medias & BCCE & 0,0001 & 1 & 0,91 & 0,70 & 0,60 & 0,75 & 0,73 \\
\hline Eberhart & $\mathrm{BA}$ & 0,0001 & 0,0001 & 1 & 0,72 & 0,62 & 0,71 & 0,74 \\
\hline Russell & BCCE & 0,0001 & 0,0001 & 0,0001 & 1 & 0,80 & 0,73 & 0,65 \\
\hline & $\mathrm{BA}$ & 0,0001 & 0,0001 & 0,0001 & 0,0001 & 1 & 0,85 & 0,78 \\
\hline AIMIMI & BCCE & 0,0001 & 0,0001 & 0,0001 & 0,0001 & 0,0001 & 1 & 0,82 \\
\hline AMMI 12 & $2 \mathrm{AMB}$ & 0,0001 & 0,0001 & 0,0001 & 0,0001 & 0,0001 & 0,0001 & 1 \\
\hline
\end{tabular}


Tabela 56. Médias das correlações de Spearman (acima da diagonal) e médias dos os respectivos níveis de significância (abaixo da diagonal) entre as médias dos experimentos em $\mathrm{BA}^{\mathrm{a}}$ (uma repetição) e em $\mathrm{BCCE}^{\mathrm{b}}$ (duas repetições), médias estimadas através das metodologias de $E R^{C}$ e AMMI, e médias estimadas pela análise AMMI para os 12 ambientes nos anos de 1998, 1999 e 2000

\begin{tabular}{|c|c|c|c|c|c|c|c|c|}
\hline \multirow{3}{*}{\multicolumn{2}{|c|}{$\begin{array}{c}1998 \\
\begin{array}{c}\text { Médias de } 4 \text { locais / } \\
\text { épocas }\end{array}\end{array}$}} & \multicolumn{6}{|c|}{ Modelos } & \multirow{3}{*}{$\begin{array}{l}\text { AMMI } 12 \\
\text { AMB }^{d}\end{array}$} \\
\hline & & \multicolumn{2}{|c|}{ Médias } & \multicolumn{2}{|c|}{ ER } & \multicolumn{2}{|c|}{ AMMI } & \\
\hline & & BAa & $\mathrm{BCCE}^{\mathrm{b}}$ & BA & BCCE & BA & BCCE & \\
\hline \multirow{2}{*}{ Médias } & BA & 1 & 0,77 & 0,71 & 0,62 & 0,67 & 0,39 & 0,57 \\
\hline & BCCE & 0,0001 & 1 & 0,67 & 0,75 & 0,71 & 0,49 & 0,66 \\
\hline \multirow{2}{*}{$\begin{array}{l}\text { Eberhart } \\
\text { Russell }\end{array}$} & BA & 0,0001 & 0,0001 & 1 & 0,85 & 0,85 & 0,53 & 0,71 \\
\hline & BCCE & 0,0001 & 0,0001 & 0,0001 & 1 & 0,78 & 0,63 & 0,67 \\
\hline \multirow{2}{*}{ AMMI } & BA & 0,0001 & 0,0001 & 0,0001 & 0,0001 & 1 & 0,62 & 0,72 \\
\hline & BCCE & 0,0723 & 0,0133 & 0,0063 & 0,0008 & 0,0005 & 1 & 0,64 \\
\hline \multicolumn{2}{|c|}{ AMMI 12 AMB } & 0,0001 & 0,0001 & 0,0001 & 0,0001 & 0,0001 & 0,0001 & 1 \\
\hline \multicolumn{2}{|l|}{1999} & \multicolumn{6}{|c|}{ Modelos } & \\
\hline \multirow{2}{*}{\multicolumn{2}{|c|}{$\begin{array}{c}\text { Médias de } 4 \text { locais / } \\
\text { épocas }\end{array}$}} & Méc & dias & \multicolumn{2}{|c|}{ ER } & \multicolumn{2}{|c|}{ AMMI } & AMMI 12 \\
\hline & & BA & BCCE & BA & BCCE & BA & BCCE & AMB \\
\hline \multirow{2}{*}{ Médias } & BA & 1 & 0,79 & 0,55 & 0,55 & 0,52 & 0,43 & 0,49 \\
\hline & BCCE & 0,0001 & 1 & 0,56 & 0,71 & 0,66 & 0,51 & 0,61 \\
\hline \multirow{2}{*}{$\begin{array}{l}\text { Eberhart } \\
\text { Russell }\end{array}$} & BA & 0,0001 & 0,0002 & 1 & 0,74 & 0,68 & 0,51 & 0,54 \\
\hline & BCCE & 0,0002 & 0,0001 & 0,0001 & 1 & 0,77 & 0,68 & 0,69 \\
\hline \multirow{2}{*}{ AMMI } & BA & 0,0002 & 0,0001 & 0,0001 & 0,0001 & 1 & 0,75 & 0,78 \\
\hline & BCCE & 0,0088 & 0,0001 & 0,0004 & 0,0001 & 0,0001 & 1 & 0,83 \\
\hline \multicolumn{2}{|c|}{ AMMI 12 AMB } & 0,0068 & 0,0001 & 0,0006 & 0,0001 & 0,0001 & 0,0001 & 1 \\
\hline \multicolumn{2}{|l|}{2000} & \multicolumn{6}{|c|}{ Modelos } & \\
\hline \multirow{2}{*}{\multicolumn{2}{|c|}{$\begin{array}{l}\text { Médias de } 4 \text { locais / } \\
\text { épocas }\end{array}$}} & Méc & dias & \multicolumn{2}{|c|}{ ER } & \multicolumn{2}{|c|}{ AMMI } & AMMI 12 \\
\hline & & $\mathrm{BA}$ & BCCE & BA & BCCE & BA & BCCE & AMB \\
\hline \multirow{2}{*}{ Médias } & BA & 1 & 0,79 & 0,59 & 0,70 & 0,69 & 0,60 & 0,56 \\
\hline & BCCE & 0,0001 & 1 & 0,61 & 0,69 & 0,60 & 0,66 & 0,65 \\
\hline \multirow{2}{*}{$\begin{array}{l}\text { Eberhart } \\
\text { Russell }\end{array}$} & BA & 0,0003 & 0,0003 & 1 & 0,71 & 0,60 & 0,68 & 0,72 \\
\hline & BCCE & 0,0001 & 0,0001 & 0,0001 & 1 & 0,70 & 0,80 & 0,72 \\
\hline \multirow{2}{*}{ AMMI } & BA & 0,0001 & 0,0001 & 0,0001 & 0,0001 & 1 & 0,75 & 0,70 \\
\hline & BCCE & 0,0003 & 0,0001 & 0,0001 & 0,0001 & 0,0001 & 1 & 0,75 \\
\hline \multicolumn{2}{|c|}{ AMMI 12 AMB } & 0,0001 & 0,0001 & 0,0001 & 0,0001 & 0,0001 & 0,0001 & 1 \\
\hline
\end{tabular}


Tabela 57. Médias das correlações de Spearman (acima da diagonal) e médias dos os respectivos níveis de significância (abaixo da diagonal) entre as médias dos experimentos em $B A^{a}$, (uma repetição) e em $B_{C C E}{ }^{b}$ (duas repetições), médias estimadas através das metodologias de $\mathrm{ER}^{\mathrm{C}}$ e $\mathrm{AMMI}$ e as médias estimadas pela análise AMMI para os 12 ambientes

\begin{tabular}{ccccccccc}
\hline & & \multicolumn{8}{c}{ Modelos } \\
\cline { 2 - 8 } Médias de 3 anos & \multicolumn{2}{c}{ Médias } & \multicolumn{3}{c}{ ER } & \multicolumn{2}{c}{ AMMI } & AMMI 12 \\
\cline { 2 - 7 } & BAa & BCCEb & BA & BCCE & BA & BCCE & AMB $^{\mathrm{d}}$ \\
\hline \multirow{2}{*}{ Médias } & BA & 1 & 0,78 & 0,62 & 0,62 & 0,63 & 0,47 & 0,54 \\
Eberhart & BCCE & 0,0001 & 1 & 0,61 & 0,72 & 0,66 & 0,55 & 0,64 \\
Russell & BCCE & 0,0005 & 0,0002 & 1 & 0,77 & 0,71 & 0,57 & 0,65 \\
AMMI & 0,0001 & 0,0001 & 1 & 0,75 & 0,70 & 0,69 \\
& BA & 0,0001 & 0,0001 & 0,0001 & 0,0001 & 1 & 0,71 & 0,73 \\
AMMI 12 AMB & 0,0271 & 0,0045 & 0,0023 & 0,0003 & 0,0002 & 1 & 0,74 \\
& BCCE & 0,0023 & 0,0001 & 0,0003 & 0,0001 & 0,0001 & 0,0001 & 1 \\
\hline
\end{tabular}

a:Blocos aumentados

b: Blocos subdivididos em conjuntos experimentais

c: Metodologia de Eberhar e Russell (1966)

d: Ambientes 


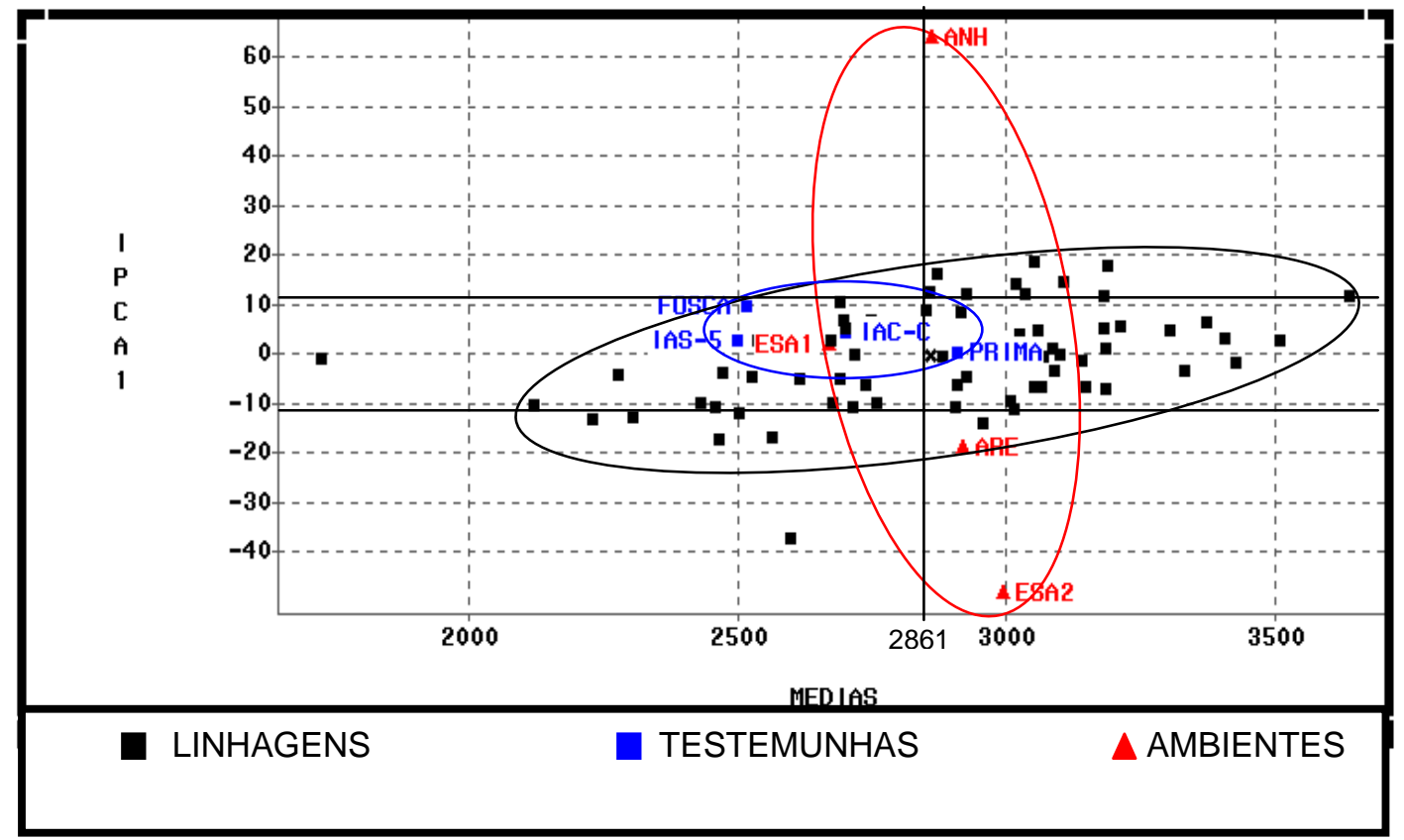

Figura 1 - Biplot de médias e IPCA 1 para AMMI 1 dos experimentos em blocos aumentados em 1998, para as 72 linhagens, quatro testemunhas e quatro locais / épocas de cultivo. Abreviações: ANH: Anhembi, ARE: Areão, ESA1: ESALQ-1, ESA2: ESALQ-2, FOSCA: IAC Foscarin-31, IAC-C: IAC-100, PRIMA: Primavera

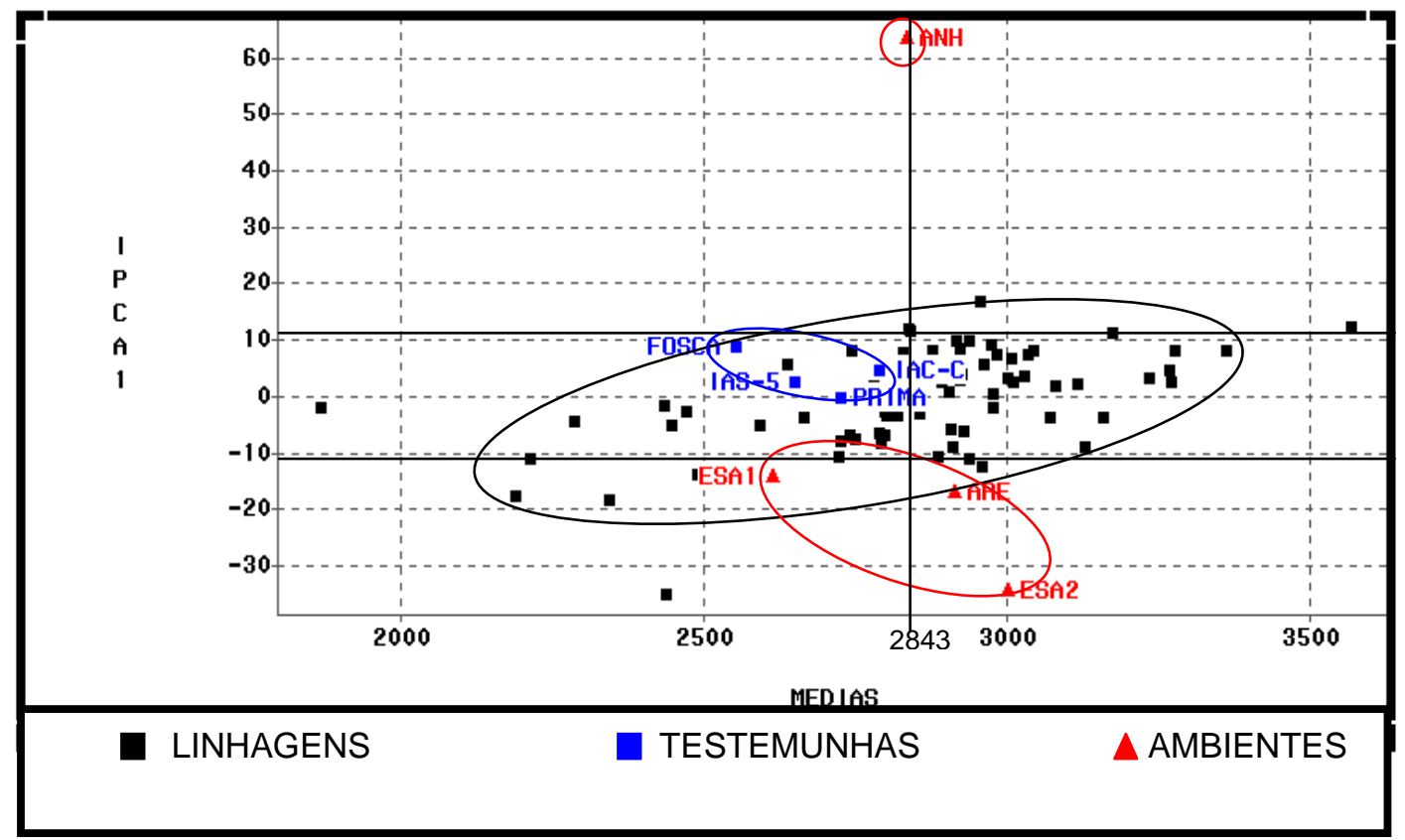

Figura 2 - Biplot de médias e IPCA 1 para AMMI 1 dos experimentos em blocos casualizados subdivididos em conjuntos experimentais em 1998, para as 72 linhagens, quatro testemunhas e quatro locais / épocas de cultivo. Abreviações: ANH: Anhembi, ARE: Areão, ESA1: ESALQ-1, ESA2: ESALQ-2, FOSCA: IAC Foscarin-31, IAC-C: IAC100, PRIMA: Primavera 


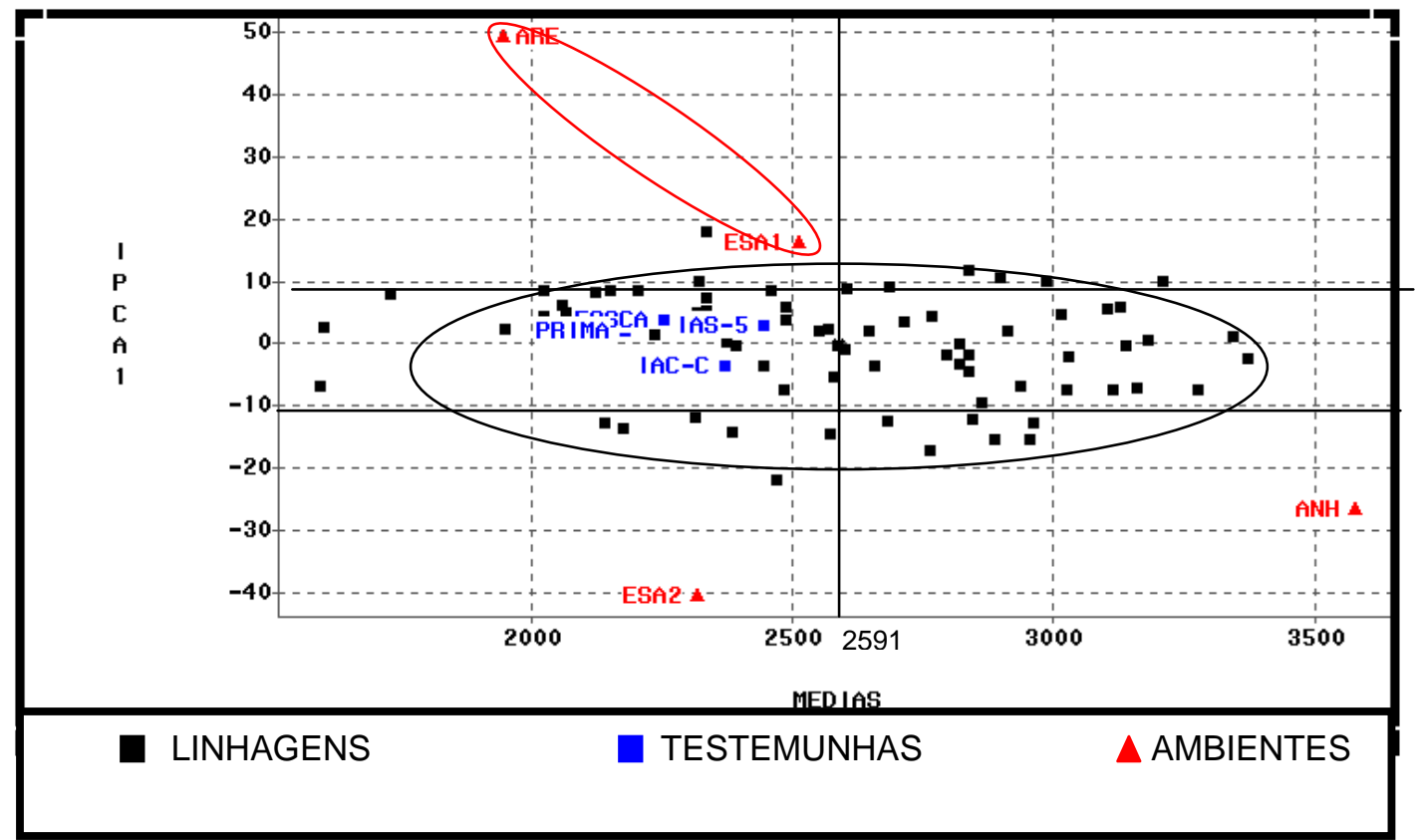

Figura 3 - Biplot de médias e IPCA 1 AMMI 1 dos experimentos em blocos aumentados em 2000, para as 72 linhagens, quatro testemunhas e quatro locais / épocas de cultivo. Abreviações: ANH: Anhembi, ARE: Areão, ESA1: ESALQ-1, ESA2: ESALQ-2, FOSCA: IAC Foscarin-31, IAC-C: IAC-100, PRIMA: Primavera

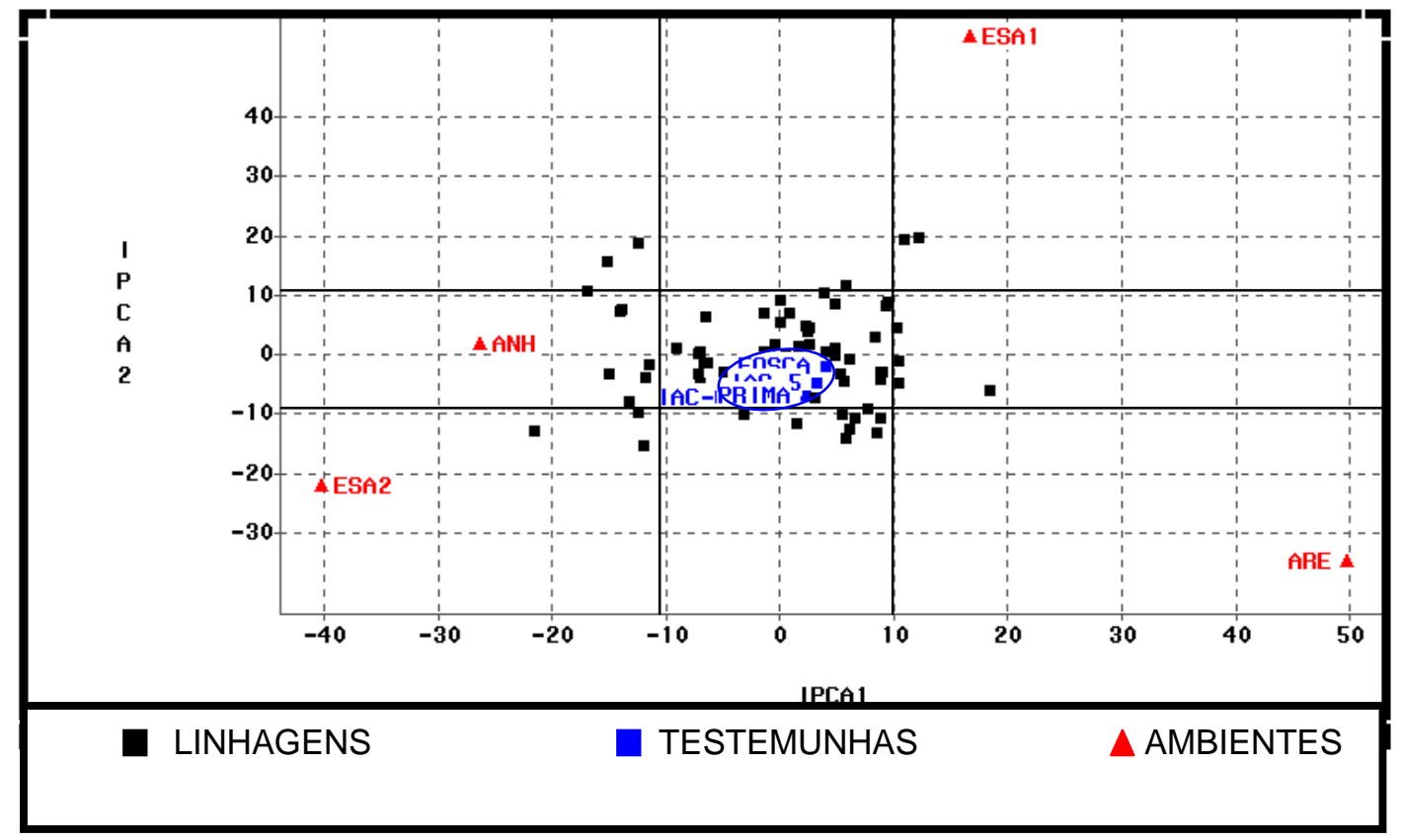

Figura 4 - Biplot de IPCA 1 e IPCA 2 para AMMI 1 dos experimentos em blocos aumentados em 2000, para as 72 linhagens, quatro testemunhas e quatro locais / épocas de cultivo. Abreviações: ANH: Anhembi, ARE: Areão, ESA1: ESALQ-1, ESA2: ESALQ-2, FOSCA: IAC Foscarin-31, IAC-C: IAC-100, PRIMA: Primavera 


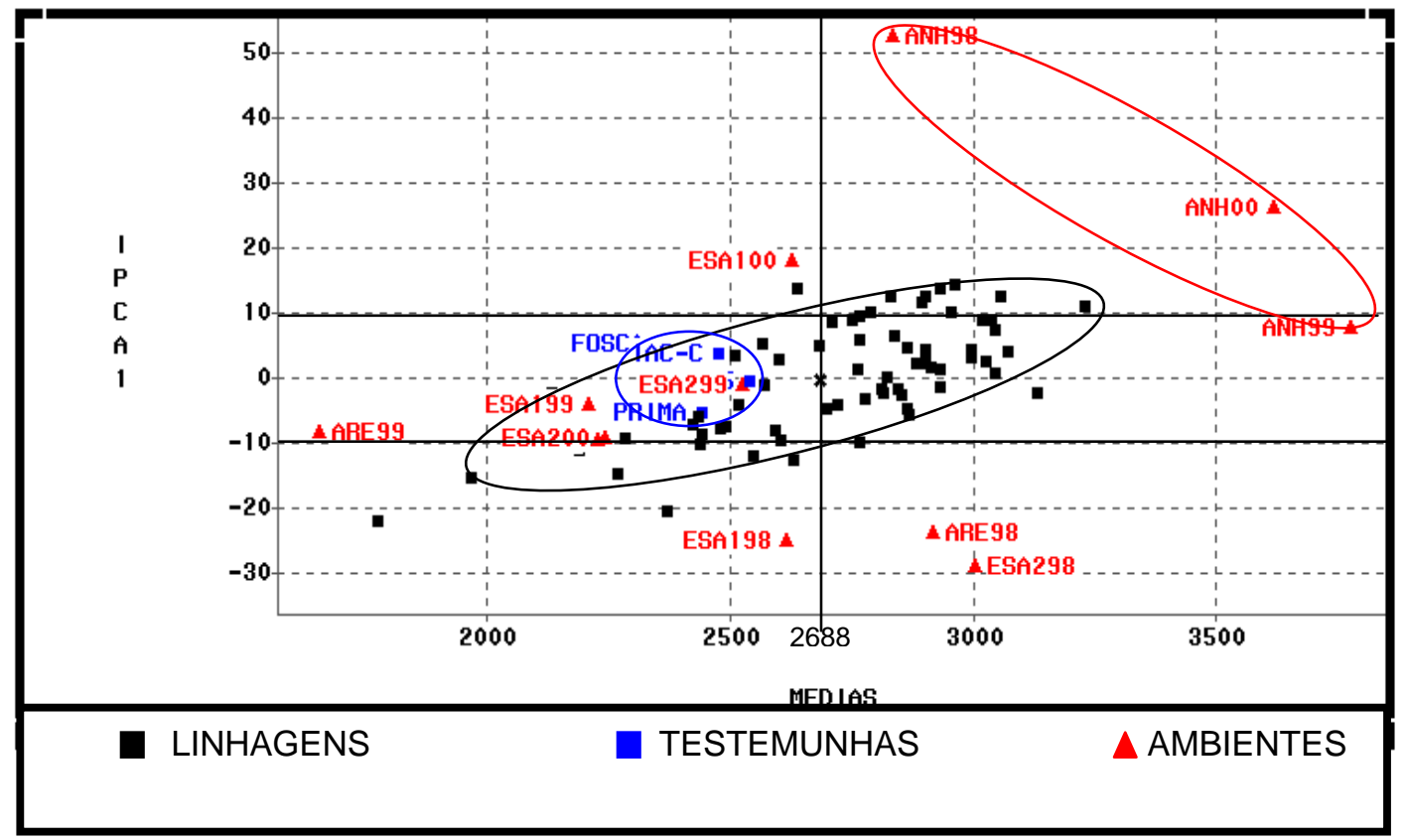

Figura 5 - Biplot das médias e IPCA 1 para AMMI dos 12 ambientes, para as 72 linhagens, quatro testemunhas e quatro locais / épocas de cultivo. Abreviações: ANH: Anhembi, ARE: Areão, ESA1: ESALQ-1, ESA2: ESALQ-2, FOSCA: IAC Foscarin-31, IAC-C: IAC-100, PRIMA: Primavera

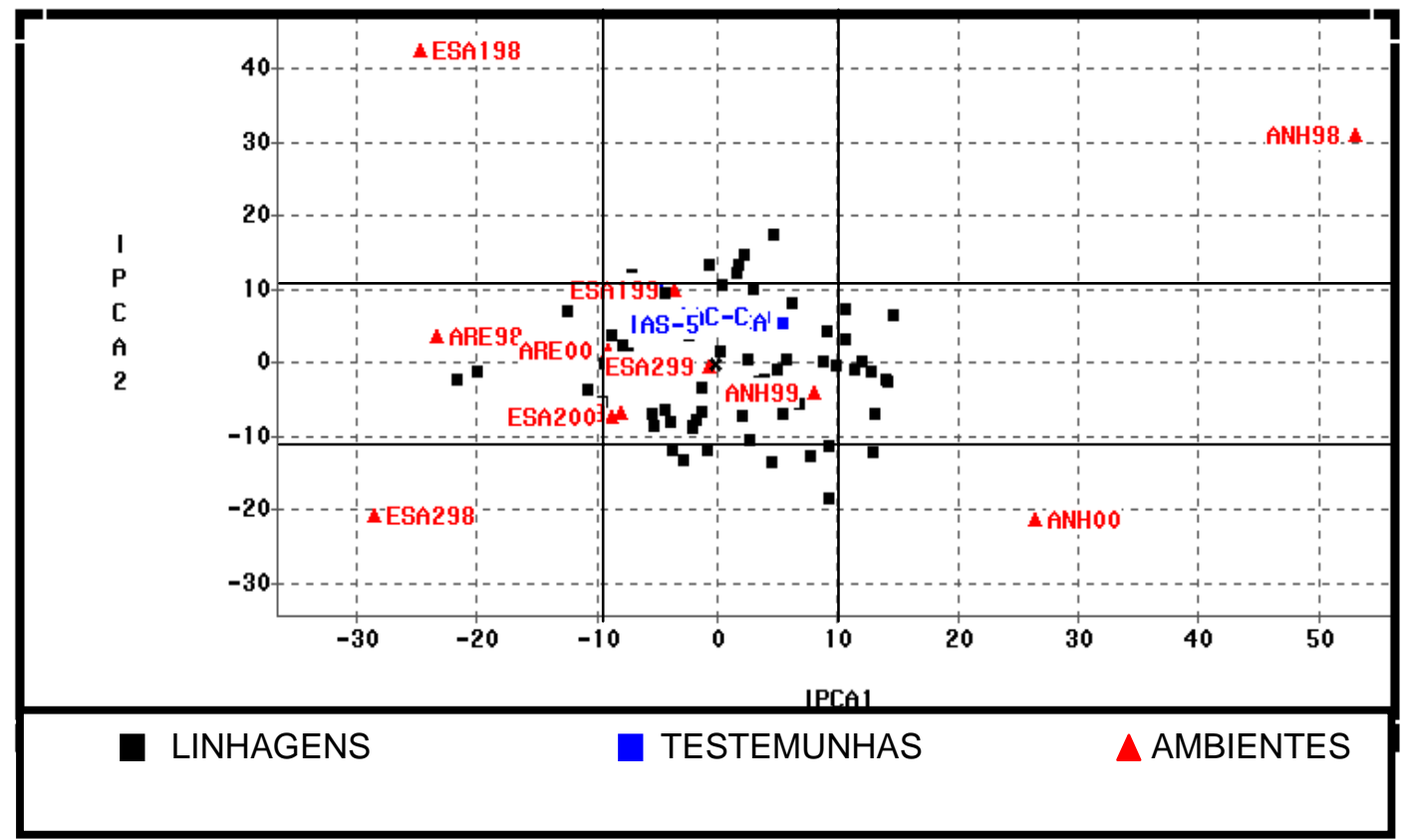

Figura 6 - Biplot de IPCA1 e IPCA 2 para AMMI dos 12 ambientes, para as 72 linhagens, quatro testemunhas e quatro locais / épocas de cultivo. Abreviações: ANH: Anhembi, ARE: Areão, ESA1: ESALQ-1, ESA2: ESALQ-2, FOSCA: IAC Foscarin-31, IAC-C: IAC100, PRIMA: Primavera 


\section{REFERÊNCIAS BIBLIOGRÁFICAS}

ABAMU, F. J.; ALLURI, K. AMMI analysis of a rainfed lowland rice (Oryza sativa) trials in Nigeria. Plant Breeding. v.117, p.359-397. 1998.

ANNICCHIARICO, P. Additive main effects and multiplicative interaction (AMMI) analysis of genotype-location interaction in variety trials repeated over years. Theoretical and Applied Genetics, v.94, p.1072-1077. 1997.

BECKER, R. Oleoquímica - óleos e gorduras: matérias primas do futuro. In: SEMINÁRIO INTERNACIONAL DE TRANSFERÊNCIA DE TECNOLOGIA, 3, Salvador, 1996. Novos rumos da agroindústria. Salvador: SEBRAE/Instituto Euvaldo Lodi, 1996. p.27-31.

BOS, I. The optimum number of replications when testing lines or families on a fixed number of plots. Euphytica, v.32, p.311-318. 1983.

CARVALHO, L.R. Blocos casualizados com tratamentos comuns: uma aplicação ao melhoramento genético de soja. Piracicaba, 1991. 82p. Dissertação (Mestrado) - Escola Superior de Agricultura "Luiz de Queiroz", Universidade de São Paulo.

CHAVES, L.J. Interação de genótipos com ambientes. In: NASS, L.L.; VALOIS, A.C.C.; MELO, I.S.; VALADARES-INGLIS, M.C. (Ed.) Recursos genéticos e melhoramento: plantas. Rondonópolis: Fundação MT, 2001. 1183 p. 
CORNELIUS, P. L.; CROSSA, J. Prediction assessment of shrikage estimators of multiplicative models for multi-environment cultivar trials. Crop Science, v.39, p. 998-1009. 1999.

CORNELIUS, P.L.; CROSSA, J.; SEYEDSADR, M.S. Statistical tests and estimators of multiplicative models for genotype-by-environment interaction. In: KANG, M. S.; GAUCH Jr, H. G. (Ed.) Genotype-by-environment interaction. Boca Raton: CRC Press, 1996, p.85-122.

CROSSA, J.; FOX, P.N.; PFEIFFER, W.H.; RAJARAM, S.; GAUCH, H.G. AMMI adjustment for statistical analysis of an international wheat yield trial. Theoretical and Applied Genetics. v. 81, n. 1, p. 27-37, 1991.

CRUZ, C.D.; REGAZZI, A.J. Modelos biométricos aplicados ao melhoramento genético. Viçosa: UFV, 1994. $390 \mathrm{p}$

DAGNELIE, P. The planning of experiments: towards a reasonable balance between treatment design and experimental design. In: REUNIÃO ANUAL DA RBRAS, 46.; SEAGRO 9., Piracicaba, 2001. Anais e Resumos. Piracicaba: ESQ/USP, 2001. p.10.

DELANNAY, X.; RODGERS, D.M.; PALMER, R.G. Relative genetic contributions among ancestral lines to North American soybean cultivars. Crop Science, v.22, p.631-637. 1993.

DUARTE, J.B. Sobre o emprego e a análise estatística do delineamento em blocos aumentados no melhoramento genético vegetal. Piracicaba, 2000. 293p. Tese (Doutorado), Escola Superior de Agricultura "Luiz de Queiroz", Universidade de São Paulo.

DUARTE, J.B.; VENCOVSKY, R. Interação genótipos $x$ ambientes: uma introdução à análise AMMI. Ribeirão Preto: Sociedade Brasileira de Genética, 1999. 60p. (Série Monografias, 9). 
EBERHART, S.A.; RUSSELL, W.L. Stability parameters for comparing varieties. Crop Science. v.6, p.36-40. 1966.

FEDERER, W.T. Augmented designs. Biometrics, v.14, p.134, 1958 /Abstract $469 /$.

FEDERER, W.T. Augmented designs with one-way elimination of heterogeneity. Biometrics, v.17, p. 447-473. 1961a.

FEDERER, W.T. Augmented designs with two- three and higher-way elimination of heterogeneity. Biometrics, v.17, p. 166. 1961b.

FEDERER, W.T. Recovery of interblock, intergradient, and intervaietal information in incomplete block and lattice rectangle designs experiments. Biometrics, v.54, p. 471-481. 1998.

FEDERER, W.T.; RAGHAVARAO, D. On augmented designs. Biometrics, V.31, p. 29-35. 1975.

FEDERER, W.T.; NAIR, R.C.; RAGHAVARAO, D. Some augmented rowcolumn designs. Biometrics, v.31, p. 36-374. 1975.

FOX, P.N.; CROSSA, J.; ROMAGOSA, I. Multi-environment testing and genotype $x$ environment interaction. In: KEMPTON, R.A.; FOX, P.N. (Ed) Statistical methods for plant variety evaluation. New York: Chapman e Hall, 1997. cap.8, p. 117-138.

GABRIEL, K. R. The biplot graphic display of matrices with application to principal component analysis. Biometrika, v.58, p. 453-467. 1971.

GAUCH Jr, H.G. Model selection and validation for yield trials with interaction. Biometrics, v.44, p. 705-715. 1988. 
GAUCH Jr, H.G. Statistical Analysis of regional yield trials: AMMI analysis of factorial designs. Amsterdam : Elsevier, 1992. cap.1, p. 1-14.

GAUCH Jr, H.G.; FURNAS, R.E. Statistical analysis of yield trials with MATMODEL. Agronomy Journal, v.83, p. 916-920. 1991.

GAUCH Jr, H.G.; ZOBEL, R.W. AMMI analysis of yield trials. In: KANG, M.S.; GAUCH Jr, H.G. (Ed.) Genotype-by-environment interaction. Boca Raton: CRC Press, 1996. cap.4, p. 85-122.

HIROMOTO, D.M. Seleção de genótipos de soja para resistência a Heterodera glycines Ichinohe e Diaporthe phaseolorum f.sp. meridionalis MorganJones. Piracicaba, 1996. 84p. Tese (Doutorado) - Escola Superior de Agricultura "Luiz de Queiroz", Universidade de São Paulo.

HIROMOTO, D.M.; VELLO, N.A. The genetic base of Brazilian soybean (Glycine $\max$ (L.) Merrill) cultivars. Revista Brasileira de Genética, v.9, n.2, p. 395-406, 1986.

INSTITUTO BRASILEIRO DE GEOGRAFIA E ESTATÍSTICA. Levantamento Sistemático da produção Agrícola, 2004. Soja. <http://www.ibge.gov.br>. (30 jan. 2004).

JOHNSON, D.E. An introduction to multiplicative interaction models sometimes called AMMI models. In: REUNIÃO ANUAL DA RBRAS, 46.; SEAGRO 9., Piracicaba, 2001. Anais e Resumos. Piracicaba: ESALQ/USP, 2001. p.9.

KEMPTON, R.A. The use of biplots in interpreting variety by environmet interactions. Journal of Agricultural Science, v.103, p. 123-135. 1984.

KEMPTON, R.A.; GLEESON, A.C. Unreplicated trials. In: KEMPTON, R.A.; FOX, P.N. (Ed) Statistical methods for plant variety evaluation. London: Chapman \& Hall, 1997. cap.6, p. 86-100. 
KIIHL, R. A. S.; BOYS, I. A.; ALMEIDA, L. A. Soybean breeding for the Brazilian tropics. In: SOYBEAN IN THE TROPICAL AND SUBTROPICAL CROPPING SYSTEMS., Tsukuba, 1983. Proceedings of a symposium. Shanhuan: The Asian Vegetable Research and Development Center, 1986. p.141-144.

LAVORANTI, J.O.; DIAS, J.T. dos S.; VENCOVSKY, R. Estudo da adaptabilidade e estabilidade genética de progênies de Eucalyptus grandis, através da metodologia AMMI. In: REUNIÃO ANUAL DA RBRAS, 46. ; SEAGRO 9., Piracicaba, 2001. Anais e Resumos. Piracicaba: ESALQ/USP, 2001. p. 118-121.

LIN, C.S.; POUSHINSKY, G. A modified augmented design for an early stage of plant selection involving a large number of test lines without replication. Biometrics, v.39, p. 553-561, 1983.

LIN, C.S.; POUSHINSKY, G. A modified augmented design (type 2) for retangular plots. Canadian Journal of Plant Science, v.65, p. 743-749, 1985.

LIN, C.S.; VOLDENG, H.D. Efficiency of type 2 modified augmented designs in soybean variety trials. Agronomy Journal, v.81, p. 512-517, 1989.

MASCARENHAS, H.A.A.; MIRANDA, M.A.C. de, TANAKA, R.T.; FALIVENE, S.M.P.; DECHEN, A.R. Comportamento de cultivares precoces de soja em solução nutritiva contendo diferentes níveis de manganês. Pesquisa Agropecuária Brasileira. V.25, p.609-615, 1990.

MAY, K.W.; KOZUB, G.C. Success of a selection program for increasing grain yield of two-row lines and evaluation of the modified augmented design (type 2). Canadian Journal of Plant Science, v.75, p. 795-799, 1995. 
MAY, K.W.; KOZUB, G.C.; SCHAALE, G.B. Field evaluation of a modified augmented design (type 2) for screening barley lines. Canadian Journal of Plant Science, v.69, p. 9-15, 1989.

MEAD, R. Design of plant breeding trials. In: KEMPTON, R.A.; FOX, P.N. (Ed.) Statistical methods for plant variety evaluation. London: Chapman \& Hall, 1997. Cap.4, p. 40-67.

MIRANDA, F.T.S. Interação genótipos $x$ ambientes em linhagens de soja selecionadas para resistência ao nematóide de cisto. Piracicaba, 1999. 141p. Dissertação (Mestrado) - Escola Superior de Agricultura "Luiz de Queiroz", Universidade de São Paulo.

MIRANDA, F.T.S. de; ROCHA, M.M.; VELLO, N.A. MARIANO, J.R. Avaliação da metodologia AMMI como ferramenta na seleção de linhagens estáveis e produtivas. In: CONGRESSO BRASILEIRO DE SOJA 2., Foz do Iguaçu, 2002. Anais. Foz do Iguaçu: Embrapa Soja,2002. p.161.

MIRANDA, M.A.C.; BRAGA, N.R.; LOURENÇÃO, A.L.; MIRANDA, F.T.S.; UNÊDA, S.E.; ITO, M.F. Descrição, podutividade e estabilidade da cultivar IAC-23, resistente a insetos. Bragantia, v.62, n.1, p.19-27, 2003a.

MIRANDA, M.A.C.; BRAGA, N.R.; LOURENÇÃO, A.L.; MIRANDA, F.T.S.; UNÊDA, S.E.; ITO, M.F. Descrição, podutividade e estabilidade da cultivar IAC-24, resistente a insetos. Bragantia, v.62, n.1, p.29-37, 2003b.

PIMENTEL GOMES, F.P. Curso de Estatística Experimental. 13 ed. Piracicaba, 1990. 467p.

ROCHA, M.M. Interação genótipos x locais em linhagens experimentais de soja com diferentes ciclos de maturação. Piracicaba, 1998. 98 p. Dissertação (Mestrado) - Escola Superior de Agricultura "Luiz de Queiroz", Universidade de São Paulo. 
ROCHA, M.M. Seleção de linhagens experimentais de soja para adaptabilidade e estabilidade fenotípica. Piracicaba, 2002. 173p. Tese (Doutorado) Escola Superior de Agricultura "Luiz de Queiroz", Universidade de São Paulo.

ROSSETO, C.J.; TISSELI FILHO, O.; RAZERA, L.F.; GALLO, P.B.; PEDRO JR.; M.J.; CAMARGO M.B.P. DE; IGUE, T.; J.P.F. Integration of resistant cultivar and date of planting for cultivation of soybean with reduced use of insecticides. In: WORLD SOYBEAN RESEARCH CONFERENCE, 4., Buenos Aires, 1989. Proceedings. Buenos Aires: SRL, 1989. p.15821587.

SCHNEIDER, J.H.M.; VAN DER BOOGERT, P.H.J.F.; ZADOKS, J.C. Exploring differential interactions between Rhizoctonia solani AG 2-t isolates and tulip cultivars. Plant Disease, v.83, n.5, p. 474-481, 1999.

SCOTT, R.A.; MILLIKEN, G.A. A SAS program for analyzing augmented randomized complete-block designs. Crop Science, v.33, p. 865-867, 1993.

SOUSA, E.A. de. Alternativas experimentais na avaliação de progênies em programas de melhoramento genético vegetal. Piracicaba, 1997. 122p. Tese (Doutorado) - Escola Superior de Agricultura "Luiz de Queiroz", Universidade de São Paulo.

STELL, R.G.D.; TORRIE, J.H. 1960. Principles and Procedures of Statistics. New York: McGraw Hill Book Company, pp. 481.

TAI, G.C.C. Genotypic stability analysis and its application to potato regional trials. Crop Science, v. 11, p. 184 - 190, 1971.

TAI, G.C.C. Cannonical variate analysis of genotype x environment interactions. Canadian Journal of Plant Science, v.79, p. 427-431, 1999. 
TALBOT, M. Resources allocation for selection systems. In: KEMPTON, R. A.; FOX, P. N. (Ed) Statistical methods for plant variety evaluation. London: Chapman \&Hall, 1997. cap.10, p. 162-174.

UNÊDA-TREVISOLI, S. H. Estabilidade fenotípica e potencialidade de progênies obtidas por cruzamentos óctuplos em soja. Piracicaba, 1999. 228 p. Tese (Doutorado) - Escola Superior de Agricultura "Luiz de Queiroz", Universidade de São Paulo.

VELLO, N.A. Efeitos da introdução de germoplasma exótico sobre a produtividade e relações com a base genética das cultivares de soja. Piracicaba, 1985. 91p. Tese (Livre Docência) - Escola Superior de Agricultura "Luiz de Queiroz", Universidade de São Paulo.

VELLO, N.A.; FEHR, W.R.; BAHRENFUS, J.B. Genetic variability and agronomic performance of soybean populations developed from plant introductions. Crop Science, v.24, n.3, p. 511-522. 1984.

VELLO, N.A.; HIROMOTO, D.M.; YORINORI, J.T.; FERREIRA, B.M.; BOOTAN, A.J.; KIIHL, R.A.S.; USP 01 a USP 11: novas linhagens de soja resistentes ao nematóide de cisto, cancro da haste, mancha olho-de-rã. Revista Brasileira de Genética, v.17, p.262.1994. Suplemento. /Apresentado ao 40. Congresso Brasileiro de Genética, Caxambu, 1994 - Resumo

VOLTAS, J. VAN EEUWIJK, F.A.; SOMBRERO, A.; LAFARGA, A; IGARTUA, E.; ROMAGOSA, I. Integrating statistical and ecophysiological analyses of genotype by environment interaction for grain filling of barley I. individual grain weight. Field Crops Research, v.62, p. 63-74. 1999.

WHITEHEAD, W.F.; ALLEN, F.L. High-vs. low-stress yield test environments for selection superior soybeans lines. Crop Science, v.30, p. 912-918, 1990. 
WILLERS, J.L.; WAGNER, T.L.; SEQUEIRA, R.A.; THESEIRA, G.W.; BOYKIN, D. L. Analysis of deterministic simulation models using methods applicable to two-way treatment structures without replication. Agronomy Journal, v.87, p. 478-492, 1995.

WOLFINGER, R.D.; FEDERER, W.T.; CORDERO-BRANA, O. Recovering information in augmented designs using SAS PROC GLM and PROC MIXED. Agronomy Journal, v.89, p. 856-859. 1997.

YAN, W.; HUNT, L. A. Biplot analysis of diallel data. Crop Science, v.42, p.2130, 2002.

YAU, S. K. Regression and AMMI analyses of genotype $x$ environment interactions: an empirical comparison. Agronomy Journal, v.87, p. 121126, 1995.

YORINORI, J.T. Cancro da haste da soja: epidemiologia e controle. Londrina: Embrapa-Soja, 1996. 75p. (Embrapa Soja. Circular Técnica, 14).

ZOBEL, R.W.; WRIGHT, M.J.; GAUCH Jr, H.G. Statistical analysis of a yield trial. Agronomy Journal, v.80, p. 388-393, 1988. 